\title{
NISTIR 89-4209
}

NEW NIST PUBLICATION

November 1989

\section{METHODS FOR \\ MEASURING LEAD CONCENTRATIONS IN PAINT FILMS}

Mary E. McKnight

W. Eric Byrd

Willard E. Roberts

Center for Bullding Tochnoloty

Eric S. Lagergren

Conter for Computing and Applled Mathematice

US. DEPARTMENT OF COMMERCE Nationd indturte of Standards and Technolocy

edtherebures mo 2089

U.S. DJPARTMENT OF COMMERCE Robert A Mocbectier, Secrotary MMTONAL DUSTIUTE OF STANDAFDS No Txcrimoor

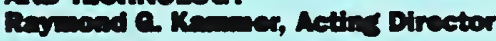

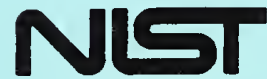



Mary E. McKnight

W. Eric Byrd

Willard E. Roberts

Center for Building Technology

Eric S. Lagergren

Center for Computing and Applied Mathematics

U.S. DEPARTMENT OF COMMERCE National Institute of Standards and Tochnology

Gaithorsburg, MD 20899

October 1989

Issued December 1989

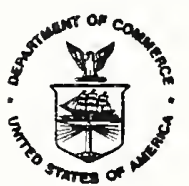

U.S. DEPARTMENT OF COMMERCE Robert A. Mosbacher, Secretary NATIONAL INSTIUUTE OF STANDARDS AND TECHNOLOGY

Raymond G. Kammer, Acting Director 



\section{ABSTRACT}

Recent legislation requi'red the U.S. Department of Housing and Urban Development (HUD) to establish procedures to abate leadbased paint in existing HUD-assisted housing. The legislation also required HUD to assess the accuracy, precision, reliability, and safety of methods for measuring lead content of paint films and to investigate the availability of testers and samplers. The National Institute of standards and Technology was requested to carry out this assessment. After reviewing the literature for possible field methods, two methods were selected for further testing: chemical spot tests and methods based upon use of portable $x$-ray fluorescence (XRF) analyzers.

With regard to accuracy and precision of field measurements, it was concluded that 1) spot tests when carried out by an experienced analytical chemistry technician can detect the presence of lead in paint films having concentrations in excess of $1 \mathrm{mg} / \mathrm{cm}^{2}$ about 90 percent of the time, 2) the estimate of the precision of a field measurement procedure using lead-specific portable XRF analyzers (based on three replicate readings and substrate correction) for lead concentrations near $1 \mathrm{mg} / \mathrm{cm}^{2}$ is $\pm 0.6 \mathrm{mg} / \mathrm{cm}^{2}$ and the estimate of the bias is $0.2 \mathrm{mg} / \mathrm{cm}^{2}$; this results in a 95 percent confidence interval of $\pm 1.4 \mathrm{mg} / \mathrm{cm}^{2}$, and 3) based upon very preliminary measurements using the latest version of the spectrum analyzer portable XRF, the 95 percent confidence interval for field measurements is estimated to be $\pm 0.5 \mathrm{mg} / \mathrm{cm}^{2}$.

In addition to field methods, standard laboratory procedures can be used to measure the lead content of paint samples to within a few percent of the quantity present over a wide range extending from less than 0.1 to over $10 \mathrm{mg} / \mathrm{cm}^{2}$. Because they can have a large effect on the results, sample collection and sample dissolution procedures were also investigated. The results of the assessments and the conclusions and recommendations based upon the results are discussed in this report.

Keywords: analysis; atomic absorption spectroscopy; coating; detection; housing; lead; lead-based paint; measurement; microscopy: paint; $x$-ray fluorescence analyzers 

ABSTRACT

Table of Contents

List of Figures

List of Tables

1. INTRODUCTION

2. PROPERTIES OF LEAD-CONTAINING PAINTS

2.1 History ${ }_{2.2}$ Lead concentration in paints

2.3 The distribution of lead in paint films from a pre-1940 house

3. IITERATURE STUDIES

3.1 Screening methods

3.2 Measurement methods

4. LABORATORY EVALUATION - PAINT FILM DETECTION OR MEASUREMENT TECHNIQUES

4.1 Portable XRF analyzers . . . . . . . . . . . . 6

4.1.1 NIST laboratory-based study of leadspecific analyzers . . . . . . . . . . . . 7

4.1.1.1 Experimental design and procedure. . 7

4.1.1.2 Materials . . . . . . . . . 9

4.1.1.3 Results . . . . . . . . . . 10

4.1.2 ASTM laboratory-based study . . . . . . . . 13

4.1.2.1 Experimental design and procedure . . 13

4.1.2.2 Materials . . . . . . . . . . 14

4.1.2.3 Results ............. 14

4.1 .3 Discussion . . . . . . . . . . . . . 16

4.1.4 Preliminary laboratory assessment of

4.2 Spot tests

spectrum analyzer . . . . . . . . . . . 19

5. PROCEDURES FOR COLLECTING AND PREPARING PAINT SAMPLES

FOR LABORATORY ANALYSIS . . . . . . . . . . . . . . . 22

5.1 Sample collection procedures . . . . . . . . . . 22

5.2 Preparation of paint samples for laboratory

analysis . . . . . . . . . . . . . . 23

5.2.1 Methods requiring dissolution . . . . . . 23

5.2.1.1 Investigation of ashing procedures . 24

5.2.1.2 Thermal stability of lead compounds

found in paint . . . . . . . 25

5.2 .2 Methods not requiring dissolution .... 27

6. FIELD EVALUATIONS . . . . . . . . . . . . . . 27

6.1 Objectives ................. . 28

6.2 Experimental plan . . . . . . . . . . . . 28

6.3 Experimental procedure ........... . 28

6.3.1 Sample location ........... 29 
6.3.2 Sample collection and analysis... . . . 29

6.3 .3 XRF testing . . . . . . . . . . . . 29

6.3 .4 spot tests................ 30

6.4 Results of field studies . . . . . . . . . . . 30

6.4 .1 Sample collection and analysis... . . . . 30

6.4.2 Measurements made with portable XRF

analyzers . . . . . . . . . . . . 31

6.4.3 Results of spot tests ........... . . 34

6.5 Other portable lead-specific XRF field data sets $\quad 35$

6.6 Discussion ................... . . 35

6.6 .1 Sample collection ............ . 35

6.6 .2 spot tests................. . 38

6.6.3 Portable XRF analyzers.......... . 38

7. TESTING PROCEDURE FOR LEAD IN PAINT . . . . . . . . . . . 39

7.1 Procedure . . . . . . . . . . . . . . . 39

7.2 Safety . . . . . . . . . . . . . . . . . 41

7.2.1 Portable XRF analyzers . . . . . . . . . 41

7.2 .2 spot tests . . . . . . . . . . . . 42

7.2.3 Laboratory procedures . . . . . . . . . . . 42

7.3 Availability of qualified testers and samplers . . 42

7.3.1 Field testing . . . . . . . . . . . . 42

7.3.2 Laboratory testing... . . . . . . . . 44

7.4 Reliability . . . . . . . . . . . . . . . 44

8. CONCLUSIONS . . . . . . . . . . . . . . . . . . . 45

9. RECOMMENDATIONS • . . . . . . . . . . . . . . . 47

10. REFERENCES • . . . . . . . • . . . . . . . . . . 49

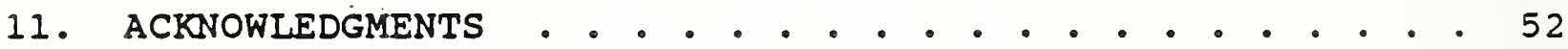




\section{List of Figures}

Figure 1. Relationship between lead concentration in terms of volume percent and mass/area in films of uniform thickness and density.

Figure 2. Scanning electron micrographs of a section through a paint film from a house in Baltimore.

a) Backscattered electron image.

b) Images of the same field as a), but with specific elements highlighted.

Figure 3. Scanning electron micrograph of a section through a paint film on wood from a house in Baltimore.

a) Overall image showing lead pigments in the uppermost pores of the wood.

b) Enlargement of area shown in a).

Figure 4. Scanning electron micrograph of a section through a paint film on wood over an apparent layer of varnish.

Figure 5. Typical results of drift measurements.

a) XRF-A analyzer.

b) XRF-B analyzer.

Figure 6. Laboratory study of substrate (blank) measurements with two XRF-A analyzers. a) XRF-AO; b) XRF-Al. Each point is the mean of two observations with an observation being the mean of three replicate readings. Substrates are 1-gypsum wallboard, 2-pine, 3-plaster, 4-steel panel, 5-oak, 6-brick, 7-concrete block, 8-pine over wallboard.

Figure 7. Laboratory study of substrate (blank) measurements with two XRF-B analyzers. a) XRF-BO; b) XRF-B1. Each point is the mean of two observations with an observation being the mean of three replicate readings. Substrates are 1-gypsum wallboard, 2-pine, 3-plaster, 4-steel panel, 5-oak, 6-brick, 7-concrete block, 8-pine over wallboard.

Figure 8. Measurements, without substrate correction, made with standard lead films over substrates for two XRF-A analyzers. NIST analyzer is XRF-AO; outside is XRFA1. Each point is the mean of three replicate measurements. Lead-film concentrațions are: a) 0.3 $\mathrm{mg} / \mathrm{cm}^{2}$, b) $1.2 \mathrm{mg} / \mathrm{cm}^{2}$, c) $2.6 \mathrm{mg} / \mathrm{cm}^{2}$, d) $5.1 \mathrm{mg} / \mathrm{cm}^{2}$. Substrates are: 1-gypsum wallboard, 2-pine, 3plaster, 4-steel panel, 5-oak, 6-brick, 7-concrete block, 8-pine over wallboard. 
List of Figures, cont.

Figure 9. Measurements, with substrate correction, made with standard lead films over substrates for two XRF-A analyzers. NIST analyzer is XRF-AO; outside is XRFA1. Each point is the mean of three replicate measurements. Lead-film concentrations are: a) 0.3 $\mathrm{mg} / \mathrm{cm}^{2}$, b) $1.2 \mathrm{mg} / \mathrm{cm}^{2}$, c) $2.6 \mathrm{mg} / \mathrm{cm}^{2}$, d) $5.1 \mathrm{mg} / \mathrm{cm}^{2}$. Substrates are: 1-gypsum wallboard, 2-pine, 3plaster, 4-steel panel, 5-oak, 6-brick, 7-concrete block, 8-pine over wallboard.

Figure 10. Measurements, without substrate correction, made with standard lead films over substrates for two XRF-B analyzers. NIST analyzer is XRF-BO; outside is XRFB1. Each point is the mean of three replicate measurements. Lead-film concentrations are: a) 0.3 $\mathrm{mg} / \mathrm{cm}^{2}$, b) $1.2 \mathrm{mg} / \mathrm{cm}^{2}$, c) $2.6 \mathrm{mg} / \mathrm{cm}^{2}$, d) $5.1 \mathrm{mg} / \mathrm{cm}^{2}$. Substrates are: 1-gypsum wallboard, 2-pine, 3plaster, 4-steel panel, 5-oak, 6-brick, 7-concrete block, 8-pine over wallboard.

Figure 11. Measurements, with substrate correction, made with standard lead films over substrates for two XRF-B analyzers. NIST analyzer is XRF-BO; outside is XRFB1. Each point is the mean of three replicate measurements. Lead-film concentrațions are: a) 0.3 $\mathrm{mg} / \mathrm{cm}^{2}$, b) $1.2 \mathrm{mg} / \mathrm{cm}^{2}$, c) $2.6 \mathrm{mg} / \mathrm{cm}^{2}$, d) $5.1 \mathrm{mg} / \mathrm{cm}^{2}$. substrates are: 1-gypsum wallboard, 2-pine, 3plaster, 4-steel panel, 5-oak, 6-brick, 7-concrete block, 8-pine over wallboard.

Figure 12. Ninety-five percent confidence levels for the true lead level for results which were not substrate corrected. The true lead concentration of the standard lead-film is plotted as " $x$ ".

Figure 13. Ninety-five percent confidence levels for the true lead level for results which were substrate corrected. The true lead concentration of the standard lead-film is plotted as " $\mathrm{x}$ ".

Figure 14. Spectra obtained using XRF-C of a bare wood substrate and of the substrate covered with lead-containing paint films on paper.

Figure 15. Mean of three replicate measurements made in the laboratory using Version 1 of the XRF-C portable XRF analyzer. Results for bare substrate and for lead paint films over a bare substrate. 
List of Figures, cont.

Figure 16. Results of Vind et al. [9] stability studies for sodium sulfide solutions.
a) Unthickened solution.
b) Solution thickened with methyl cellulose.

Figure 17. Thermogravimetric curves for lead-based pigments and inorganic compounds; analyses carried out in air.
a) Basic carbonate white lead.
b) Lead chloride.
c) Lead dioxide.
d) Lead nitrate.
e) Red lead.

Figure 18. Thermogravimetric curves for lead-containing paint and paste; analyses carried out in air.
a) NIST SRM 1579, lead-based paint.
b) Lead-based paint.
c) White-lead paste.

Figure 19. Thermogravimetric curves for two paint components; analyses carried out in air.
a) Linseed oil.
b) Lead drier.

Figure 20. Results of thermogravimetric isothermal experiments.
a) NIST SRM 1579 heated in air to 300,500 and $700^{\circ} \mathrm{C}$, then held isothermally.
b) Lead drier heated in air to $500^{\circ} \mathrm{C}$ then held isothermally.

Figure 21. Field study -- measurements using XRF-AO analyzer. Difference between XRF and FAAS results plotted vs FAAS result.

Figure 22. Field study -- measurements using XRF-BO analyzer. Difference between XRF and FAAS results plotted vs FAAS result.

Figure 23. Frequency distribution of field observations using $X R F-A O$ and XRF-BO made over bare substrates. An observation is the mean of three replicate measurements.

Figure 24. Field study -- measurements using XRF-C instrument. Difference between XRF and FAAS results plotted vs FAAS result. a) Version 1 ; b) Version 2 .

Figure 25. Spectrum of a paint film having a lead concentration of $15 \mathrm{mg} / \mathrm{cm}^{2}$ obtained in the field using an XRF-C analyzer. 
Table 1. Estimates of blank precision of a laboratory measurement procedure using lead-specific portable XRF analyzers

Table 2. Estimates of error of a laboratory measurement procedure using lead-specific portable XRF analyzers

Table 3. Estimates of precision of measurements made with XRF-A analyzers in ASTM round-robin study

Table 4. Estimates of precision of measurements made with XRF-B analyzers in round-robin study

Table 5. Results of laboratory-based spot tests

Table 6. Effect of ashing temperature on measured lead concentration of NIST SRM 1579

Table 7. Comparison of mass loss at $700^{\circ} \mathrm{C}$ determined by using TGA with the calculated loss upon decomposition of lead materials to $\mathrm{Pbo}$

Table 8. Field measurements -- estimated error using leadspecific portable XRF analyzer XRF-AO

Table 9. Field measurements -- estimated error using leadspecific portable XRF analyzer XRF-BO

Table 10. Estimated error of field measurements made with leadspecific portable XRF analyzers from abatement demonstration data

Table 11. Estimated error of substrate corrected field measurements made with lead-specific portable XRF-B analyzers from data from $S$. Lewis (GTI)

Table 12. Radiation levels, measured near portable XRF analyzers using a Geiger counter, and OSHA limits for exposure to radiation. 


\section{List of Appendix Tables}

Table Al. Raw data from laboratory evaluation of lead-specific portable XRF analyzers.

Table A2. Raw data from ASTM round-robin experiment, an XRF-A analyzer

Table A3. Raw data from ASTM round-robin experiment, an XRF-B analyzer

Table A4. Raw data from laboratory experiments conducted with XRF-CI instrument

Table A5. Field data taken with XRF-AO analyzer

Table A6. Field data taken with XRF-BO analyzer

Table A7. Field data taken with XRF-Cl analyzer

Table A8. Field data taken with XRF-C2 analyzer 

In response to amendments to the Lead-Based paint Poisoning Prevention Act by Section 566 of the Housing and Community Development Act of 1987 (Public Law 100-242, approved February 5, 1988), the National Institute of Standards and Technology (NIST) was requested by the Department of Housing and Urban Development (HUD) to investigate concerns associated with the measurement of lead concentrations in existing paint films in residential structures. The project carried out by NIST consisted of assessing potential procedures for detecting and measuring lead in paint based on the following major criteria: 1) reliability, 2) safety, 3) accuracy (or bias) and precision, and 4) availability of qualified samplers and testers. This document reports the results of this investigation.

The study included a review of the literature to identify potential detection and measurement methods and laboratory and field studies to estimate the precision and accuracy of available methods. Information on the safety and reliability of the methods was obtained from the literature, from NIST experience, and from others experienced in carrying out similar measurements. Information on availability of qualified testers and samplers was obtained from the literature and from a limited survey of people concerned with training, manufacture of testing instruments, and laboratory testing.

\section{PROPERTIES OF LEAD-CONTAINING PAINTS}

\subsection{History}

Although current regulations limit the lead concentration in paints for residential use to 0.06 percent $(600 \mathrm{ppm})$ by mass of the non-volatile portion, lead-containing pigments and lead driers were widely used in residential paints in the past. White-lead pigments were used in Greece in the fourth century B.C. and the first white-lead factory was established in the United States in 1804 in Philadelphia [1]. Beginning in the 1920 's, lithophone ( $\mathrm{ZnS} / \mathrm{BaSO}_{4}$ ) was used to supplement or replace white-lead pigments in interior paints, and in the 1940's, titanium dioxide was introduced as a hiding pigment. These pigments supplemented or replaced the lead hiding pigments because they were cheaper [2], had better hiding power and were more compatible with some resin systems [1]. However, small amounts of basic carbonate white lead continued to be used in exterior house paints to improve adhesion and durability [3].

Lead pigments were also used to color residential paints and lead was used in paint driers in concentrations of about 0.3 to 1 percent of the mass of the vehicle solid [3]. Thus, based upon the history of pigment use, lead concentrations were probably highest in paints applied before 1920 and lead can be expected to be found in both white and colored paints. 


\subsection{Lead concentration in paints}

Many of the specifications for paints used by Federal Agencies were based upon a specific formulation [4]. Assuming that Federal specification paints were reasonably representative of U.S. paints, the lead concentration in films of old residential paints formulated with lead-based pigments or driers can be estimated. For example, the concentration of lead in the dry film of an old Federal specification white finish coat for exterior wood pigmented with basic carbonate white lead is 65 percent by mass [5], while the lead concentration in the dry film of a yellow paint colored with lead chromate, TT-P-529 [6], could reach 20 percent by mass. The concentration of lead in a paint with a lead drier but no lead-containing pigments was often a few tenths of a percent of the mass of the binder [2].

Since the unit of lead concentration in the regulation is mass/area, a relationship between percent and mass/area is needed to compare the lead concentrations of the paints described above to the regulatory standard. The relationship is

mass per unit area $\left(\mathrm{mg} / \mathrm{cm}^{2}\right)=$ percent by mass $x$ dry film thickness $(\mathrm{cm}) \times$ dry film density $\left(\mathrm{mg} / \mathrm{cm}^{3}\right) / 100$.

The relation is illustrated in figure 1 for three film thicknesses and two film densities. Thus, a paint film having a lead concentration of about 65 percent by mass, a density of $2.4 \mathrm{~g} / \mathrm{cm}^{3}$, and a thickness of about $0.05 \mathrm{~mm} 10.002 \mathrm{in} \mathrm{--} \mathrm{one}$ coat) would have an area lead concentration of about $8 \mathrm{mg} / \mathrm{cm}^{2}$. Similarily, the area lead concentration of a paint film such as TT-P-529 (with a lead concentration of 20 percent) would be about $2.5 \mathrm{mg} / \mathrm{cm}^{2}$. However, for a paint with lead driers but no leadcontaining pigments, the area lead concentration in a coat of typical thickness would be about $0.05 \mathrm{mg} / \mathrm{cm}^{2}$. For a residential paint containing the current maximum allowable amount of lead, i.e., 0.06 percent, the area lead concentration of $a 0.05 \mathrm{~mm}$ film would be $0.006 \mathrm{mg} / \mathrm{cm}^{2}$ (a dry film density of $2 \mathrm{~g} / \mathrm{cm}^{3}$ has been assumed).

2.3 The distribution of lead in paint films from a pre-1940 house

To investigate the distribution of lead in paint films from an old house (pre-1940), paint film samples were collected and examined using a scanning electron microscope (SEM) equipped with an energy dispersive $x$-ray spectrometer (EDS). The samples of paint films were prepared for SEM analysis by embedding a small chip attached to the substrate, if present, in an epoxy resin, allowing the epoxy to cure, cutting the sample to expose the various paint layers using a diamond saw and then polishing it. 
All the samples were sputter-coated with a thin film of carbon to prevent charging during the analysis.

A beam energy of $15 \mathrm{kv}$ was used to obtain the backscattered electron images and carry out the EDS analysis. Pictures of these images are shown in figures 2 through 4 . Grey levels in these images are directly related to the atomic numbers of the elements making up the sample. That is, the brightest areas in the image correspond to the areas containing elements with the highest atomic number and the darkest to those elements having the lowest atomic number. For example, if lead pigments are present in the sample, then they would likely appear the brightest in the image. Titanium, aluminum, calcium, sulfur and other lighter elements that are often found in pigments or extenders in paints would appear darker. The paint binder will appear the darkest since it is primarily composed of carbon, oxygen and hydrogen. To determine the element present in a given area of an image, such as the one shown in figure 2, the photons generated when the electrons hit the surface of the specimen are analyzed using an energy dispersive $x$-ray spectrometer, similar to those used in some laboratory and field $x$-ray fluorescence analyzers.

The results of the analysis for a paint film taken from a window sill of a Baltimore house are shown in figure 2. Figure 2-a is an overall view of the cross section of the paint. The wood substrate is beneath the layers of paint that appear brightest in the image. From the image, it appears that there are about 25 layers of paint for a total thickness exceeding $0.6 \mathrm{~mm}$. Figure $2-b$ is a composite of images obtained by mapping a bright spot onto an area where the element noted in the figure was found using EDS. For this paint sample, lead is present in the bottom layers, zinc is present in some middle layers and titanium is present in the top layers. The presence of lead in a sample taken adjacent to the sample analyzed in the SEM was confirmed in the laboratory by atomic adsorption spectroscopy.

From the SEM image of a sample taken from a wooden molding, as shown in figure 3-a, and from the identification of the brightest areas as containing lead using EDS, one can see that lead pigments entered into the outer-most pores of the wood, but did not go deeply into the wood. The few spotted white areas in the photograph over the wood are assumed to be caused by smearing of the lead pigments during the polishing process. This assumption is supported by the image of a paint film on wood in which there are some bright spots over the wood, but in which the first layer of the film appears to contain no pigments and was probably a varnish as shown in figure 4 .

These and other analyses indicate that lead in paint chip samples taken from old houses is usually present in the first layers of paint. Barium was often present in many of the layers, probably 
as both a hiding pigment, lithopone, and as an extender, barium sulfate.

3 LITERATURE STUDIES

\subsection{Screening methods}

Because of the number of homes that may have lead-based paint, HUD needs a simple, fast screening method for eliminating from further test paint films which do not contain lead at or above the regulatory limit of $1 \mathrm{mg} / \mathrm{cm}^{2}$. Hence, the literature was reviewed [7] for potential screening methods to meet this need. For a screening method to satisfy this need, it must have sufficient precision so that films having a lead concentration less than $1 \mathrm{mg} / \mathrm{cm}^{2}$ can be statistically distinguished from ones having a concentration greater than or equal to $1 \mathrm{mg} / \mathrm{cm}^{2}$. If the measurement precision is too large, this can never happen.

In more detail, a screening method is used to test the null hypothesis that the lead concentration in a paint film is at least equal to $1 \mathrm{mg} / \mathrm{cm}^{2}$. Suppose, for example, that the significance level is $\alpha=0.05$ (i.e., false negative risk is 5 percent) and the method is unbiased with standard deviation $\sigma$. If $n$ replicates of the measurement method, made on the same sample, have average $\boldsymbol{x}$, the null hypothesis (i.e., lead concentration is at least $1 \mathrm{mg} / \mathrm{cm}^{2}$ ) can only be rejected if

$$
x<1-1.6 \sigma / \sqrt{ } \mathrm{n}=\mathrm{C} \text {. }
$$

However, a screening method should also identify samples in which the null hypothesis is false, but cannot be rejected by the above test, to minimize the need for follow-up testing. If the probability of not rejecting the null hypothesis when the lead concentration is zero is chosen to be 0.05 (i.e., a false positive risk of 5 percent), then the cutoff $C$ must be greater than $1.6 \sigma / \sqrt{ } n$, which means that

$$
\sigma / \sqrt{\mathrm{n}}<0.3 \mathrm{mg} / \mathrm{cm}^{2} \text {. }
$$

In particular, if only one replicate of the measurement method is made, the standard deviation of the method must be less than $0.3 \mathrm{mg} / \mathrm{cm}^{2}$. It may be helpful to note that for this case the precision required to make a decision of not detected at a 95 percent confidence level is 33 percent of the detection level, but the minimum precision desired by many analytical chemists for a quantitative method is 10 percent of the measured result [8].

Two types of methods have been used for screening: chemical spot tests and lead-specific portable $x$-ray fluorescence (XRF) instruments. In-situ spot tests on paint films using sodium sulfide and other chemicals have been reported to be sensitive enough to detect lead in concentrations of 0.5 percent $(5000$ parts per 
million (ppm)) [7] and of 0.2 to 0.3 percent under favorable conditions [9]. The detection limit of a spot test based upon dithizone for lead ions in solution was reported to be 0.08 percent $(800 \mathrm{ppm})[10]$. For a method based upon the use of a single reading of a portable XRF analyzer and using a manufacturer's specification of precision of an individual measurement and assuming no additional variance and no bias, the detection limit was estimated as $1.6 \mathrm{mg} / \mathrm{cm}^{2}[7]$.

\subsection{Measurement methods}

The literature was also reviewed for potential measurement methods for lead in paint [11]. Each method was evaluated on the basis of the following essential criteria: reliability, safety, and accuracy and precision. In addition, the following desirable criteria were also considered: ease of use, speed, destructiveness, and cost. The methods were divided into two general types: in-situ field methods and laboratory methods. The laboratory methods were also divided into two major groups: 1) those requiring dissolution of the sample, and 2) those not requiring dissolution (i.e., as a solid).

Based upon the review, the only procedure that could be used insitu to nondestructively measure the concentration of lead in a dry paint film uses a portable $x$-ray fluorescence (XRF) analyzer. Several procedures are described in the literature for measuring lead concentrations in paint samples brought to the laboratory. Most involve dissolution of the lead. A method of preparing a solid sample for measurement using a laboratory XRF analyzer was also reported.

Thus, additional studies were carried out to characterize potentially feasible field and laboratory measurements. With respect to field measurements, work was carried out to characterize the sensitivity and accuracy of measurements made with spot tests and the precision and accuracy of measurements made with portable XRF analyzers. In addition to carrying out field studies using the chemical spot tests and portable XRF analyzers, laboratory-based studies were conducted to help establish best-case estimates of precision and bias for these methods. Sample collection and sample dissolution procedures were investigated since the greatest uncertainty to laboratory measurements was contributed to them. The results of the laboratory-based studies of methods used to detect or measure lead in paint samples in the field are discussed first followed by a discussion of laboratory methods requiring dissolution of a sample film. The field studies are reported last. 
4 LABORATORY EVALUATION - PAINT FILM DETECTION OR MEASUREMENT TECHNIQUES

\subsection{Portable XRF analyzers}

From the literature review [11], it was concluded that measurement procedures based upon the use of some portable XRF analyzers could meet the essential and desirable criteria cited above. currently, both $K$ and $L \mathrm{X}$-ray analyzers are available. However, based upon previous studies [12], it was concluded that portable instruments based upon lead $L$ x-ray lines would not be suitable because of the matrix effect of the paint sample. The L lead $x-$ rays are significantly less energetic and can be more readily absorbed by materials commonly found in paints than lead $\mathrm{k} x-$ rays. For thick paint films, absorption of the $I$ x-rays could be nearly complete. Although these effects can be taken into account in laboratory measurements, the required procedures are not practical for present field-based measurements. Thus, only portable XRF analyzers based upon analysis of lead $K$ x-rays were included in this study. Two generic types of portable XRF analyzers were used in the laboratory study; they are a leadspecific type available from two manufacturers (XRF-A and XRF-B) and a spectrum analyzer type $(\mathrm{XRF}-\mathrm{C})$.

Portable XRF analyzers detect and determine the amount of lead in a sample in the same manner as laboratory devices. That is, the instrument provides a source of high energy photons ( $x$-rays) which bombard the sample. Lead electrons can be ejected from their place or shell in the atom by these bombarding photons. A characteristic $x$-ray photon is emitted as another electron in the excited lead atom filis the vacancy [13] $]_{57}$ Both types of XRF analyzers evaluated in this study use $\mathrm{CO}^{57}$ as the excitation source but the detectors and the procedures for minimizing the effect of the backscattered x-rays on the measured concentration are different. All of the instruments have digital display, are relatively lightweight (probes are less than $2 \mathrm{~kg}$ ) and are powered by rechargeable batteries which provide about 8 hours continuous use. The XRF-A and $X R F-C$ analyzers have a probe separate from the rest of the instrument, while the $\mathrm{XRF}-\mathrm{B}$ analyzer consists of a single unit. They are all operated in essentially the same manner. The probe is placed over the surface, a shutter is released exposing the surface of the paint under the probe to the photons emitted by the radioactive source, and the $x$-rays emitted by the return of excited lead $\mathrm{K}$ electrons to the ground state are detected and counted for a predetermined length of time. The counting time required is determined automatically for the XRF-A and XRF-B instruments and preset by the operator for the XRF-C instrument.

The objectives of the laboratory studies of XRF analyzers were 1) to determine precision and bias of a blank measurement, and 2 ) to estimate the effect of substrate, time, operator, lead 
concentration and paint matrix on the results and on the precision and bias of the measurement procedure. Two separate laboratory-based studies of the lead-specific type analyzers were carried out in order to increase the number of instruments included in the study.

As discussed in the report on screening methods [7], the precision of a measurement procedure for a blank sample determines the lower bound for the precision of the measurement method (i.e., standard deviation of the measurement method) and the detection limit of the measurement method. Since the regulatory level ( $1 \mathrm{mg} / \mathrm{cm}^{2}$ ) of lead was near the detection limit of these instruments, measurements were conducted to estimate the precision of a blank measurement. It is expected that a measurement procedure carried out in the laboratory will have the same or better precision and bias than when it is carried out in the field. Thus, laboratory work was carried out to determine the precision and bias of a blank measurement for several typical residential building substrates.

\subsubsection{NIST laboratory-based study of lead-specific analyzers}

\subsubsection{Experimental design and procedure}

The following experimental variables were included in the NIST laboratory study: substrate type, time, operator, lead concentration, and paint matrix (thickness of paint layer placed over lead $\mathrm{film}$ ). Other variables are also reported to influence the results of XRF measurements but were not included because their effects can be minimized in the experimental procedure for using the instrument. These other variables include effects of electrical fields, buried pipes, and temperature changes.

Two types of experiments were carried out to investigate the parameter of time on the measurement results. The first experiment was done to determine whether there was a predictable drift in the measurement results before making additional measurements; the second was carried out in conjunction with assessment of other variables to estimate the variance between observations. The procedure for the first experiment consisted of 1) charging the batteries in an instrument overnight, 2) taking a set of 5 or more repetitive measurements on the same area of a bare substrate, using battery power (as would be done in the field), 3) waiting an hour and taking another set of 5 or more repetitive measurements and 4) repeating step 3 four to six times during a day. These types of measurements were repeated for three or four days for each irstrument.

To obtain estimates of the precision of blank measurements and to determine the variability arising from substrate type, paint matrix, lead concentration, operator, and time on the results of 
measurements made using lead-specific portable XRF instruments in the laboratory, a specific set of measurements to be carried out was developed using a randomized block design [14]. Included were two instruments of each type, eight substrates, four lead concentrations (in addition to the blank), two paint film thicknesses (paint matrix), and three operators. The experiment included a total of 1536 observations (384 for each instrument), equally divided between measurements of blanks (run in duplicate) and measurements of lead-containing films, with the blank and lead-film observations combined and the order properly randomized. For the lead study, half of all the possible instrument, substrate, lead concentration, paint thickness and operator combinations were run for a total of 768 observations (192 for each instrument). Each observation consisted of three individual replicate measurements. For the instruments used in this study, the time to make one complete observation was about one minute (measurement time depends upon the source strength and increases as the source decays). The measurements were carried out according to the manufacturer's instructions, except for XRF-A, whose manufacturer recommends rezeroing an instrument as the substrate changes. Instead, substrate corrections were made by subtraction of the reading over a bare substrate. XRF-A instruments were rezeroed on a gypsum substrate, as stipulated in the manufacturer's instructions, before beginning measurements each morning. The zero of each of XRF-B instruments was checked each morning, but the instrument could not be zeroed in the laboratory. Measurements of each manufacturer's supplied lead standard were also made before and after each day's set of observations.

To keep extraneous parameters as constant as possible, the samples for this experiment were made by combining a substrate sample, a lead coated polymeric film, and a free paint film to form a kind of sandwich. The combinations were changed as required in the experimental design. To the best of the operator's ability, the instrument was placed over the same part of the lead film for each measurement (estimated variability in placement is $\pm 1 \mathrm{~cm})$. All measurements were made with the sample placed over about a $0.4 \mathrm{~m}$ thickness of polystyrene foam to minimize the effect of a distant substrate. The edges of a substrate were supported by a rigid wooden frame. 
The substrates used in this study were chosen to represent those typically found in residential housing. They were:

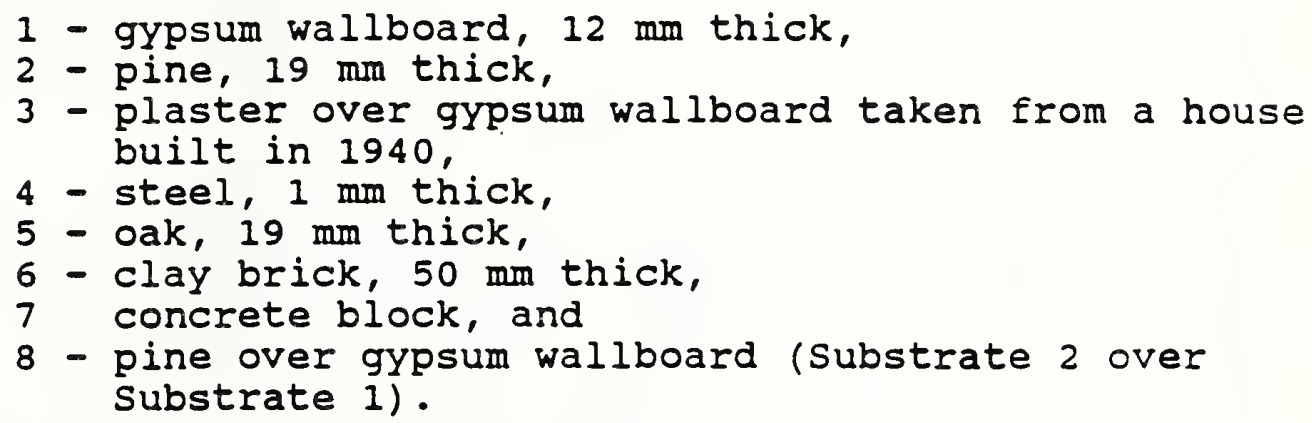

Lead films were prepared by evaporating lead in a vacuum evaporator and depositing it onto $125 \times 125 \mathrm{~mm}$ pieces of $0.18 \mathrm{~mm}-$ thick polyethylene terephthalate (PET). The thickness of lead on the PET was measured interferometrically as it was being deposited. Several samples of each nominal thicknesses of $0.3,1$, 1.5 , and $5 \mathrm{~mm}$ were prepared. Films having nominal lead thicknesses of 1 and $1.5 \mu \mathrm{m}$ were combined by stacking a $1 \mu \mathrm{m} l e a d$ film over a $1.5 \mathrm{\mu m}$ one, each with the lead film upward, for one of the lead film samples. Upon completion of the laboratory observations, the concentrations of lead of three $25 \mathrm{~mm} \times 25 \mathrm{~mm}$ square areas of each of the four standard films were determined. The samples were taken such that their centers were parallel to an edge of the large film, $35 \mathrm{~mm}$ distant, with one square taken from the middle of the film. The lead concentration of each of these samples was determined by flame atomic absorption spectroscopy (FAAS) according to ASTM Test Method D 3335 [15]. The mean concentration of the three samples for each film used in the experiment as determined by FAAS was $0.3,1.2,2.6$ (for the one made by combining 1 and $1.5 \mu \mathrm{m}$ films) and $5.1 \mathrm{mg} / \mathrm{cm}^{2}$ with coefficients of variation of $10,8,3$, and 10 percent for the lead concentrations of $0.3,1.2,2.6$, and $5.1 \mathrm{mg} / \mathrm{cm}^{2}$, respectively. Since the samples taken from the film included areas outside the area over which measurements were made and since the lead concentration of all films increased from one side of the film to the other, the coefficient of variation of the lead concentration of the active area of the film should be smaller than that listed above.

The free paint films were prepared from a typical, commercial, $\mathrm{TiO}_{2}$-pigmented interior water-based paint by drawing down a film of the material over a smooth polyfluorinated polymeric material, allowing it to dry and cure, and then peeling it from the substrate. The mean thicknesses of the two paint films used in this experiment as overlays were 0.1 and $0.7 \mathrm{~mm}$; the coefficient of variation was 10 percent. 


\subsubsection{Results}

The results of the drift over time studies for the portable XRF instruments evaluated in this study showed that the change in the result of an observation from one time to another was random according to a nonparametric test for randomness of a sequence of consecutive observations [16]. That is, no prediction of a

future reading could be made from past ones. Typical results for these measurements are shown in figure 5.

The results of the raw data obtained to determine the effect of the experimental variables on the measured results are included in Table Al in the appendix. The mean of the three replicate measurements making up an observation was plotted by analyzer and lead concentration, as shown in figures 6 - 11. (Since there were two of each manufacturer's analyzers included in the experiment, they have been distinguished by adding either 0 or 1 to the analyzer label.) Figures 6 and 7 show the results obtained for bare substrates (the blank measurements) for each of the two analyzers from manufacturers $A$ and $B$, respectively. For each analyzer and each substrate, each of the three operators carried out two blank observations on each of the three days for a total of 12 observations. Each point in the bare-substrate plots is the mean of the two observations made by the same operator on the same day. Figures 8 and 9 show the results for the XRF-A analyzers for each lead concentration without and with a substrate correction, respectively. Each point represents the result of one observation carried out by one of the three operators on one of the three days. All the points for a given combination of analyzer, substrate, and lead concentration are grouped together in the figures since the variance associated with the thickness of the film overlays was small. Hence there are six points for each of these combinations (i.e., one half of 2 paint thicknesses, 3 operators and 3 days). Figures 10 and 11 are the corresponding figures for XRF-B analyzers. The substrate correction made to an XRF reading consisted of subtracting the mean of the corresponding blank readings made on the same day by the same operator using the same instrument. The total estimated precision and the precision associated with each of the variables is shown in table 1 for measurement of a bare substrate (blank) and in table 2 for measurements of a lead-containing system. These precision estimates were obtained using standard analysis of variance procedures for a random effects model [14].

As shown in figures 8 through 11, the observations obtained with all the analyzers are slightly less than the lead concentration of the standard. Hence, the data was analyzed to obtain estimates of bias. These estimates, as shown in table 2 , were calculated in the following way. First, the overall average of the results of all 48 measurements made with a given analyzer, substrate and lead concentration was determined, and next, the difference between the average and the lead standard 
Table 1. Estimates of blank precision of a laboratory measurement procedure using lead-specific portable XRF analyzers

Precision of blank measurements without substrate correction, in $\mathrm{mg} / \mathrm{cm}^{2}$

$\begin{array}{lrrrrrr}\text { Analyzer } & \sigma_{T} & \sigma_{\text {sub }} & \sigma_{\text {day }} & \sigma_{\text {oper }} & \sigma_{\text {bet }} & \sigma_{\text {within }} \\ \text { XRF-AO } & 0.36 & 0.33 & 0.04 & 0.01 & 0.02 & 0.14 \\ \text { XRF-AI } & 0.23 & 0.16 & 0.04 & 0.02 & 0.05 & 0.15 \\ \text { XRF-BO } & 0.34 & 0.29 & 0.03 & 0.03 & 0.07 & 0.17 \\ \text { XRF-BI } & 0.48 & 0.39 & 0.00 & 0.04 & 0.10 & 0.25\end{array}$

Precision of blank measurements with substrate correction, in $\mathrm{mg} / \mathrm{cm}^{2}$

$\begin{array}{lccc}\text { Analyzer } & \sigma_{T} & \sigma_{\text {bet }} & \sigma_{\text {within }} \\ \text { XRF-AO } & 0.20 & 0.03 & 0.20 \\ \text { XRF-A1 } & 0.23 & 0.07 & 0.22 \\ \text { XRF-BO } & 0.26 & 0.10 & 0.24 \\ \text { XRF-B1 } & 0.39 & 0.14 & 0.36\end{array}$

(Note - variability due to substrate has been removed by the substrate correction.)

$\sigma_{T}$ is the estimate of total precision; the others are measures of variability associated with each of the experimental variables: substrate, $\sigma_{\text {sub }}$ day, $\sigma_{\text {day, }}$ operator, $\sigma_{\text {oper, }}$ between observations, $\sigma_{\text {bet }}$ and between replicate measurements within an observation, $\sigma_{w i t h i n}$. 


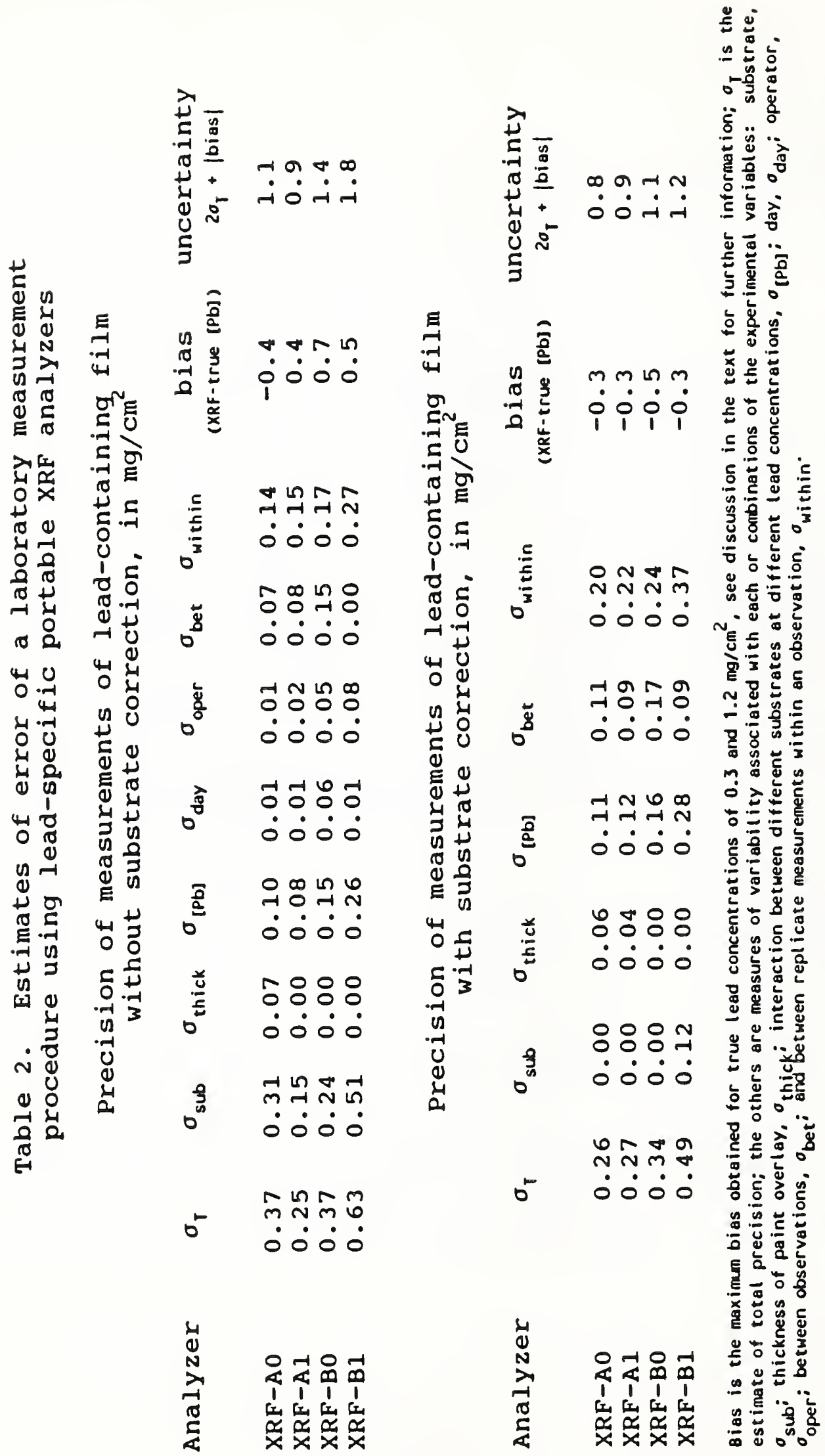


concentration was calculated. Since the lead concentrations of greatest interest are those near $1 \mathrm{mg} / \mathrm{cm}^{2}$, the greater of the absolute value of the bias estimates for the 0.3 and $1.2 \mathrm{mg} / \mathrm{cm}^{2}$ lead concentrations was used as the overall bias estimate. Evidence of bias in these measurements is further illustrated in figures 12 and 13 in which the confidence intervals associated with the 48 measurements of a given lead concentration, substrate, and analyzer are plotted together with the bias estimates, denoted by an " $x$ ". Figure 12 shows the 95 percent confidence interval for each mean of all the measurements for a given analyzer for each lead concentration prior to substrate correction. Figure 13 shows the corresponding intervals for results which were substrate corrected.

Based upon this laboratory experiment, two-sided 95 percent confidence intervals were calculated for results obtained with each of the analyzers in which three measurements of a specimen are made. These intervals are of the form

$$
\mathrm{X}= \pm \mathrm{U}
$$

where $x$ is the mean of three replicate measurements and $U=2 \sigma_{T}+$ bias, as shown in table 2. Note that the multiplier, 2 , is different than the multiplier 1.6 cited in the hypothesis in section 3.1 because this confidence interval is two-sided, and that for the hypothesis test was one-sided.

\subsubsection{ASTM laboratory-based study}

Upon our recommendation, a task group in the committee on Paints and Related Coatings and Materials (DOI) of the American Society for Testing and Materials (ASTM) was formed to investigate the feasibility of preparing a standard guide for the use of portable XRF instruments for measuring the lead content of paint films. Prior to initiating work on a guide, the task group (D01.21.41) agreed to conduct a round-robin experiment to investigate laboratory-based precision and bias of lead concentration measurements based on use of lead-specific analyzers for a limited set of substrates and paint-film matrices. The experiment included portable instruments XRF-A and XRF-B. Data was obtained using four XRF-A and Six XRF-B instruments. Each set of data was obtained using a different instrument.

\subsubsection{Experimental design and procedure}

The experimental design for the round-robin was a complete factorial, i.e., 16 observations, repeated five times for a total of 80 observations [14]. Three replicate measurements were made within each observation for a grand total of 240 individual measurements per analyzer. The order of the observations was randomized. Each participant received a data sheet describing the specimen for each observation. Participants were asked to 
follow the manufacturer's procedure for making measurements, which meant often discarding the first reading taken on a substrate when using one of the XRF-A instruments, except that they were asked not to re-zero the instrument between observations.

To avoid unwanted effects due to materials near the sample, other than the substrate provided, the participant was asked to place the specimen over the center of a sheet of polystyrene (22 $\mathrm{x} 14 \mathrm{x}$ $5 \mathrm{~cm}$ ) supplied with the test materials before taking any measurements on the specimen. For each specimen, the participant recorded the results of three individual measurements.

In addition, participants were asked to make zero and leadconcentration readings of a manufacturer-supplied standard substrate and lead standard before beginning the set of observations. In every case but one, the instruments read the zero and the lead standard within the precision range specified by the manufacturer.

\subsubsection{Materials}

Four substrates, three paint films with different lead concentrations and a blank, were included in the study. The substrates were 1) gypsum wallboard, $13 \mathrm{~mm}$ thick, 2) pine, $18 \mathrm{~mm}$ thick, 3) steel, $0.8 \mathrm{~mm}$ thick, and 4) concrete block, $50 \mathrm{~mm}$ thick. The lead-containing films were made by applying a paint containing an oil/alkyd resin and lead chromate and lead molybdate pigments to a $0.175 \mathrm{~mm}$ paper substrate. Samples of these materials, each having a dimension of about $100 \mathrm{~mm} \times 150 \mathrm{~mm}$, were sent to each round-robin participant. Specimens for the measurements were either bare substrates or a lead-containing paint film over a bare substrate. The lead-paint films were made as part of a previous study conducted at the NIST. The lead concentrations were $0.5,1.6$, and $3.0 \mathrm{mg} / \mathrm{cm}^{2}$. In the previous study, the homogeneity of films was characterized using laboratory XRF. The coefficient of variation of the lead concentration across a film was found to be less than \pm 3 percent. Paint films on paper, rather than thin films of lead evaporated on a polymeric substrate were used in this study because of their increased durability.

\section{1 .2 .3 Results}

The raw data from these experiments are shown in Tables A2 and A3 in the appendix. The mean of each set of three replicate readings was calculated and these data were analyzed according to ASTM E 691 [17] for intralaboratory and interlaboratory precision. ASTM D 3980 [18] was used to test for outliers among individual replicate measurements at the 99 percent confidence level as recommended by the standard for intralaboratory results, while the consistency statistics, $h$ and $k$, of ASTM E 691 were 
used to test for outliers among means of individual measurements. No outliers were detected. Since the initial zero of the instruments was zero plus or minus the manufacturer's stated tolerance on a manufacturer's supplied substrate, the data were analyzed with and without a substrate correction. (However, the data obtained using instrument Number 122 were not included in the analysis in which no substrate correction was made because the mean of the initial readings on the manufacturer supplied wood substrate was $-0.8 \mathrm{mg} / \mathrm{cm}^{2}$ ). For each group of 16 measurements, the substrate correction was made to each reading of a leadcontaining system by subtracting the reading over the corresponding bare substrate obtained within the group of 16 measurements.

The results of the analysis of the data to determine estimates of intralaboratory precision, $s_{r}$, and interlaboratory precision, $s_{R}$, according to ASTM E 691 for the measurement method are shown in tables 3 and 4 for each combination of lead concentration and substrate. Table 3 shows the results of the analysis for XRF-A instruments while table 4 shows the results for XRF-B instruments.

The amount two readings can differ and still statistically represent the same value for the two measurement procedures at the $95 \%$ confidence level were calculated according to the procedure given in ASTM E 691 and are also shown in tables 3 and 4 and labeled $r$ and $R$. The values in the $r$ column correspond to measurements made by the same operator and analyzer in the same laboratory. The values for $R$ correspond to measurements made by different operators using different instruments.

Based upon the Bartlett test [14], the variances (squares of the standard deviation) for measurements over wood and gypsum are not statistically different at a 95 percent confidence level. Since wood and gypsum are the most common substrates for paint in housing, these values were pooled to obtain an improved estimate of precision over these substrates. The pooled results are also included in tables 3 and 4 along with the corresponding values of $r$ and $R$.

Improvements in the measurements could be made by making more than three replicate measurements. The size of the improvement can be estimated by separating the variance into two parts; that associated with replicate measurements within an observation and that due to all the other sources. Since variances are additive, $v_{T}=v_{\text {other }}+v_{\text {ind }} / n$, where $v_{T}$ is the total variance or the square of the interlaboratory precision, $v_{\text {other }}$ is the variance due to all factors except replicate measurements, $v_{\text {ind }}$ is the variance associated with replicate individual measurements, and $n$ is the number of replicate measurements. (When a substrate correction is made the variance associated with $\mathrm{n}$ individual measurements of the substrate and the substrate plus film becomes $2 v_{\text {ind }} / n_{\text {.) }}$ For example, for the XRF-A analyzers, the estimate of 
the interlaboratory variance for the measurement procedure in which three replicate measurements are made and the results are substrate corrected is $0.068 \mathrm{mg}^{2} / \mathrm{cm}^{4}$; of this, the variance due to replicate individual measurements is $0.027 \mathrm{mg}^{2} / \mathrm{cm}^{4}$ in these measurements, leaving $0.041 \mathrm{mg}^{2} / \mathrm{cm}^{4}$ associated with other sources of variability.

Based upon this laboratory experiment for gypsum and wood and the estimates of precision, the estimates of $95 \%$ confidence limits of a measurement procedure in which three replicate measurements and a substrate correction are made for measurements near $1 \mathrm{mg} / \mathrm{cm}^{2}$ are $\pm 0.5 \mathrm{mg} / \mathrm{cm}^{2}$ for XRF-A instruments and $\pm 0.9 \mathrm{mg} / \mathrm{cm}^{2}$ for $X R F-B$ instruments. The corresponding numbers for steel and concrete would be different. The precision of measurements made on concrete is apparently poorer than that on wood and gypsum. For the B analyzers, there appears to be a slight positive bias which would increase the estimates of confidence limits slightly.

Finally, but of great importance, is the fact that these estimates of precision do not include 1) errors that may be associated with making these measurements in the field, 2) paint matrix effects, or 3) other possible parameters that may cause uncertainties.

\subsubsection{Discussion}

Similar estimates of intralaboratory precision were obtained for $X R F-A$ and $X R F-B$ instruments in both experiments. The pooled estimates of intralaboratory precision for the XRF-A instruments for measurements that were substrate corrected were $0.26 \mathrm{mg} / \mathrm{cm}^{2}$ and $0.25 \mathrm{mg} / \mathrm{cm}^{2}$ for the NIST and the ASTM experiments, respectively. For the XRF-B analyzers, the analogous numbers are $0.42 \mathrm{mg} / \mathrm{cm}^{2}$ and $0.33 \mathrm{mg} / \mathrm{cm}^{2}$. The slightly larger values obtained in the NIST study may be related to the greater number of substrates included in the study.

The estimates of bias obtained in the two laboratory-based experiments are not the same, however. In the NIST study, the portable XRF results tended to be lower than the lead concentrations of the standards, but in the ASTM study the results tended to be slightly higher than the standard values. The materials making up the standards were different in the two cases, however. In the NIST study, the standards were made up by depositing lead metal on a $0.18 \mathrm{~mm}-t h i c k$ polyethylene terephthalate film, while in the ASTM study the standards were made by applying paint containing a lead chromate pigment (with some lead molybdate in the $3.0 \mathrm{mg} / \mathrm{cm}^{2}$ standard) to a $0.175 \mathrm{~mm}$ thick sealed paper substrate. Although the differences between the means of many measurements and the concentrations of the lead standards nearly fall within the manufacturer's specifications, these data suggest there is either a systematic error in the concentrations of the films or a sizable backscatter effect due to the substrate. In 
Table 3. Estimates of precision of measurements made with XRF-A analyzers in ASTM round-robin study

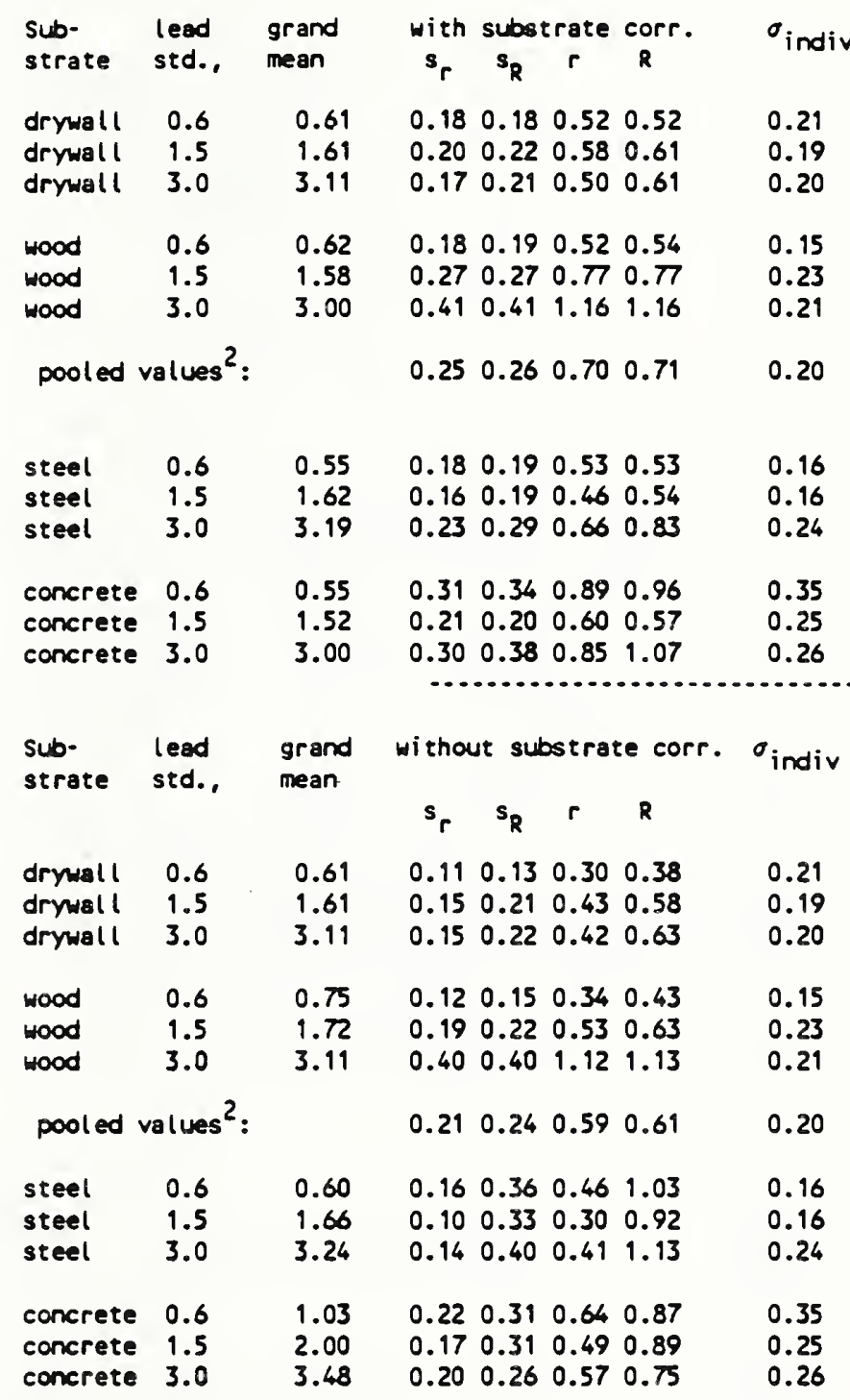

$1_{\text {All }}$ values are expressed in $\mathrm{mg} / \mathrm{cm}^{2}$. Colum headings are type of substrate making up specimen, concentration of lead in the paint film standard, the mean of all measurements made with all the instruments of the corresponding standard and substrate, the estimate of intralaboratory precision, $s$, the estimate of interlaboratory precision, $s_{p}$, the intralaboratory estimate of the difference by which two results can differ and be statistically the same, $r$, the interlaboratory estimate of the difference by which two results can differ and be statistically the same, $R$, and the estimate of precision of individual replicate measurements, $\sigma$ indiv.

${ }^{2}$ The pooled values are estimates of the corresponding parameters pooled over drywall and wood. 
Table 4. Estimates of precision of measurements made with
XRF-B analyzers in ASTM round-robin study

\begin{tabular}{|c|c|c|c|c|c|c|c|}
\hline $\begin{array}{l}\text { Sub- } \\
\text { strate }\end{array}$ & $\begin{array}{l}\text { lead } \\
\text { std., }\end{array}$ & $\begin{array}{l}\text { grand } \\
\text { mean }\end{array}$ & $\begin{array}{c}\text { with } \\
s_{r}\end{array}$ & $\begin{array}{c}\text { h subs } \\
s_{R}\end{array}$ & $\begin{array}{c}\text { serate } \\
r\end{array}$ & $\begin{array}{c}\text { corr. } \\
R\end{array}$ & $\sigma_{\text {indiv }}$ \\
\hline $\begin{array}{l}\text { drywal l } \\
\text { drywal l } \\
\text { drywall }\end{array}$ & $\begin{array}{l}0.6 \\
1.5 \\
3.0\end{array}$ & $\begin{array}{l}0.63 \\
1.72 \\
3.21\end{array}$ & $\begin{array}{l}0.22 \\
0.45 \\
0.28\end{array}$ & $\begin{array}{l}0.22 \\
0.48 \\
0.52\end{array}$ & $\begin{array}{l}0.61 \\
1.28 \\
0.80\end{array}$ & $\begin{array}{l}0.64 \\
1.35 \\
1.45\end{array}$ & $\begin{array}{l}0.34 \\
0.28 \\
0.34\end{array}$ \\
\hline $\begin{array}{l}\text { wood } \\
\text { Hood } \\
\text { wood }\end{array}$ & $\begin{array}{l}0.6 \\
1.5 \\
3.0\end{array}$ & $\begin{array}{l}0.53 \\
1.67 \\
3.03\end{array}$ & $\begin{array}{l}0.32 \\
0.30 \\
0.38\end{array}$ & $\begin{array}{l}0.37 \\
0.45 \\
0.73\end{array}$ & $\begin{array}{l}0.90 \\
0.85 \\
1.08\end{array}$ & $\begin{array}{l}1.04 \\
1.26 \\
2.05\end{array}$ & $\begin{array}{l}0.35 \\
0.45 \\
0.31\end{array}$ \\
\hline \multicolumn{3}{|c|}{ pooled values ${ }^{2}$ : } & 0.33 & 0.49 & 0.94 & 1.37 & 0.35 \\
\hline $\begin{array}{l}\text { steel } \\
\text { steel } \\
\text { steel }\end{array}$ & $\begin{array}{l}0.6 \\
1.5 \\
3.0\end{array}$ & $\begin{array}{l}0.58 \\
1.77 \\
3.34\end{array}$ & $\begin{array}{l}0.27 \\
0.29 \\
0.22\end{array}$ & $\begin{array}{l}0.27 \\
0.44 \\
0.66\end{array}$ & $\begin{array}{l}0.76 \\
0.81 \\
0.62\end{array}$ & $\begin{array}{l}0.77 \\
1.25 \\
1.85\end{array}$ & $\begin{array}{l}0.26 \\
0.29 \\
0.36\end{array}$ \\
\hline $\begin{array}{l}\text { concrete } \\
\text { concrete } \\
\text { concrete }\end{array}$ & $\begin{array}{l}0.6 \\
1.5 \\
3.0\end{array}$ & $\begin{array}{l}0.37 \\
1.13 \\
2.43\end{array}$ & $\begin{array}{l}0.36 \\
0.36 \\
0.41\end{array}$ & $\begin{array}{l}0.48 \\
0.75 \\
0.68\end{array}$ & $\begin{array}{l}1.01 \\
1.01 \\
1.14\end{array}$ & $\begin{array}{l}1.36 \\
2.10 \\
1.90\end{array}$ & $\begin{array}{l}0.56 \\
0.52 \\
0.63\end{array}$ \\
\hline $\begin{array}{l}\text { Sub- } \\
\text { strate }\end{array}$ & $\begin{array}{l}\text { lead } \\
\text { std., }\end{array}$ & $\begin{array}{l}\text { grand } \\
\text { mean }\end{array}$ & $\begin{array}{c}\text { wi thou } \\
s_{r}\end{array}$ & ut sub & $\begin{array}{c}\text { bstrat } \\
r\end{array}$ & $\begin{array}{l}\text { ite corr. } \\
R\end{array}$ & $\sigma_{\text {indiv }}$ \\
\hline $\begin{array}{l}\text { drywal l } \\
\text { drywal l } \\
\text { drywal l }\end{array}$ & $\begin{array}{l}0.6 \\
1.5 \\
3.0\end{array}$ & $\begin{array}{l}0.71 \\
1.76 \\
3.16\end{array}$ & $\begin{array}{l}0.19 \\
0.43 \\
0.19\end{array}$ & $\begin{array}{l}0.25 \\
0.57 \\
0.48\end{array}$ & $\begin{array}{l}0.30 \\
0.43 \\
0.42\end{array}$ & $\begin{array}{l}0.38 \\
0.58 \\
0.63\end{array}$ & $\begin{array}{l}0.34 \\
0.28 \\
0.34\end{array}$ \\
\hline $\begin{array}{l}\text { wood } \\
\text { wood } \\
\text { wood }\end{array}$ & $\begin{array}{l}0.6 \\
1.5 \\
3.0\end{array}$ & $\begin{array}{l}0.54 \\
1.66 \\
2.90\end{array}$ & $\begin{array}{l}0.18 \\
0.20 \\
0.29\end{array}$ & $\begin{array}{l}0.33 \\
0.44 \\
0.48\end{array}$ & $\begin{array}{l}0.34 \\
0.53 \\
1.12\end{array}$ & $\begin{array}{l}0.43 \\
0.63 \\
1.13\end{array}$ & $\begin{array}{l}0.35 \\
0.45 \\
0.31\end{array}$ \\
\hline pooled & values ${ }^{2}$ & & 0.26 & 0.44 & 0.74 & 1.24 & 0.35 \\
\hline $\begin{array}{l}\text { steel } \\
\text { steel } \\
\text { steel }\end{array}$ & $\begin{array}{l}0.6 \\
1.5 \\
3.0\end{array}$ & $\begin{array}{l}1.43 \\
2.50 \\
4.03\end{array}$ & $\begin{array}{l}0.24 \\
0.19 \\
0.19\end{array}$ & $\begin{array}{l}0.43 \\
0.48 \\
0.80\end{array}$ & $\begin{array}{l}0.46 \\
0.30 \\
0.41\end{array}$ & $\begin{array}{l}1.03 \\
0.92 \\
1.13\end{array}$ & $\begin{array}{l}0.26 \\
0.29 \\
0.36\end{array}$ \\
\hline $\begin{array}{l}\text { concrete } \\
\text { concrete } \\
\text { concrete }\end{array}$ & $\begin{array}{l}0.6 \\
1.5 \\
3.0\end{array}$ & $\begin{array}{l}0.87 \\
1.56 \\
2.82\end{array}$ & $\begin{array}{l}0.27 \\
0.30 \\
0.34\end{array}$ & $\begin{array}{l}0.63 \\
0.70 \\
0.59\end{array}$ & $\begin{array}{l}0.64 \\
0.49 \\
0.57\end{array}$ & $\begin{array}{l}0.87 \\
0.89 \\
0.75\end{array}$ & $\begin{array}{l}0.56 \\
0.52 \\
0.63\end{array}$ \\
\hline
\end{tabular}

${ }^{\prime}$ All values are expressed in $\mathrm{mg} / \mathrm{cm}^{2}$. Colum headings are type of substrate making up specimen, concentration of lead in the paint film standard, the mean of all measurements made with all the instruments of the corresponding standard and substrate, the estimate of intralaboratory precision, $s$, the estimate of interlaboratory precision, $s_{R}$, the intralaboratory estimate of the difference by which two results can differ and be statistically the same, $r$, the interlaboratory estimate of the difference by which two results can differ and be statistically the same, $R$, and the estimate of precision of individual replicate measurements, $\sigma_{\text {indiv }}$.

2 The pooled values are estimates of the corresponding parameters pooled over drywall and wood. 
either case, these results indicate the need to develop standard reference materials for lead-paint films.

4.1.4 Preliminary laboratory assessment of spectrum analyzer

In addition to the detailed analyses of XRF-A and XRF-B instruments, a preliminary assessment of an analyzer which can provide spectral information $(X R F-C$ ) was carried out. XRF-Cl (XRF-C, with the initial version of the spectrum analysis software) was evaluated differently than the lead-specific type because only one instrument was available at the time of NIST's laboratory assessment of XRFs, measurements took longer than those of the other portable instruments and the XRF-C was not available for marketing until late in the NIST study. This analyzer was developed for, and is used by, the mining industry. It uses a $\mathrm{Co}^{57}$ source, a silicon detector and a multi-channel analyzer to obtain spectral information. Depending upon the configuration of the microprocessor, it is possible to store either the results of about 1000 analyses, or several hundred raw spectra. The configuration of the instrument available for use in the preliminary assessment stored many XRF concentration results but only the last spectrum obtained. Typical spectra obtained with this instrument are shown for bare pine and lead-paint films over pine in figure 14. The counting time used was that required to obtain $0.1 \mathrm{mg} / \mathrm{cm}^{2}$ precision for individual replicate measurements over wood. The $x$-axis label is channel number. Channel number can be related to energy by calibration with known radioactive sources. When this is done, the peak at about Channel Number 150 is found to be the lead $K$ peak and the one at about 25 the lead $I$ peak. Note that the $I$ peak is much larger than the $K$ peak. This peak can be used in the field to help detect the presence of low levels of lead that are near the surface of a film.

In the initial evaluation of one of these instruments, measurements were made using an experimental design similar to the one described earlier for XRF-A and XRF-B instruments. For XRF-C instruments, the operator selects the measurement time which is related to the precision of the measurements. (That is, for random error only, the precision increases as the reciprocal of the counting time [19].) An acquisition time of about 2 minutes was chosen for measurements in this study, which resulted in a $0.15 \mathrm{mg} / \mathrm{cm}^{2}$ precision for replicate measurements over wood. The variables included in the experiment were four substrates, four lead concentrations, and two types of paint matrices, one containing 20 percent by mass barium and the other containing only titanium and typical low atomic weight extender pigments.

The results of the laboratory work are reported in Table A4 and are shown in figure 15. This figure shows the means of three individual replicate measurements made on each of the four bare substrates (the zero measurements are biased slightly on the high 
side since all negative results are set equal to zero prior to displaying the measurement result) and the mean of three individual replicate measurements made on each of the substrates for three of the four lead concentrations included in the study. These means were not substrate corrected.

These results were not analyzed further since the manufacturer had revised the software to enhance the lead measurement capabilities of the instrument prior to completion of this project.

\subsection{Spot tests}

As described in the NIST report on screening methods [7], sulfide spot tests have been used to screen for the presence of lead in paint films. Vind and Mathews [20] reported a color change when an $8 \%$ sodium sulfide solution was placed on a light colored paint film containing more than 0.5 percent lead. Sayre and Wilson [21] reported a color change when the lead concentration was greater than $0.8 \%$.

Vind et al [9] also provided information on the stability of approximately 10 and 3 percent sodium sulfide solutions. He characterized solutions thickened with $3 \mathrm{~g} / \mathrm{l}$ of methyl cellulose and solutions containing no thickener. These solutions were held at one of three constant temperatures $\left(5^{\circ} \mathrm{C}, 20^{\circ} \mathrm{C}\right.$, or $\left.35^{\circ} \mathrm{C}\right)$ for nearly a year. The sulfide concentration was determined using an iodometric procedure involving back-titration with sodium thiosulfate solution and a starch indicator. The results of the stability studies for the 10 percent solutions are shown in figure 16. The rate of decrease of sulfide concentration in the 3 percent solutions was nearly the same as that of the 10 percent solutions when stored at $5^{\circ} \mathrm{C}$.

Other spot tests using dithizone, rhodizonate and iodide have also been reported [10]. In tests using dithizone, the lead was dissolved using acid digestion or a combination of dry ashing and acid digestion, the solution was made basic and the lead ions were extracted by dithizone in chloroform or carbon tetrachloride solution to form the red lead-dithizone complex. Since this procedure would be difficult to use in the field, it was not investigated further. Rhodizonate produces a red compound from weakly acid solutions and iodide a yellow compound.

As part of this study, the use of a 8 percent sodium sulfide solution and a commercially available spot test kit in which a red color is obtained in the presence of lead were evaluated with freshly prepared paint films containing known amounts of lead. The paint films were made by mixing a lead free oil-based paint with known amounts of a lead paste containing the basic carbonate white lead pigment (similar to $T T-W-251$ [5]). The amount of lead in the paste was determined using ASTM D 3335 [15], modified as necessary to accommodate the high lead concentration of the 
paste. The paste was added in appropriate amounts to make wet films containing $0.1,0.2,0.5,1$ and 2 percent by mass of the wet film. The wet paint contained 70 percent solids. In some cases the lead-containing films were overcoated by the lead-free oil-based paint to form films having a thickness of $0.6 \mathrm{~mm}$.

In all cases, the tests were conducted by first cutting a groove in the paint using a shave-hook tool, designed with a triangular shaped cutting edge (available from tool supply houses) to form a beveled edge in the paint film. A similar cut could be made with a knife or other sharp blade by cutting the film at an oblique angle to the surface. Next, for the sodium sulfide test, a drop of the test solution was applied on the cut and the surface examined with a $5 x$ magnifying glass for color change. Color change was observed after a few seconds for the films containing 1.4 and 2.8 percent lead while it took several minutes for the color change to be noticeable on the film containing 0.1 percent lead. The manufacturer's directions were followed for the other spot test. As for the sodium sulfide test, the color change took a minute or so to develop.

The results of using the sodium sulfide spot test and the commercially available test on these films in the laboratory is shown in table 5. As can be seen from the results, color changes were observed by both operators for lead concentrations greater than 0.28 percent for both tests. Color changes for concentrations of 0.14 and 0.28 percent were reported to be slight by one operator and not observed by. the other operator. 
Table 5. Results of laboratory-based spot tests

\begin{tabular}{|c|c|c|c|c|c|c|}
\hline \multicolumn{2}{|c|}{} & \multicolumn{2}{c|}{$\begin{array}{c}\text { sodium } \\
\text { sulfide }\end{array}$} & \multicolumn{2}{c|}{$\begin{array}{c}\text { proprietary } \\
\text { spot test }\end{array}$} \\
\hline $\begin{array}{c}{[\mathrm{Pb}],} \\
8\end{array}$ & $\begin{array}{c}\text { theor. [ } \mathrm{Pb}]^{1}, \\
\mathrm{mg} / \mathrm{Cm}^{2}\end{array}$ & $\begin{array}{c}\text { painted } \\
\text { over }\end{array}$ & Op. $1^{3}$ & op. 2 & Op. 1 & Op. 2 \\
\hline 0.14 & 0.014 & no & $+t^{4}$ & $+t^{4}$ & + & - \\
0.28 & 0.028 & no & + & + & + & - \\
0.7 & 0.07 & no & + & + & + & + \\
0.7 & 0.07 & Yes & + & + & + & + \\
1.4 & 0.14 & no & + & + & + & + \\
1.4 & 0.14 & yes & + & + & + & + \\
2.8 & 0.28 & no & + & + & + & + \\
2.8 & 0.28 & Yes & + & + & + & + \\
\hline
\end{tabular}

Theoretical lead concentration in the paint film calculated from the percentage of lead in the films knowing the dry film thickness of the lead-containing film $(50 \mu \mathrm{m})$ and assuming a film density of $2 \mathrm{~g} / \mathrm{ml}$.

${ }^{2}$ Films having a lead concentration of at least 0.7 percent were painted over with additional layers of non-leadcontaining paint. The total film thickness of the nonlead containing paint film was about $0.6 \mathrm{~mm}$.

${ }^{3}$ Two people (operators), identified as op. 1 and op. 2, performed these spot tests in the laboratory.

"After several minutes, a very slight grey color was produced where the film was wet with sodium sulfide solution.

\section{PROCEDURES FOR COLLECTING AND PREPARING PAINT SAMPLES FOR LABORATORY ANALYSIS}

\subsection{Sample collection procedures}

Common to all analytical laboratory methods for determining lead concentration is the problem of collecting a representative sample from an existing paint film. In the collection of any paint sample, it is necessary to ensure that all layers making up the paint film are collected and in the proper relative amounts. If it is desired to express the lead concentration in percent or parts per million by mass of the sample, the substrate must be excluded from the sample, otherwise, the lead concentration will be diluted by the mass fraction of the substrate in the sample. When it is desired to express the lead concentration in terms of mass/area, then the area of the sample must be known, but 
inclusion of small amounts of the substrate should not affect the results.

The procedure used for sample collection in this study was aimed at obtaining samples for mass/area analysis. The procedure used was to 1) apply clear pressure sensitive adhesive tape over an area slightly larger than the sample to be collected, 2) cut through the paint layers and into the substrate using a square punch or template/sharp knife combination, and 3) remove the paint and a thin layer of the substrate beneath it using a sharp chisel having the same dimension as a side of the square. A tray was held under the sample during the removal to collect the pieces of paint if the sample crumbled during cutting or removal. For the most part, the samples taken in this study did not crumble.

other collection procedures have been used and reported. On metal and plaster substrates, some inspectors found that a large piece of the film could be removed by gently heating the film, allowing it to cool and reheating it, cycling this procedure until the film could be removed from the substrate with a putty knife. Others have scraped paint films from a substrate and into a container using a knife or other sharp tool. In any case, each sample must be marked to identify the location from which it is taken.

\subsection{Preparation of paint samples for laboratory analysis.}

Standard laboratory analysis procedures are available for determining the lead content of paint and other materials. These procedures can be divided into two major groups according to the method of sample preparation: 1) those that require dissolution of the lead-containing pigments and driers and 2) those that do not require dissolution of the material.

\subsubsection{Methods requiring dissolution}

Several studies have been conducted to investigate the effectiveness of dissolution procedures. As examples of the procedures available, the standard procedures ASTM D 3335 [15] and NIOSH 7082 [22] are quite different. In the ASTM procedure, the steps are to 1) place the dry film sample in a crucible and char it over a hot plate, 2) ash the sample in a muffle furnace at 475 to $500^{\circ} \mathrm{C}$ until complete, 1 to 2 hours, 3) after cooling, digest the sample in 1:1 $\left.\mathrm{HNO}_{3}, 4\right)$ filter the sample and wash the residue on the filter with a hot ammonium acetate solution three times and, finally, wash the residue with water. In the NIOSH method, the ashing is done at $200^{\circ} \mathrm{C}$ and there is no final rinsing with an acetate solution. Other studies have compared wet ashing with a dry ashing procedure similar to the one described above [23]. 
Because of the differences in the standard test methods, preliminary reports of large differences, in the amount of lead recovered using the two standard procedures and differences in the amount of lead extracted using several extraction procedures [23], two types of experiments were carried out in the present project. First, analyses were carried out using the NIST standard reference paint material (NIST SRM 1579) according to the ASTM D 3335 procedure, except that the ashing temperature was varied and sample size and dissolution procedures were scaled to accommodate the high lead content of the SRM. Second, thermogravimetric analysis was used to study the thermal stability of common lead pigments, paints and a lead-based drier.

\subsubsection{Investigation of ashing procedures}

The SRM paint, NIST 1579, is a heterogeneous mixture of many different kinds of paints which are ground to produce a fine powder [24]. The certified value of 11.87 percent lead is the result of the weighted average of 32 determinations by FAAS and 16 by polarography with a standard error of $0.02 \%$.

Analyses of the SRM paint using the ASTM D 3335 method, modified to accommodate the high lead content of the reference paint, were carried out at four ashing temperatures, $300^{\circ} \mathrm{C}, 400^{\circ} \mathrm{C}, 500^{\circ} \mathrm{C}$, and $600^{\circ} \mathrm{C}$. The results of analysis for lead content at these temperatures is shown in table 6 , including the sample standard deviation, which is slightly less than the interlaboratory precision stated in ASTM D 3335 [15] of $0.4 \%$. (Results at $500^{\circ} \mathrm{C}$, which were obtained as part of the quality control procedure for analysis of field samples, are also included in these results.) Based upon the student's t test, the values obtained at $300^{\circ} \mathrm{C}$, $400^{\circ} \mathrm{C}$, and $600^{\circ} \mathrm{C}$ are statistically significantly lower at a 95 percent confidence level than that obtained at $500^{\circ} \mathrm{C}$. Thus, there appears to be a slight lead loss or incomplete recovery of about 4 percent at these temperatures as compared with that at $500^{\circ} \mathrm{C}$. However, these differences are much less than those reported by Gutknecht (up to 2 times) or reported by Hausknecht et al ( 0.9 times) [23].

Table 6. Effect of ashing temperature on measured lead concentration of NIST SRM 1579

$\begin{array}{cccc}\begin{array}{c}\text { Ashing } \\ \text { Temperature }\end{array} & \text { No. of Meas. } & \begin{array}{c}\text { Percent lead } \\ \text { (mean) }\end{array} & \begin{array}{c}\text { Standard } \\ \text { deviation, } \%\end{array} \\ 300^{\circ} \mathrm{C} & 3 & 10.93 & 0.32 \\ 400^{\circ} \mathrm{C} & 3 & 11.41 & 0.08 \\ 500^{\circ} \mathrm{C} & 13 & 11.77 & 0.26 \\ 600^{\circ} \mathrm{C} & 5 & 11.23 & 0.28\end{array}$

'Private communication with $W$. Gutknecht, Research Triangle Institute, Research Triangle Park, NC, July, 1989. 
5.2.1.2 Thermal stability of lead compounds found in paint

To better sample the wide variability in paint films, thermogravimetric analysis (TGA) was carried out on commonly-used lead pigments to determine the thermal stability of these materials. The number of lead-containing pigments and additives is obviously much less than the number of different lead-containing paints. Two lead-containing paints and paint components were also analyzed using TGA.

Thermogravimetric analysis is a commonly-used procedure to determine the thermal stability of materials. It measures mass changes in a sample as its temperature is increased or while it is held at some constant temperature. Practically, a small amount of material (a few $\mathrm{mg}$ ) is placed in a platinum boat which is hung from a sensitive balance and surrounded by a furnace in a closed environment. Various gases can be fed into the closed environment. The instrument is designed so that the temperature in the furnace can be programmed to follow a predetermined schedule. Typical rates of temperature change are 10 to 20 degrees per minute. The loss of mass of the sample is recorded as a function of temperature, time or both.

Prior to making the measurements described in this section, the temperature scale was calibrated by using four materials with magnetic transitions (Curie-point) in the temperature range of interest, i.e., between $100^{\circ} \mathrm{C}$ and $1000^{\circ} \mathrm{C}[25]$. The temperature differences between the displayed temperature and the Curie-point temperatures were less than $8^{\circ}$ across the temperature range from 200 to $800^{\circ} \mathrm{C}$.

Thermogravimetric analysis was performed in an air environment with a heating rate of $20^{\circ} \mathrm{C} / \mathrm{min}$ on the following materials: $\mathrm{PbO}_{2}, \mathrm{~Pb}_{3} \mathrm{O}_{4}$ (red lead), basic carbonate white lead (usually $\left.\left(\mathrm{PbCO}_{3}\right) \cdot 2 \mathrm{~Pb}(\mathrm{OH})_{2}\right)$, lead nitrate, lead chloride and a lead drier (lead napthenate), several commercial paints, white lead paste, the NIST standard reference material (SRM 1579), linseed oil (a common binder for lead-pigmented paints) and a lead paint sample taken from a house in Baltimore. The results of these analyses are shown in figures 17 through 19. In these cases, the percent mass remaining is plotted as a function of temperature.

According to Nordyke [26], basic lead carbonate and red lead decompose in air at about $600^{\circ} \mathrm{C}$ to form $\mathrm{Pbo}$ in the orthorombic state. Table 7 shows the expected mass loss for these lead compounds, as well as lead nitrate, based upon decomposition to $\mathrm{PbO}$ and the measured mass loss by thermogravimetric analysis. The largest difference in the expected loss based upon decomposition to $\mathrm{PbO}$ and the measured mass loss is for $\mathrm{PbNO}_{3}$. This is the lead compound for which the TGA curve was not smooth but had discontinuous jumps. Decomposition of $\mathrm{PbNO}_{3}$ occurs by loss of $\mathrm{NO}_{x}$ gases. It is speculated that gas created in the sample may 
cause a slight puff of material and hence discontinuous loss of mass from the solid sample with a greater than expected total loss of material. It should be noted, however, that lead nitrate is not used in coatings, although it is sometimes used in quality control samples as a source of lead.

Table 7. Comparison of mass loss at $700^{\circ} \mathrm{C}$ determined by TGA with the calculated loss upon decomposition of lead materials to $\mathrm{PbO}$

Material

red lead

basic carbonate white lead

lead nitrate

lead paste ${ }^{1}$
\% mass loss

as measured

by TGA mass loss calculated$$
4
$$

60

28

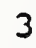

13

67

25

'calculations for lead paste based upon formulation described in TT-W-251, that is 12 percent oil and 88 percent basic carbonate white lead.

From these data, it is apparent that, with the exception of lead nitrate, there is a regular decrease in mass until about $500^{\circ} \mathrm{C}$ and then the materials are essentially stable until a temperature of about $900^{\circ} \mathrm{C}$. It is also interesting to note that linseed oil did not completely decompose until a temperature of about $550^{\circ} \mathrm{C}$ was reached.

Since in the dry-ashing procedure specified in the ASTM D 3335 method and commonly used in the analysis of paint, a specimen is ashed for an hour or more, some TGA runs were carried out in which the temperature of the sample was increased at a rate of $20^{\circ} \mathrm{C} / \mathrm{min}$ until a temperature of 300,500 , or $700^{\circ} \mathrm{C}$ was reached and then the temperature of the sample was held constant for 1 hour. The results of these experiments for the paint SRM and a lead-drier are shown in figure 20. The loss of mass that occurred during the $700^{\circ} \mathrm{C}$ run at about 30 minutes could correspond to the change in mass that occurred at about $650^{\circ} \mathrm{C}$ degrees as shown in figure 20-a. From the TGA data of the lead-based pigments, it seems likely that the loss of mass was not associated with a loss of lead-based pigment but rather with some other pigment or extender that was contained in the SRM paint sample. 
Thus, for commonly used, lead-based pigments, such as basic carbonate white lead, it can be concluded that the loss of lead in dry ashing of a film specimen should be negligible at temperatures less than $600^{\circ} \mathrm{C}$.

5.2.2 Methods not requiring dissolution

In previous research carried out in the NIST, a laboratory method for determining the lead concentration in paint films using a laboratory XRF instrument was developed. Since the results of the research were not widely distributed [27], they are summarized in this section. No additional work was done using laboratory XRF in this study because there was no available standard reference material.

The method involved the following steps and could be carried out in 10 minutes:

1. Crush paint chips in mortar and transfer to crushing vial.

2. Crush in mixer-mill.

3. Weigh $200 \mathrm{mg}$ sample into mixing bottle which contains (preweighed) $1.00 \mathrm{~g} \mathrm{zno}$ and $1.00 \mathrm{~g}$ cellulose. Add mixing balls.

4. Mix in mixer-mill.

5 Transfer to $x$-ray sample cup.

6. Measure lead $L_{\beta} x$-ray intensity.

7. Use calibration curve to determine result.

Since paint compositions vary widely, with the two extremes for lead $L \mathrm{x}$-ray analysis being those containing $\mathrm{ZnO}$ and $\mathrm{TiO}_{2}$, $\mathrm{ZnO}$ is added to reduce the differences in paint compositions to a common matrix so far as XRF is concerned, making possible the use of a single calibration curve. Cellulose was added to aid efficient pulverization and mixing.

In the evaluation of 15 sample paints of known lead content formulated with one or more of $\mathrm{Pb}_{3} \mathrm{O}_{4}$, leaded-zinc oxide, basic lead carbonate, or lead chromate, the mean of the set of differences between the known and XRF values was 0.19 percent and the estimate of the standard deviation of the set of differences was 0.27 percent. The paints had from 0.6 to 1.9 percent lead by mass. The films from which the ground samples were made were from 0.05 to $0.1 \mathrm{~mm}$ thick, so the area lead concentration ranged from about 0.05 to $0.2 \mathrm{mg} / \mathrm{cm}^{2}$.

\section{FIELD EVALUATIONS}

Field evaluations were conducted in nine HUD-owned housing units in the Baltimore/Washington, DC area. These houses were being used in the abatement demonstration program. They were all vacant and without electrical power. The windows of several of 
the houses had been boarded-up and the interiors were dark. Such conditions, which hinder testing, might be expected to occur in other HUD-assisted housing. The lack of electrical power limited sample collection to manual removal of samples.

\section{1 objectives}

The objectives of the field study were 1) to estimate the errors in making portable XRF measurements and spot tests under typical field conditions and 2) to develop recommended procedures for collecting paint samples for laboratory analysis. Emphasis was placed on determining the precision and accuracy of measurement methods near the regulatory limit of $1 \mathrm{mg} / \mathrm{cm}^{2}$.

\subsection{Experimental plan}

The experimental plan was to make 20 to 30 measurements and take samples of paint films having apparent lead concentrations near $1 \mathrm{mg} / \mathrm{cm}^{2}$ over each of the four major substrates: gypsum wallboard or gypsum plaster, wood, metal and concrete (or brick or stucco). Using these data, paired t-tests [14] would be carried out on the differences of the substrate-corrected XRF readings and the FAAS result for each substrate to estimate the error of field measurements made with portable XRF analyzers. (The mean of the difference distribution provides an estimate of systematic error associated with field measurements while the standard deviation provides an estimate of the precision of the measurements.) Unfortunately, in the nine houses used in the field study, there were few metal and concrete substrates and few paint films appeared to have lead concentrations of $1 \mathrm{mg} / \mathrm{cm}^{2}$. Hence, more measurements were made over wood, gypsum wallboard and gypsum plaster than over metal and concrete, and the estimates of error of the field measurements are from measurements made over films with low lead contents.

\subsection{Experimental procedure}

Three steps were carried out: 1) obtaining measurements of bare and painted substrates using portable XRF analyzers, 2) sampling of paints for laboratory analysis, and 3) performing spot tests. The details of the procedure are given below. Briefly, first a paint-film sample location was chosen. Large flat areas were chosen such that painted surface was exposed around the entire face of the largest analyzer. Also, areas beneath which pipes or wires were expected were avoided. At the center of this location, XRF measurements were made, a sample was taken for analysis in the laboratory and spot testing was carried out. Because of the variability in the XRF readings made on bare substrates in the laboratory, the field measurement procedure included making measurements on bare substrates so that appropriate corrections to the measurements made over painted substrates could be made. 


\section{3 .1 Sample location}

Since the major objectives of the field tests were to obtain estimates of 1) the error of measurements made with portable XRF analyzers and 2) the false negative and false positive rates of spot tests at lead concentrations near $1 \mathrm{mg} / \mathrm{cm}^{2}$, an attempt was first made using one of the portable XRF analyzers to screen sample locations in each housing unit to find lead concentrations near $1 \mathrm{mg} / \mathrm{cm}^{2}$. When such locations could not be found, samples were chosen with screened-lead concentrations over a much wider range, but usually less than $10 \mathrm{mg} / \mathrm{cm}^{2}$. For each sample location chosen, a code was assigned to the location and the area was marked with a pen so that XRF measurements and sample collection would be carried out in the same location.

\subsubsection{Sample collection and analysis}

Samples were collected by the method described in section 5.1, that is using tape to reduce crumbling, cutting through a known area of the paint film into the substrate and removing the sample with a chisel. Samples were placed in plastic bags that were marked with the location code. Analysis of each sample was carried out in the laboratory using the ASTM standard procedure for determining lead in paint, D 3335 [15]. Either a blank control or a paint SRM was inserted in the sample stream after every fifth sample.

\subsubsection{XRF testing}

Both types of XRF analyzers (lead-specific and spectrum analyzer) were used in carrying out the field tests. Two versions of the spectrum analyzer were used; XRF-CI was the same as assessed in the laboratory. XRF-C2 contained software which had been modified to enhance its lead measurement capabilities. The procedure used in the field essentially followed the recommendations of the manufacturers of the portable instruments and was similar to that typically used by people making these tests in the field. First, as a check of instrument stability, five measurements were made on a manufacturer-supplied blank substrate and on the manufacturer-supplied lead substrate for instrument calibration. The results and the time at which the measurements were made were recorded. For XRF-A, the gypsum sample was used for the zero measurements. Appropriate zero and lead-standard corrections were made for XRF-A when the readings were not in the tolerance range given by the manufacturer. Readings for $X R F-B$ were within the tolerance stated by the manufacturer.

Bare substrates corresponding to painted surfaces were prepared by scraping the paint until a bare area of substrate was obtained. The typical size of the scraped area was about $100 \mathrm{~mm} \times$ $100 \mathrm{~mm}$. In all cases the area was substantially larger than the 
face of an analyzer. Three measurements were made on the bare substrate and three on corresponding painted substrates. The zero and manufacturer's standard were checked at least every two hours.

\section{3 .4 Spot tests}

spot tests using sodium sulfide and a proprietary kit that forms a red indicator material in the presence of lead were carried out in many of the sample locations. The sodium sulfide solution was a freshly prepared, unthickened solution containing 8 percent sodium sulfide. A drop of the solution was placed on a freshly made oblique cut through the paint film. Any darkening of the area (except for that which was known to be associated with wetting) was considered to be a positive test. The proprietary test was carried out as described in section 4.2 , using the manufacturer's directions; any reddish color change was considered a positive test.

\subsection{Results of field studies}

\subsubsection{Sample collection and analysis}

The FAAS results using ASTM D 3335 [15] for the field samples are shown in tables $A 5$ and $A 6$ in the appendix. A blank or paint SRM control sample was inserted into the sample stream after every fifth sample. The mean value of the blank quality control samples was $0.00 \mathrm{mg} / \mathrm{cm}^{2}$ with a standard deviation of $0.01 \mathrm{mg} / \mathrm{cm}^{2}$. The mean value of the paint SRM samples (true value is $11.87 \pm$ 0.04 percent by mass) was 11.80 percent with a standard deviation of 0.28 percent.

Several replicate samples of paint films were collected in the field studies to investigate the variability of the sampling procedure itself, although it is not possible to separate variability due to the collection procedure from that due to sample inhomogeneity. Seven sets of three replicate samples were collected. The pooled estimate of precision of the replicate measurements was $0.22 \mathrm{mg} / \mathrm{cm}^{2}$ for six sets of data. This estimate of precision includes error due to sample collection procedure, sample inhomogeneity and FAAs analysis. For one set of samples collected, the FAAS results were very different $\left(4.2 \mathrm{mg} / \mathrm{cm}^{2}\right.$, $0.75 \mathrm{mg} / \mathrm{cm}^{2}$ and $1.34 \mathrm{mg} / \mathrm{cm}^{2}$ ). The sample precision was treated as an outlier and was not included in the pooled estimate. It is thought that a localized area of the lead-containing layer of paint had peeled or been scraped away prior to the time the layer was recoated since no reasonable estimate of error due to collection or analysis could account for the differences in results. 
The results of the NIST field tests, in which measurements were made with one instrument of each type, are reported in raw-data form in tables A5 through A8. For the lead-specific portable XRF analyzers (XRF-A and XRF-B), the differences between the XRF and FAAS results are shown for the three major substrates tested-wood, gypsum board and gypsum plaster--in figures 21 and 22 with and without a substrate correction. To further illustrate the size of the bare substrate correction for the lead-specific instruments, the distribution of readings over bare substrates is shown in figure 23. The difference between XRF results obtained with an XRF-C instrument and FAAS results is plotted against FAAS results in figure 24 .

A paired t-test was used to obtain estimates of error of measurements made with these instruments for lead concentrations near $1 \mathrm{mg} / \mathrm{cm}^{2}$. In this procedure, the difference between corresponding readings (i.e., XRF - FAAS) is determined and the mean and standard deviation of the difference distribution are estimated. Only results for which the FAAs reading was less than 2 $\mathrm{mg} / \mathrm{cm}^{2}$ were included in the analysis. The results of these calculations for each substrate and each instrument type are shown in tables 8 and 9 for distributions obtained using corrected values of the portable XRF readings (i.e., corrected with readings over bare substrates, except for the wooden doors when the value obtained over the manufacturer's standard was used.) Since there were several apparent outliers in the difference data, the estimated mean and standard deviation of the difference distributions in which these values were excluded were also calculated. These parameters are shown in tables 8 and 9 in the columns marked "outliers removed." The 95 percent confidence limits of the estimates of the mean and standard deviation of these distributions are also shown. These confidence limits were determined using the $t$ and $x^{2}$ distributions, respectively [14]. The pooled estimate of individual replicate measurements for each of the substrates is shown in the tables 8 and 9 to use in comparing with that obtained in laboratory measurements. From table 2 , since $\sigma_{\text {within }}$ is equal to $\sigma_{\text {ind }} / \sqrt{3}$ for measurements with no substrate correction, it can be observed that the precision of individual replicate measurements is similar in laboratory and field measurements.

Based upon these results, the pooled estimate of precision of measurements for both instruments over wood is $0.7 \mathrm{mg} / \mathrm{cm}^{2}$ and over plaster and gypsum wallboard is $0.4 \mathrm{mg} / \mathrm{cm}^{2}$; the pooled estimate of precision of measurements for both instruments over wood, plaster and gypsum wallboard is $0.6 \mathrm{mg} / \mathrm{cm}^{\frac{2}{2}}$.

The mean of the distribution is a measure of the average difference of XRF and FAAS results. A non-zero mean indicates a systematic difference between the two measurement methods, which 


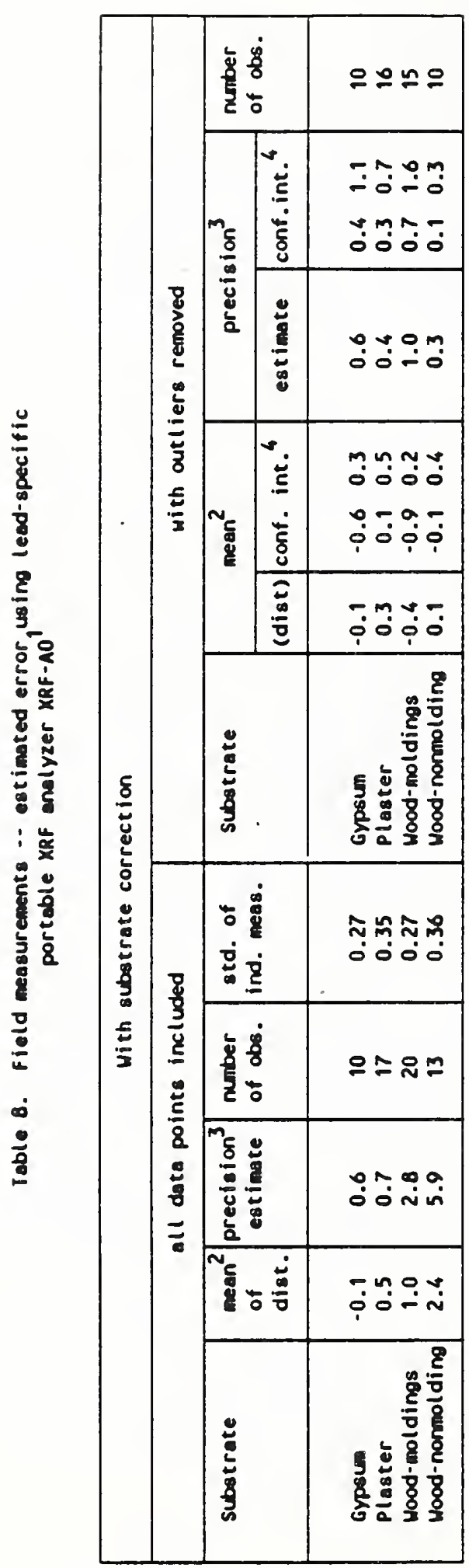

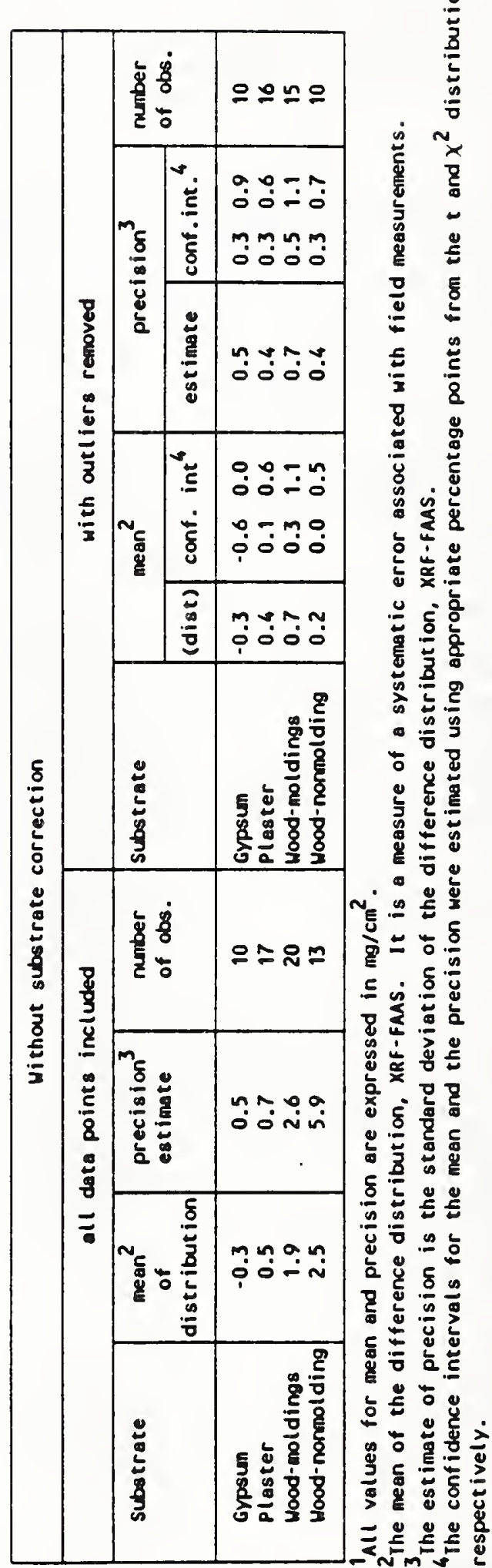



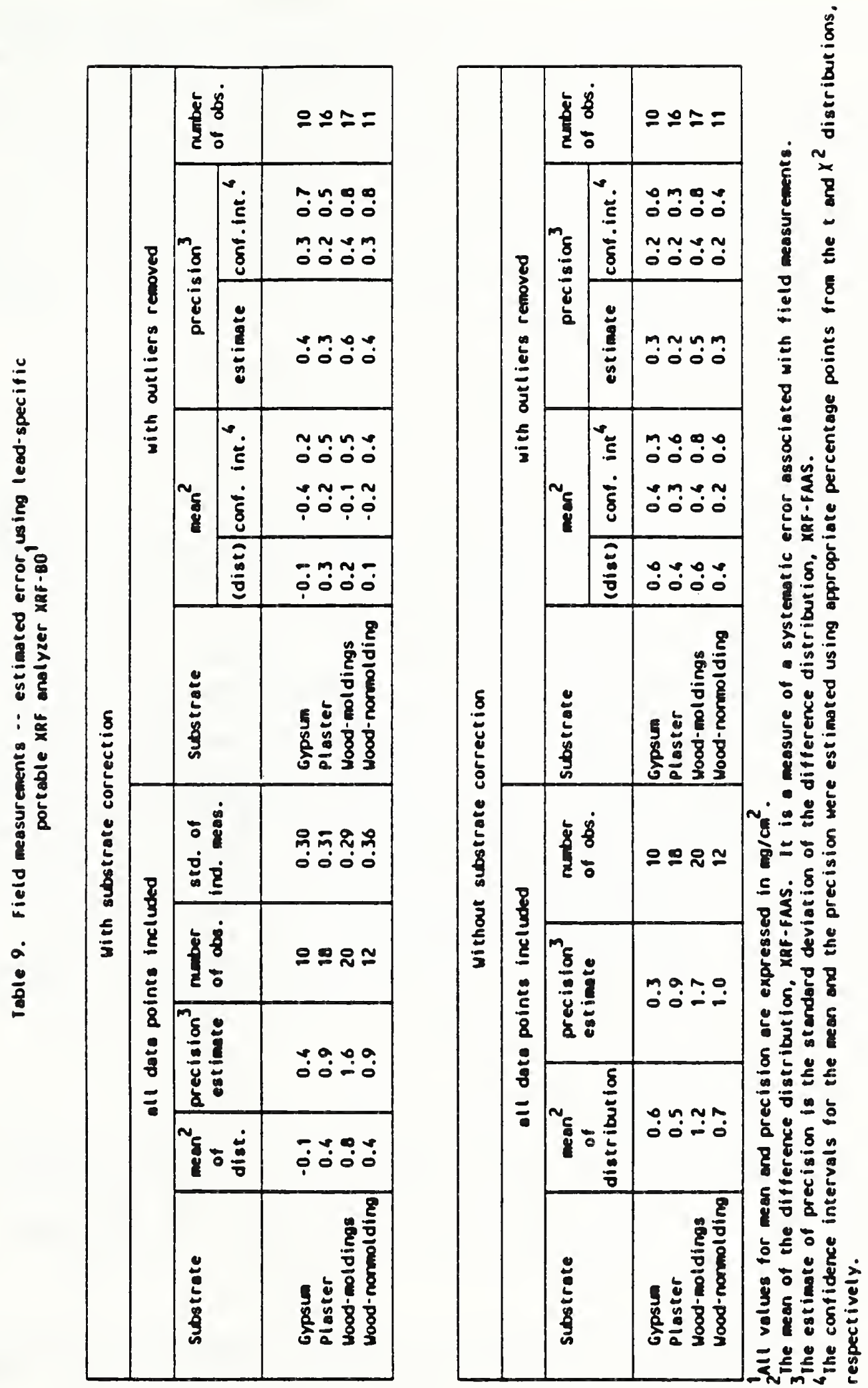
is designated systematic error. The average of the absolute values of the estimates of systematic error for both instruments over wood is $0.2 \mathrm{mg} / \mathrm{cm}^{2}$ and over plaster and gypsum wallboard is also $0.2 \mathrm{mg} / \mathrm{cm}^{2}$. As expected, the results which were obtained by applying a substrate correction appear to have less systematic error than those which were not. Unlike the estimates of precision for replicate individual measurements which were similar in laboratory and field measurements, the precision of the measurement method is poorer for measurements carried out in the field than for those carried out in the laboratory. The mean of the difference distribution, in general, is of the opposite sign of the bias observed in laboratory measurements. These results are discussed further in section 6.6 .3 .

Insufficient data was collected to determine estimates of error for the other substrates. The raw data is shown in the tables in the appendix.

Only limited data were obtained using the spectrum analyzer portable XRF instrument. If wood and plaster substrates are treated together, the mean and standard deviation of the distribution of the difference of XRF and FAAS readings for the Version 1 software are 0.4 and $0.4 \mathrm{mg} / \mathrm{cm}^{2}$ with no outliers.

During the time this study was being conducted, the spectrum analysis software for the XRF-C instrument was revised. In a very brief field evaluation of the instrument with the new software, the data shown in the appendix were obtained. An example of a spectrum of a paint film containing lead is shown in figure 25. Lead $K$ and $L$ peaks are apparent as well as a barium $K$ peak. The estimated mean and standard deviation of the difference distribution for FAAS values less than $2 \mathrm{mg} / \mathrm{cm}^{2}$ are 0.1 and $0.2 \mathrm{mg} / \mathrm{cm}^{2}$, respectively, with two apparent outliers excluded from the analysis. These estimates were based on 16 data points. The 95 percent confidence interval for the mean is 0 to $0.2 \mathrm{mg} / \mathrm{cm}^{2}$ and the 95 percent confidence interval for the standard deviation is 0.15 to $0.3 \mathrm{mg} / \mathrm{cm}^{2}$, estimated using appropriate percentage points from the $t$ and $x^{2}$ distributions, respectively [14].

\subsubsection{Results of spot tests}

Sodium sulfide spot tests were carried out in 68 locations. In 48 of these locations, the lead concentration in the paint film was less than $1 \mathrm{mg} / \mathrm{cm}^{2}$. The false positive rate was $6 / 48$ or 12.5 percent. The false negative rate was $2 / 20$ or 10 percent. The 95 percent confidence interval for the false negative rate is 0 to 23 percent [28].

Tests using the proprietary test were carried out in 22 locations. The false negative rate was $1 / 9$, or 11 percent, while the false positive rate was $1 / 13$, or 8 percent. 
Both of these tests were carried out by people experienced in performing chemical analyses, including spot tests. Plausible scenarios can easily be developed which would result in a false negative decision if the tests were not properly carried out. These include not getting indicator solution in contact with the entire film thickness, failure to detect weak color changes, and allowing insufficient time for the color to develop. In addition, false negative decisions also may occur when the paint film is very thick, thereby diluting the lead concentration. Training of testers may be adequate to negate the concerns with the technique, but more testing is needed to investigate the potential causes of an erroneous testing result.

\section{5 other portable lead-specific XRF field data sets}

Two other sets of field data are available in which measurements were carried out in the field using lead-specific portable XRF analyzers and samples were collected from the same location for comparative laboratory analysis. One set is from data obtained by KTA-Tator, Inc., testers in the abatement demonstration project, and the other for work carried out in lead-based paint characterization by $S$. Lewis at Georgia Technical Institute (GTI). In the abatement demonstration data, laboratory analyses were carried out using FAAS in accordance with ASTM D 3335 . The results of the analysis of the difference distribution (XRF-FAAS) are shown in table 10 for data which were substrate-corrected and for data which were not corrected for the substrate. For the other data set for coatings over wood and metal substrates, intact paint films were removed from the substrate by alternately heating and cooling the surface with a hot-air gun, until the entire paint film could be peeled.from the substrate. The lead concentration of the paint film was determined by laboratory XRF analysis of the lead $\mathrm{K} x$-ray. The portable XRF results were obtained by performing the appropriate substrate correction. The results of the analysis of the difference distribution (XRF$X R F_{(a b)}$ for laboratory-determined lead concentrations less than $2 \mathrm{mg} / \mathrm{cm}^{2}$ is shown in table 11.

Based on the first data set, the pooled estimates of precision over plaster, drywall and wood for all instruments is $0.5 \mathrm{mg} / \mathrm{cm}^{2}$. The weighted estimate of the systematic error associated with field measurements over these substrates is $0.4 \mathrm{mg} / \mathrm{cm}^{2}$. Based on the second data set, the corresponding pooled estimates are 0.6 $\mathrm{mg} / \mathrm{cm}^{2}$ and $0.1 \mathrm{mg} / \mathrm{cm}^{2}$.

\subsection{Discussion}

\subsubsection{Sample collection}

The sample collection procedure, described in section 5.1 above, worked well to remove the entire thickness of a paint film. As 
Table 10. Estimated error of field measurements

made with lead-specific portable XRF analyzers from abatement demonstration data

With substrate correction

$\mathrm{XRF}-\mathrm{A}$ analyzers

(all data points included) $X R F-B$ analyzers mean prec., no. of mean prec., no of $(\sigma)$

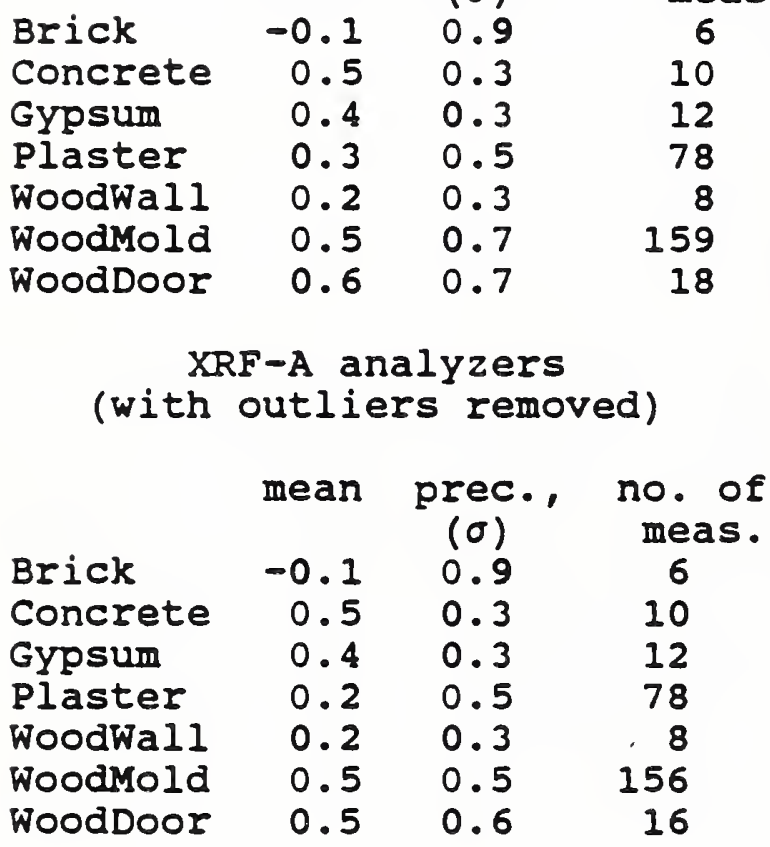

Without substrate correction XRF-A analyzers XRF-B analyzers

(all data points included)

mean prec., no. of

( $\sigma)$ meas.
Brick

Concrete (too few data pts)

Gypsum

Plaster $0.4 \quad 0.6$

WoodWall $0.3 \quad 0.1$

WoodMold

WoodDoor

0.3

0.6

0.20 .3

20
7
20
8

meas. 
Table 11. Estimated error of substrate corrected field measurements made with lead-specific portable $X R F-B$ analyzers from data from $S$. Lewis (GTI)'

\begin{tabular}{|c|c|c|c|c|c|c|}
\hline \multirow[b]{2}{*}{ Substrate } & \multicolumn{3}{|c|}{$\begin{array}{l}\text { analyzer \#1 } \\
\text { (all data points }\end{array}$} & \multicolumn{2}{|c|}{$\begin{array}{l}\text { analyzer \#2 } \\
\text { included) }\end{array}$} & \multirow[b]{2}{*}{$\begin{array}{l}\text { no. of } \\
\text { meas. }\end{array}$} \\
\hline & mean & $\begin{array}{l}\text { prec. } \\
(\sigma)\end{array}$ & $\begin{array}{l}\text { no. of } \\
\text { meas. }\end{array}$ & mean & $\begin{array}{l}\text { prec., } \\
(\sigma)\end{array}$ & \\
\hline \multirow[t]{2}{*}{$\begin{array}{l}\text { Wood } \\
\text { Steel }\end{array}$} & $\begin{array}{l}0.2 \\
0.4\end{array}$ & $\begin{array}{l}0.8 \\
0.5\end{array}$ & $\begin{array}{l}32 \\
20\end{array}$ & $\begin{array}{l}0.2 \\
0.2\end{array}$ & $\begin{array}{l}0.9 \\
0.4\end{array}$ & $\begin{array}{l}32 \\
21\end{array}$ \\
\hline & \multicolumn{3}{|c|}{$\begin{array}{l}\text { analyzer \#1 } \\
\text { (with outlier }\end{array}$} & removed) & zer \#2 & \\
\hline Substrate & mean & $\begin{array}{l}\text { prec., } \\
(\sigma)\end{array}$ & $\begin{array}{l}\text { no. of } \\
\text { meas. }\end{array}$ & mean & $\begin{array}{l}\text { prec., } \\
(\sigma)\end{array}$ & $\begin{array}{l}\text { no. of } \\
\text { meas. }\end{array}$ \\
\hline Wood & 0.1 & 0.6 & 31 & 0.1 & 0.7 & 31 \\
\hline
\end{tabular}

${ }^{1}$ All values for mean and precision are expressed in $\mathrm{mg} / \mathrm{cm}^{2}$; the mean is the mean of the difference distribution, $X R F-X R F_{\text {lab, }}$ and the estimate of the precision is the standard deviation, $\sigma$, of the difference distribution.

is apparent from the microscopic and EDS evidence presented earlier in this report, it is essential to remove the upper part of the substrate to ensure complete recovery of lead paint pigments. Using this procedure, paint samples were removed from wood, plaster, gypsum wallboard, metal, and concrete. External power is not required and only simple tools are used. However, some damage is done to the substrate. On painted surfaces, the damage could be easily repaired, but on a varnished wood surface, the damage would probably be unacceptable. Hence, there may be situations when other removal methods would be more desirable.

It is difficult to determine the precision of the sample collection method in the field since there is no way to determine the degree of homogeneity of the film. Only slight differences in the thickness or continuity of an old film having a high lead concentration would cause big differences in lead concentration in a sample collected in the field, and there are many reasons for the existence of inhomogeneous paint films, including nonuniform application of paint and wearing-away and peeling of old layers. However, the reproducibility of lead concentrations in some of the replicate samples collected was good. 


\section{6 .2 spot tests}

Based upon the results of this study, spot tests performed by experienced analytical chemistry technicians may be useful to indicate whether or not lead is present at or near the $1 \mathrm{mg} / \mathrm{cm}^{2}$ level. Further evaluation is required, however, before a recommendation to use spot tests for detecting lead in paint can be made. The variability associated with operator and paint matrix on the results must be determined. In addition, since the response to the test is directly related to percent lead, film thickness is an important parameter. That is, as the film thickness increases, the expected ability of detecting lead at $1 \mathrm{mg} / \mathrm{cm}^{2}$ decreases, since the volume concentration is decreasing.

\subsubsection{Portable XRF analyzers}

The estimates of precision and the systematic error associated with field measurements of the three data sets for the leadspecific portable XRF instruments presented above are in good agreement; That is, the estimate of precision is $0.5 \mathrm{mg} / \mathrm{cm}^{2}$ to $0.6 \mathrm{mg} / \mathrm{cm}^{2}$, while that for systematic error is about $0.2 \mathrm{mg} / \mathrm{cm}^{2}$. The precision of measurements over wood was generally poorer and the systematic error higher than over plaster or gypsum wallboard. This is probably due to the wide variability of composite substrates in which wood is the outer layer. As expected, the results which were obtained by applying a substrate correction were in better agreement with the FAAS results than than those which were not.

The precision for the field-based measurements is poorer than that obtained in the two laboratory-based experiments. This is not surprising because of the many substrates and combinations of substrates found in the field, as well as the presence of some uncontrollable parameters reported to affect results, such as extreme temperatures, difficult working conditions, and presence of power lines and pipes. The laboratory estimates of precision were expected to be "best-case" estimates since experimental parameters could be better controlled in the laboratory. However, the means of the difference distributions for substratecorrected data tend to have the opposite sign of the bias observed in the NIST laboratory experiment. The two most reasonable explanations are related to substrate effect on the portable XRF measurements and errors arising from sample collection procedures for the laboratory analysis. As observed in the laboratory-based measurements, small changes in a substrate appear to affect the measurement result. Although samples collected for laboratory evaluation in this experiment contained the surface of the substrate and were thought to contain all the paint material, it could be possible that some 
lead-containing material was not collected, including lead that may be contained in the substrate itself.

Some large differences in concentrations determined using XRF and FAAS were observed in the data sets. These differences could be associated with the presence of lead beneath the most recent layers of paint. In one case, for example, readings of $4 \mathrm{mg} / \mathrm{cm}^{2}$ or greater were obtained using both types of lead-specific analyzers, but no lead was found during a sodium sulfide spot test on site (later confirmed by laboratory testing) and the paint film was very thin. Since this house was scheduled for major renovation, it was determined by cutting a hole in the wall that gypsum wallboard had been applied over a lead-containing paint (as confirmed by laboratory analysis) on a plaster wall. This reasoning was supported by laboratory measurements in which a film having a lead concentration of about $6 \mathrm{mg} / \mathrm{cm}^{2}$ was placed beneath a piece of gypsum wallboard over a plaster substrate. A mean of ten measurements obtained using XRF-AO was $2.1 \mathrm{mg} / \mathrm{cm}^{2}$ and using XRF-BO was $0.5 \mathrm{mg} / \mathrm{cm}^{2}$. It is suspected that many of the large differences between the XRF result and the FAAS result may be due to similar situations.

The multi-channel analyzer device provides information that could be used in determining the relative depth of the lead. Since signals associated with both $K$ and $L$-ray lead lines can be observed, a comparison can be made. I lead x-rays are more readily attenuated by building materials than $k$ x-rays. Hence, the presence of a large peak associated with $\mathrm{K} x$-rays, but only a small peak associated with $L$ x-rays, would suggest that the lead was buried either beneath many paint layers or some other thick material.

\section{TESTING PROCEDURE FOR LEAD IN PAINT FILMS}

\subsection{Procedure}

The objective of the testing procedure is to identify films having lead concentrations equal to or exceeding $1 \mathrm{mg} / \mathrm{cm}^{2}$. Since there is always a degree of imprecision and systematic error associated with measurement procedures, there is always at least a slight risk that a decision based upon a measurement will be wrong. However, once an acceptable risk of a false decision is defined, confidence intervals can be determined or hypothesis testing carried out for a given measurement procedure using standard statistical procedures, provided the precision, $\sigma$, and bias (or systematic error), $\delta$, of the measurement method are known.

For example, using hypothesis testing and permitting a 5 percent risk level of a wrong decision, the null hypothesis that the true lead concentration of a film is at least $1 \mathrm{mg} / \mathrm{cm}^{2}$ can be rejected when a measured value, $x$, meets the criterion 


$$
x<1-1.6 \sigma-|\delta|
$$

Similarly, the null hypothesis that the true lead concentration is less than $1 \mathrm{mg} / \mathrm{cm}^{2}$ can be rejected when

$$
x \geq 1+1.6 \sigma+|\delta| \text {. }
$$

This is based on the reasonable assumption that replicate results are normally distributed. For measurement results between [ 1 $1.6 \sigma-|\delta|]$ and $[1+1.6 \sigma+|\delta|]$, a decision that the true concentration is at least $1 \mathrm{mg} / \mathrm{cm}^{2}$ or less than $1 \mathrm{mg} / \mathrm{cm}^{2}$ cannot be made at the 5 percent risk level. (The $\sigma$ multiplier is 1.6 since a one-sided interval is appropriate when testing either of these two conditions. However, a $\sigma$ multiplier of 2 would be used to determine the 95 percent confidence interval for the true concentration based upon an experimental result, $x_{.}$) Thus, using estimates of error given in section 6.6.3, for a measurement method based on the use of a lead-specific portable XRF analyzer with substrate correction, and assuming a 5 percent risk of error, the null hypothesis that the true lead concentration is less than $1 \mathrm{mg} / \mathrm{cm}^{2}$ can be rejected when a measurement result is at least $2.2 \mathrm{mg} / \mathrm{cm}^{2}$. For a risk level of 10 percent, the corresponding requirement is $2 \mathrm{mg} / \mathrm{cm}^{2}$.

The values of a measurement result required for rejection of either of the null hypotheses tend toward $1 \mathrm{mg} / \mathrm{cm}^{2}$ as the precision of the measurement procedure improves. Hence, because of its higher precision, laboratory testing will be required if it is essential to know the lead concentration of a painted area to within a few percent of the total concentration. (Laboratory results based upon ASTM D 3335 have been estimated to have an interlaboratory precision of 9 percent of the lead concentration [15]: thus, for concentrations near $1 \mathrm{mg} / \mathrm{cm}^{2}$, the estimated precision would be $0.1 \mathrm{mg} / \mathrm{cm}^{2}$.)

The sample collection procedure will be affected by the units in which one wants to express the lead concentration, but in any situation, a representative sample of paint film must be collected. If the units are to be percent of lead by mass of sample, the substrate content of the film must be kept to a minimum or be able to be determined. On the other hand, if the units are to be mass of lead per unit area, the area of the sample must be known and all of the film from the area must be collected, but inclusion of some of the substrate will not matter.

However, if the question to be answered is whether the lead concentration is typical of that associated with a thin film of a paint formulated with lead pigments (e.g., to prioritize abatements according to lead concentration), then portable XRF testing can be used with no substrate correction. For example, based upon the NIST data and the abatement demonstration data, a 
conservative estimate of a positive bound for the systematic error associated with a a bare substrate reading is $3 \mathrm{mg} / \mathrm{cm}^{2}$. Hence, when the result of a measurement with an analyzer having an estimated precision of $0.6 \mathrm{mg} / \mathrm{cm}^{2}$ is greater than $1.60+3=4$ $\mathrm{mg} / \mathrm{cm}^{2}$, there is only a 5 percent chance that the true concentration is less than $1 \mathrm{mg} / \mathrm{cm}^{2}$. Thus, a lead-specific portable XRF analyzer will be useful in screening for high levels of lead in paint films.

Further characterization of two additional procedures -- chemical spot tests and the use of a spectrum analyzer portable XRF device -- is needed to determine their precision and accuracy before the statistical tests described above can be applied to them.

Nonetheless, based on preliminary data, chemical spot tests may provide the basis for a screening method to eliminate some surfaces from further evalaution and a measurement method using the spectrum analyzer XRF instrument shows promise for improvement in the confidence of in-situ XRF measurement results.

For any measurement procedure selected, quality assurance procedures must be defined and carried out to ensure that data meet the necessary standards of quality. The specifics of the quality assurance program will depend upon the measurement methods.

Detailed guidance on developing quality assurance/quality control procedures is available $[\mathrm{e} .9 ., 29,30,31]$.

\subsection{Safety}

As discussed in section 6, four measurement procedures would primarily be involved in a testing procedure to determine lead concentrations in paint films. These are 1) use of portable XRF analyzers, 2) sampling for laboratory evaluation, 3) use of spot tests, and 4) carrying out laboratory procedures. No exceptional hazards are associated with these procedures if they are carried out using accepted safety practices. Comments on the measurement procedures follow.

\subsubsection{Portable XRF analyzers}

All portable XRF analyzers evaluated in this study contain a sealed radioactive source. The two major concerns associated with their use are personal exposure to radiation and contamination of the environment with a radioactive material. Results of measurements of radiation levels made at NIST near the analyzers using a Geiger counter are shown in table 12 together with the OSHA requirements for health and safety. To ensure that the source remains sealed, wipe tests are required to be carried out every six months. (When not in use, these devices should be stored in a secure area and in a place that will minimize exposure to people, thereby reducing their contribution towards the allowed radiation limits as shown in table 12.) 
The two lead-specific devices are equipped with a "fail-safe" shutter mechanism, i.e., a trigger must be manually pulled or pushed to open the shutter (although either could be over-ridden by an operator). However, the shutter mechanism of the spectrum analyzer device is operated using a key. Hence, the shutter could be left open accidentally while measurements were not being made or during storage. Proper training of operators is essential to minimize the possibilities of improper use of the analyzers.

\section{2 .2 spot tests}

spot test solutions made with sodium sulfide are caustic and should not be allowed to come into contact with the skin. If the solution does come into contact with the skin, the skin must be flushed with water. The solution also has an odor which is irritating to some people. Reagents in other spot test kits could also be harmful and the manufacturer's instructions on safety should be followed.

\subsubsection{Laboratory procedures}

All of the laboratory procedures discussed in this report are similar to procedures routinely conducted in many laboratories and are considered safe if carried out following the equipment manufacturer's instructions and accepted laboratory practices.

\subsection{Availability of qualified testers and samplers}

Although testing for lead in paint in buildings has been carried out for several years and training courses are given by government agencies and university groups, certification programs for testers have not been developed. Since there are basically two types of testing conducted in determining the concentration of lead in paint films, field and laboratory, each will be discussed separately.

\subsubsection{Field testing}

The manufacturers of portable XRF instruments provide the major source of training for testing of paint films based upon the use of their instruments. Although detailed records are not available for the number of people they have trained, one manufacturer estimated that a total of 2000 people have been trained by manufacturers. A manufacturer also estimated that there are 700 to 1000 portable lead-specific XRF devices available for use. No estimate could be obtained on the number of people carrying out spot tests, although sodium sulfide spot tests are accepted for use in the state of Massachusetts to determine the lead contents of paint films. 
Table 12. Radiation levels, measured near portable XRF analyzers using a Geiger counter, and OSHA limits for exposure to radiation

Radiation levels measured near portable XRF analyzers

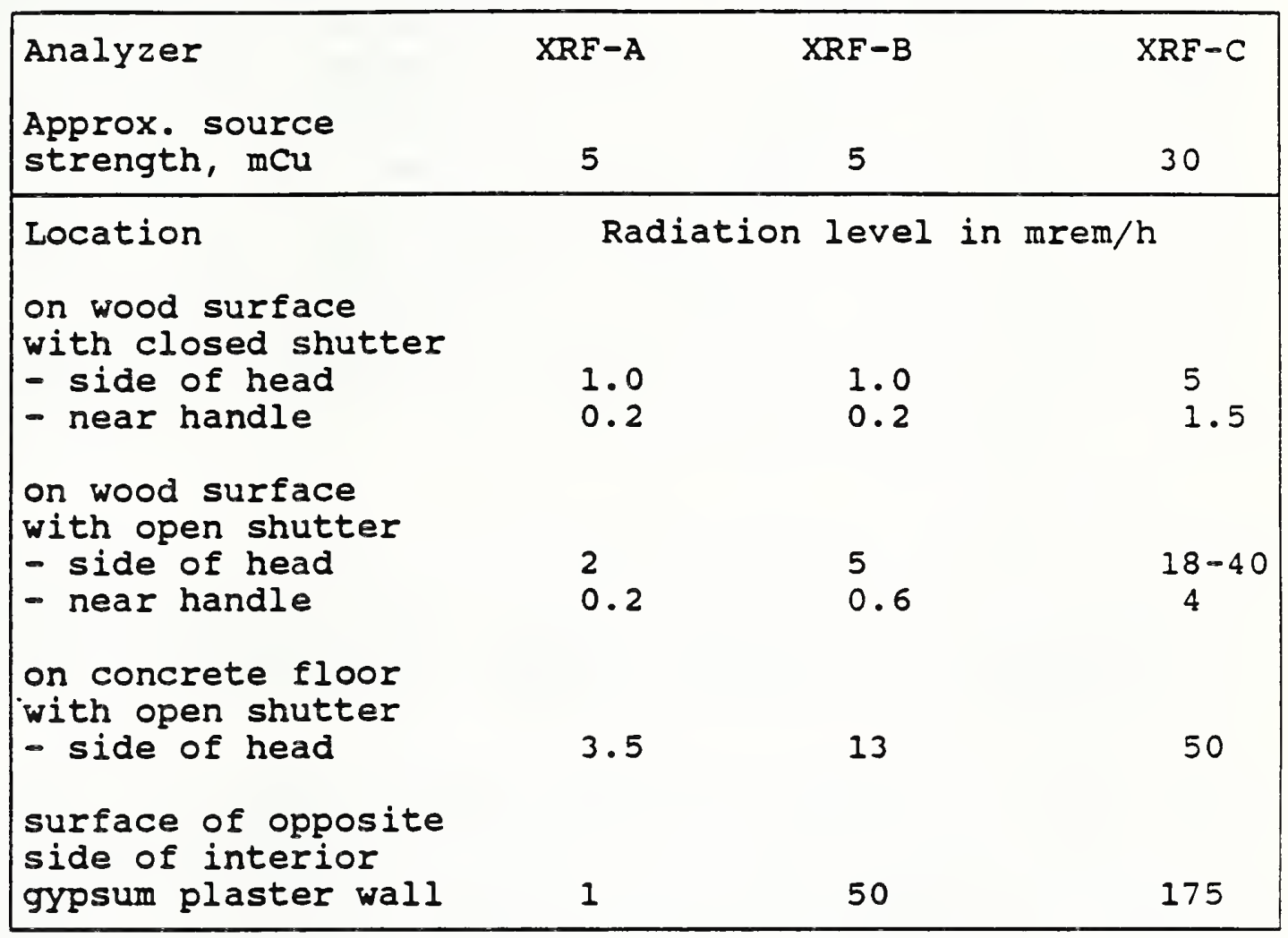

OSHA limits for individual exposure to radiation ${ }^{1}$ (see document for specified exceptions)

\begin{tabular}{|lc|}
\hline Exposed area & $\begin{array}{c}\text { mrems per } \\
\text { calendar } \\
\text { quarter }\end{array}$ \\
\hline $\begin{array}{l}\text { Whole body: Head and trunk; active blood- } \\
\text { forming organs; lens of eyes; gonads }\end{array}$ & 1250 \\
Hands and forearms; feet and ankles & 8750 \\
Skin of whole body & 500 \\
\hline
\end{tabular}

'OSHA Safety and Heal th Standards (29 CRF 1910.96), U.S. Dept. of Labor, Occupational Safety and Health Administration, Revised March 11, 1983. 


\subsubsection{Laboratory testing}

Many laboratories have capabilities to perform analysis of lead in paint. For example, the ASTM Directory of Testing Laboratories [32] lists about 350 laboratories that carry out spectroscopic measurements. Two laboratories are accredited under the Department of Commerce's National Voluntary Laboratory Accreditation Program (NVLAP) for performing the ASTM D 3335 test for lead in paint. Several other programs are in place for certifying testing carried out by laboratories. For example, the U.S. Environmental protection Agency (EPA) has a quality assurance policy that requires all EPA organizational units, as well as activities supported through EPA contracts, grants or other formal agreements, involved in environmentally-related measurements, to participate in an Agency-wide quality assurance program [33]. However, no specific EPA program is in place for measuring lead content of paint.

\subsection{Reliability}

For the purposes of this section, the reliability of a procedure to measure or detect lead in paint films is defined as meaning its dependability. That is, the probability that the equipment or materials will function properly when a tester wants to make a measurement.

For field measurement procedures, the primary concern is about down-time with the portable XRF analyzers and the deterioration of sulfide or other chemicals used in the spot tests. A portable XRF device will require periodic replacement of its radioactive source. $\mathrm{Co}^{57}$, which was used as the source in all the instruments included in this study, has a half life of 0.74 years [13]. Since the time required to complete a measurement depends upon the source strength, operators will probably elect to replace the source when it decays to between one half and one fourth of its original value or in a year or so. In addition, the electrical and mechanical portions of a portable XRF devices may also malfunction and require repair. For example, during the time this study was conducted, instruments XRF-AO and XRF-BO were returned to the manufacturers for repair. In each case, the time for repair, including shipping, was approximately two weeks. sulfide solutions gradually lose sulfide concentration as shown in figure 16. Other chemical spot tests may also deteriorate with time. However, this behavior can be dealt with by making new solutions and repeatedly testing old ones. spot tests should be reliable if properly used.

Some downtime is to be expected with analytical laboratory instruments, as well. The effect this would have on the time required to produce test results would depend on the type of equipment problem and the laboratories' backup capability. 
Laboratory and field studies were carried out to assist HUD in preparing responses to the following areas of concern, as contained in public Law 100-242:

- The most reliable technology available for detecting lead-based paint

- The precision and accuracy of testing procedures

- Safety conditions in testing

- Availability of qualified samplers and testers.

The conclusions of the study are summarized below according to each area of concern.

On the most reliable technology available for detecting leadbased paint

Two general types of testing methods were assessed; these are detection (or "screening") methods and measurement methods. Detection methods are simple fast procedures designed to determine whether paint films have lead concentrations exceeding the regulation 1 imit of $1 \mathrm{mg} / \mathrm{cm}^{2}$. Both chemical spot tests and lead-specific x-ray fluorescence (XRF) analyzers were assessed for potential use as detection methods. Based upon limited data, it is concluded that an experienced analytical chemistry technician can conduct spot tests to detect lead concentrations in excess of $1 \mathrm{ma} / \mathrm{cm}^{2}$ with a false negative risk of about 10 percent. The false positive risk is about 20 percent. Chemical spot tests, as used in this study, could not be used to measure the lead concentration of paint films. Further testing is needed to assess the effect of experimental variables such as paint matrix, paint thickness, and tester on the precision and accuracy of the method.

Measurement methods are of two types, field- and laboratorybased. As distinguished from detection methods, measurement methods are those which provide a quantitative measure of the content of lead in a paint film. It is concluded that there are standard laboratory analysis procedures capable of measuring concentrations of lead in paint films of less than $1 \mathrm{mg} / \mathrm{cm}^{2}$. However, with the possible exception of a method based upon the use of the spectrum-analyzer XRF device, none of the methods studied in this project are capable of guantitative in-situ field measurement of lead in paint films at the level of $1 \mathrm{mg} / \mathrm{cm}^{2}$. 
In some situations, portable lead-specific XRF analyzers can be used to detect lead in films without substrate correction. Specifically, it is concluded that when the mean of three readings, without substrate correction, is greater than $4 \mathrm{ma} / \mathrm{cm}^{2}$, the true lead concentration of the film will be greater than $1 \mathrm{mg} / \mathrm{cm}^{2}$ about $95 \%$ percent of the time.

Based upon the evidence and data obtained in this study, the method for collection of field samples described in this report provides representative, reproducible samples.

\section{On the precision and accuracy of testing procedures}

Two types of measurement procedures were studied. These were laboratory methods and field methods based upon the use of portable XRF analyzers. Laboratory analysis of paint films for lead using the ASTM standard procedure D 3335 , Test Method for Low Concentrations of Lead, Cadmium and Cobalt in Paint by Atomic Absorption spectroscopy, resulted in the correct concentration for the NIST Standard Reference Material paint with a precision of 0.3 percent or a coefficient of variation of 2.5 percent. The coefficients of variation for intralaboratory and interlaboratory measurements reported in the ASTM D 3335 method are 3.4 and 9 percent for concentrations from 0.01 to 5 percent, respectively.

For in-situ field measurement of lead concentration in paint films using lead-specific portable XRF analyzers as described in this report, it is concluded that the best estimate of precision of measurements made over wood, plaster and drywall is $0.6 \mathrm{mg} / \mathrm{cm}^{2}$. The estimated systematic error of the procedure is $0.2 \mathrm{mg} / \mathrm{cm}^{2}$. (This implies that 95 percent of the time, the true concentration should be within $\pm 1.4 \mathrm{mg} / \mathrm{cm}^{2}$ of the experimental outcome and that 67 percent of the time, the true concentration should be within \pm 0.8 $\mathrm{mg} / \mathrm{Cm}^{2}$ of the experimental outcome.) These estimates are based on data obtained from field measurements which has lower precision than data obtained in the laboratory using the same measurement procedure.

Based upon the laboratory studies, the field precision of measurements made on concrete and brick is expected to be less than on wood and drywall.

Bare substrate readings in excess of $2 \mathrm{mg} / \mathrm{cm}^{2}$ were observed in two of the field data sets described in section 6 , implying that, when no substrate correction is made, a systematic error of more than $2 \mathrm{mg} / \mathrm{cm}^{2}$ could occur. A conservative estimate of this error of $3 \mathrm{mg} / \mathrm{cm}^{2}$ was made. Hence, it is concluded that large errors could occur if the substrate correction is not made. 
The portable XRF analyses detected lead in lead-containing paint films beneath gypsum wallboard in both laboratory and field measurements. Thus, it may be possible to detect lead-based paint which has been encapsulated.

\section{on safety}

The screening and measurement methods investigated, using portable or laboratory equipment, are similar to procedures routinely conducted in the field and in many laboratories and are considered safe if carried out following the manufacturer's instructions. For example, testers using portable XRF instruments must use proper radiation safety procedures; those carrying out chemical spot tests must use proper procedures for using chemical solutions; and laboratory safety procedures must be followed in performing lead-laboratory tests. Hence, it is concluded that no exceptional hazard is associated with any of the methods discussed in this report, if the methods are carried out using accepted safety procedures.

\section{on the availability of qualified testers and samplers}

Manufacturers of portable XRF instruments have conducted day-long training courses in their use for an estimated 2000 people. Training courses are also available for the use of analytical laboratory equipment. It is estimated that there are several hundred laboratories in the country that are equipped to perform standard laboratory analysis for lead concentration in paints. However, no accreditation or certification programs or formal training courses specifically designed for lead-in-paint measurements are available for testers or laboratory personnel.

\section{RECOMMENDATIONS}

To develop improved measurement methods for lead in paint films, the following recommendations are made:

- Lead-containing standard reference films should be developed for use in calibration and characterization of XRF devices. Such films are also needed in preparing paint films to use as quality control samples in sample analysis.

- The spectrum-analyzer portable XRF instrument should be further evaluated to improve estimates of accuracy and precision of measurement methods based upon its use and to assess its reliability. 
- Research should be conducted to improve the precision and accuracy of portable XRF instruments for conducting nondestructive in-situ field measurements.

- Evaluation of spot tests should be continued to assess the causes of erroneous results and to investigate variabilities in results due to the tester and to paint film properties. Large sample sizes are desirable.

- The need for accreditation of laboratory testing should be considered. Programs, such as the U.S. Department of Commerce's National Voluntary laboratory Accreditation Program (NVLAP), could be used.

- The need for certification of testers for lead-based paint should be considered. Training courses should be developed which could support certification, if it should be required. 
10. REFERENCES

1. Mattiello, J.J., Protective and Decorative coatings, Vol. II, John Wiley and Sons, Inc., New York, 1942.

2. Parker, D.H., Principles of surface coating Technology, John Wiley and Sons, New York, 1964.

3. Stewart, W.J., Paint Driers and Additives, Federation Series on Coatings Technology, Federation of Societies for Paint Technology, Philadelphia, PA, 1969.

4. Walker, P.W. and Hickson, E.F., Paint Manual with Particular Reference to Federal specifications, Building Materials and Structures Report, BMS105, Superintendent of Documents, washington, D.C., 1945.

5. Federal specification, TT-W-251C, White-Lead, Basic Carbonate, Dry, Paste-in-oil and Semipaste Containing Volatile Thinner, U.S. Government Printing Office, May 1954.

6. Federal Specification, TT-P-529, Enamel, Alkyd, Semigloss, U.S. Government Printing office, May 1966.

7. McKnight, M.E. and Byrd, W.E., "Screening Procedures for Detecting Lead in Existing Paint Films: A Literature Review," NISTIR 89-0449, National Institute of standards and Technology, Gaithersburg, MD 20899, 1989.

8. Keith, L.H., Crummett W., Deegan, Jr., J., Libby, R.A., Taylor, J.K., Wentler, G., "Principles of Environmental Analysis," Anal. Chem., 55, (1983) 2210.

9. Vind, H.P., Mathews, C.W., Alumbaugh, R.I., and Hamilton, G.W., "Implementation of the Lead-based Paint Poisoning Prevention Act at Navy Facilities," TN No. N-1533, Naval Civil Engineering Laboratory, Port Hueneme, CA 93043, 1978.

10. Feigl, F., Anger, V., and Oesper, R.E., spot Tests in Inorganic Analysis, Elsevier Publishing Company, London, 1972, pp. 285-286.

11. Byrd, W.E. and Mcknight, M.E., "Potential Methods for Measuring and Detecting Lead in Existing Paint Films: A Literature Review," NISTIR 89-4205, National Institute of standards and Technology, Gaithersburg, MD, 20899, 1989.

12. Rasberry, S.D., "Investigation of Portable X-ray Fluorescence Analyzers for Determining Lead on Painted Surfaces," Applied Spectroscopy, 27, No. 2 (1973) 102. 
13. Jenkins, R., Gould, R.W. and Gedcke, D., Quantitative X-ray Spectrometry, Marcel Dekker, Inc., New York, 1981.

14. Montgomery, D.C., Design and Analysis of Experiments, John Wiley and Sons, New York, 1976.

15. ASTM D 3335, Test Method for Low Concentrations of Lead, Cadmium and Cobalt in Paint by Atomic Absorption Spectroscopy, Annual Book of ASTM Standards, Vol. 6.01, American Society for Testing and Materials, Philadelphia, PA 19103, 1989 .

16. Brownlee, K.A., Statistical Theory and Methodology in Science and Engineering, John Wiley and Sons, Inc., New York, 1960, p. 170 .

17. ASTM E 691, "Practice for Conducting an Interlaboratory Test Program to Determine the Precision of Test Methods," Annual Book of ASTM Standards, Vol. 14.02, American Society for Testing and Materials, Philadelphia, PA 19103, 1989.

18. ASTM D 3980, "Practice for Interlaboratory Testing of Paint and Related Materials," Annual Book of ASTM Standards, Vol. 6.01, American Society for Testing and Materials, Philadelphia, PA 19103, 1989.

19. Currie, L.A., "Detection and Quantitation in X-ray Fluorescence Spectrometry," Chapter 25, X-ray Fluorescence Analysis of Environmental Samples, T. Dzubany, Ed., Ann Arbor Science Publishers, Inc., p. 289, (1977).

20. Vind, H.P. and Mathews, C.W., "Field Test for Detecting Lead-Based Paints," Technical Note N-1455, Civil Engineering Laboratory, Port Hueneme, CA, 1976.

21. Sayre, J.W. and Wilson, D.J., "A Spot Test for Detection of Lead In Paint," Pediatrics, 46, 1970, p.783.

22. Williams, S.R., "Design of a National Survey of Lead-based Paint in Housing, Pretest Report," RTI/4403/MR-04/1, Research Triangle Institute, Research Triangle Park, NC, 27709,1989 .

23. Hausknecht, K.A., Ryan, E.A., and Leonard, L.P., "Determination of Lead in Paint Chips using a Modified Ashing Procedure and Atomic Absorption spectrophotometry," Atomic Spectroscopy, 3 , No. 2, (1982) 53 .

24. Data sheet for Standard Reference Material, 1579, National Institute of standards and Technology, Gaithersburg, MD, 1972 . 
25. Wendlandt, Wesley, Thermal Methods of Analysis, John Wiley and Sons, New York, 1974.

26. Nordyke, J.S., "Lead Compounds and Their Properties," in Lead in the World of Ceramics, J. Nordyke, Ed., American Ceramic Society, Inc., Columbus, OH, 1984, pp. 1-5.

27. Greifer, B., Rasberry, S.D., Rains, T.C., Maienthal, E.J., Deardorff, E.R., "Comparison of Laboratory Methods for Determining Lead in Dried Paint Films," National Bureau of Standards Report, $10966,1973$.

28. Bethea, R.M., Duran, B.S., Boullion, T.L., Statistical Methods for Engineers and Scientists, Marcel Dekker, Inc., New York, 1985, p. 165.

29. Taylor, J. K., Quality Assurance of Chemical Measurements, Lewis Publishers, Inc., Chelsea, MI, 1987.

30. Buston, B., OTS Guidance Document for the Preparation of Quality Assurance Project Plans, Battelle Columbus, Columbus, $\mathrm{OH}$, Contract No. 68-02-4243, prepared for Office Toxic Substances, U.S. Environmental Protection Agency, Washington, DC, 1987.

31. Gilbert, R.0., Statistical Methods for Environmental Pollution Monitoring, Van Nostrand Reinhold Co., New York, 1987 .

32. Directory of Testing Laboratories, 1988 Edition, American Society for Testing and Materials, Philadelphia, PA 19103, 1987.

33. Stanley, T.W., and Verner, S.S., "The U.S. Environmental Protection Agency's Quality Assurance Program," in Quality Assurance for Environmental Measurements, ASTM STP 867 , J.K. Taylor and T.W. Stanley, Eds., American Society for Testing and Materials, Philadelphia, PA, 1985, pp 12-19. 


\section{ACKNOWLEDGMENTS}

The authors gratefully knowledge the cooperation of the manufacturers of the portable XRF instruments and spot test kits and helpful discussions with Mr. L. Masters and Dr. G. Frohnsdorff. They also thank Mr. Paul Stutzman of the NIST Center for Building Technology for carrying out scanning electron microscopic evaluations of paint film specimens and Ms. Susannah schiller of the NIST Center for Computing and Applied Mathematics for her contributions in designing the laboratory experiment, analyzing data and for many useful discussions, as well as the many chemists in NIST's Center for Analytical Chemistry who provided technical support. 


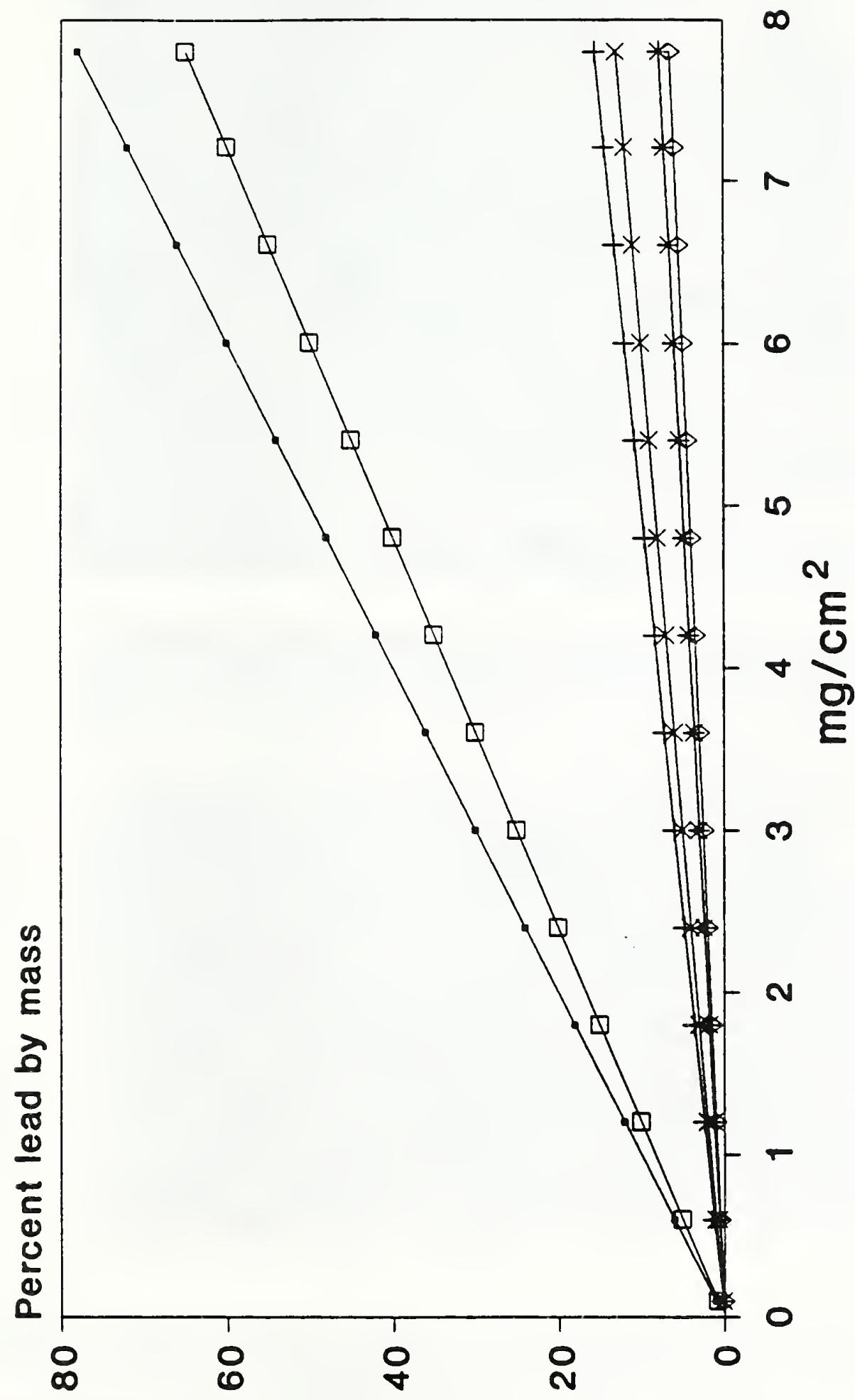

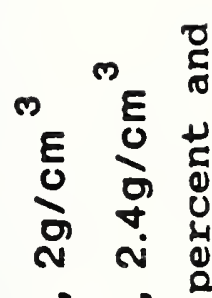

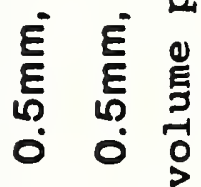

* $\phi$ 出

๑ 密气

O E ل

ㅇํㅇ 듀

ठ

ง ก

E E

है

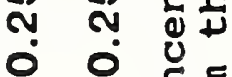

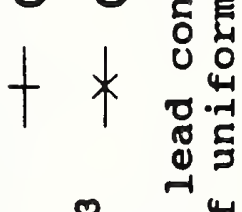

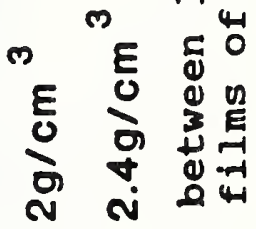

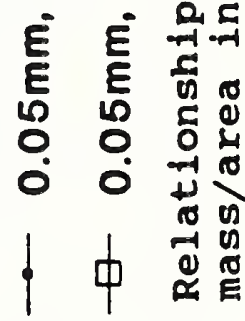

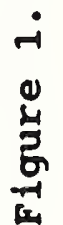


a)

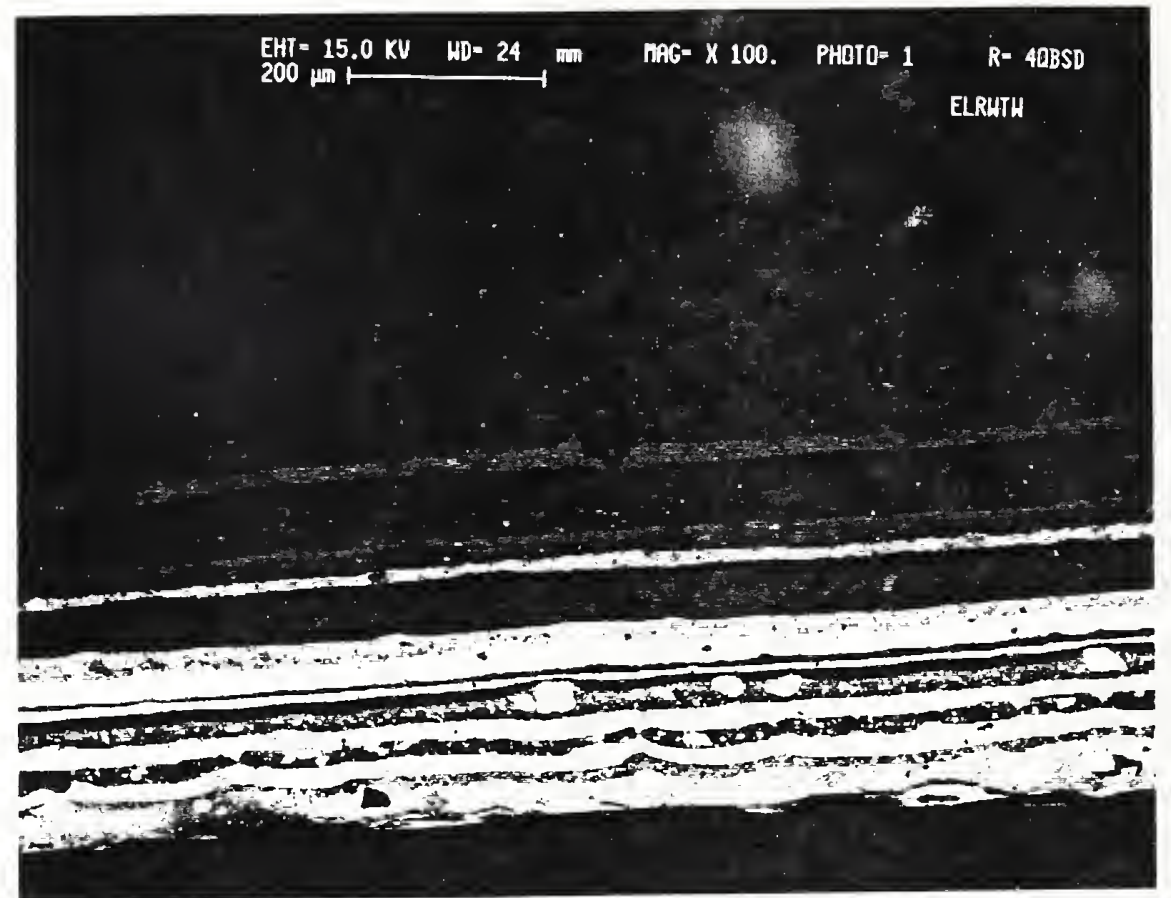

b)

s

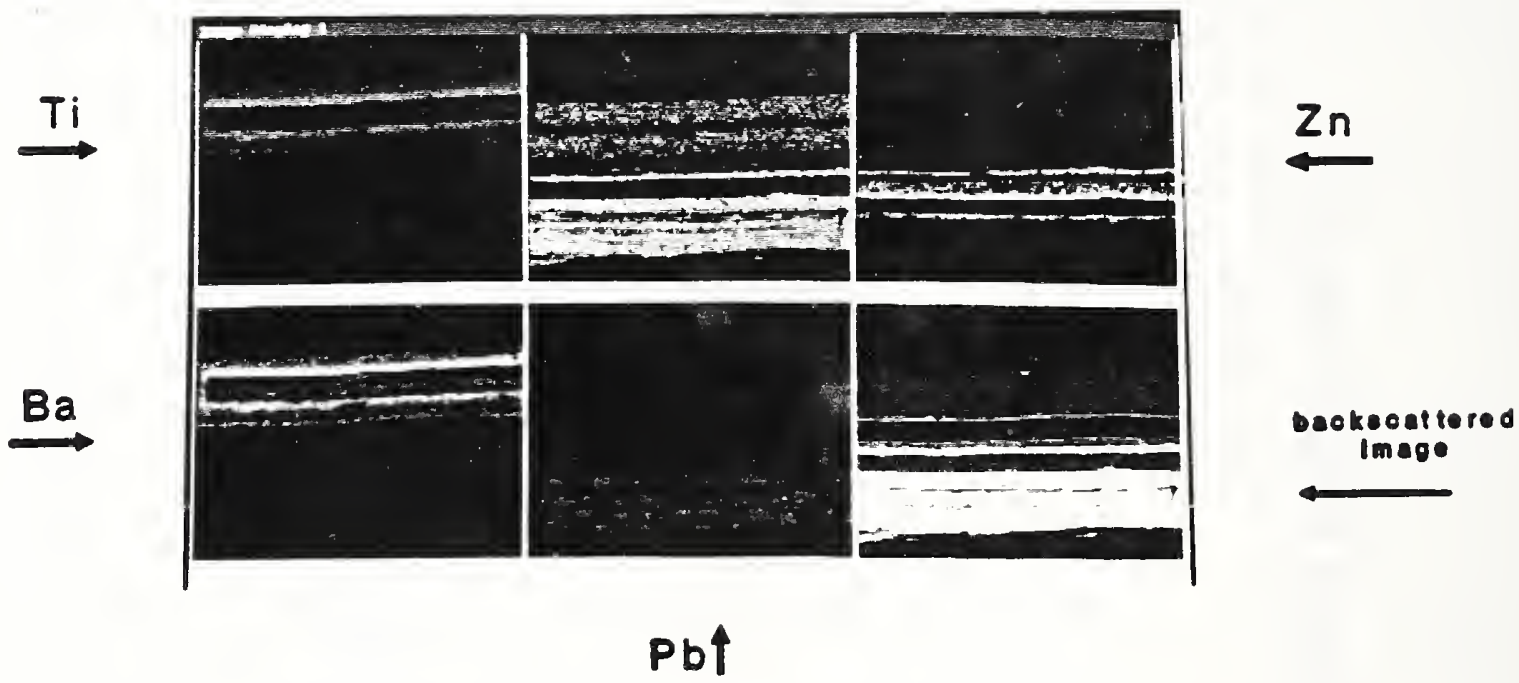

Figure 2. Scanning electron micrographs of a section through a paint film from a house in Baltimore.

a) Backscattered electron image.

b) Images of the same field as a), but with specific elements highlighted. 
a)

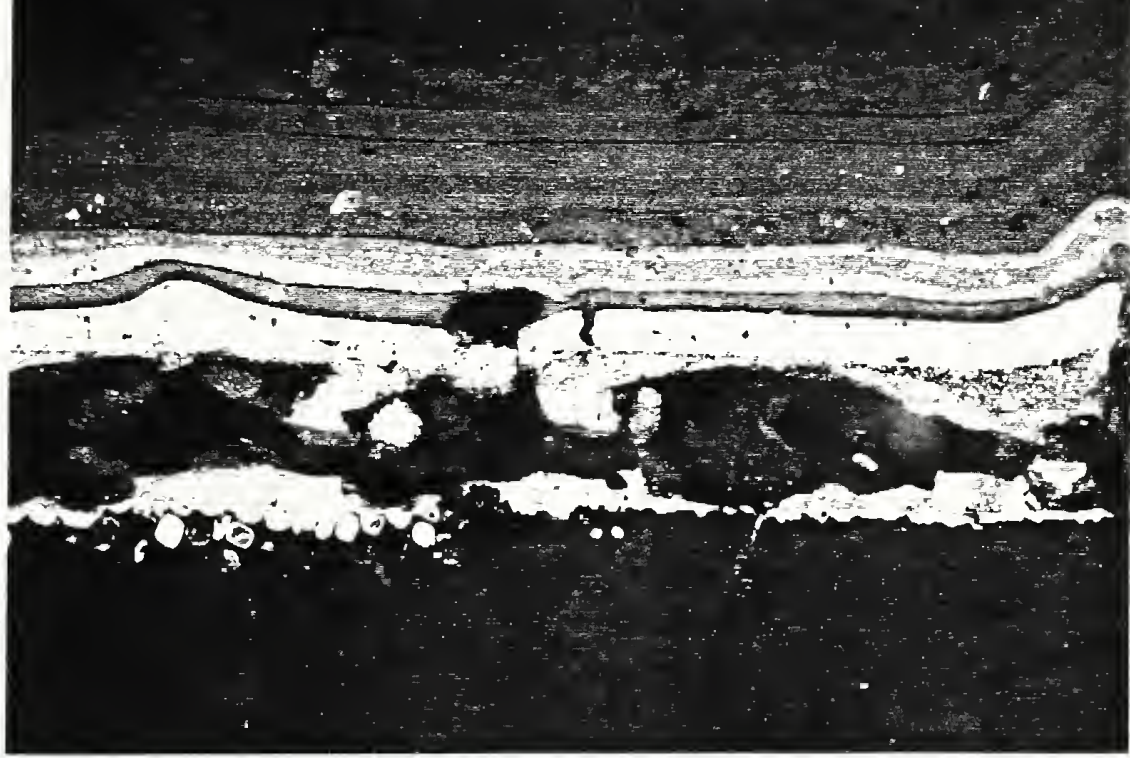

b)

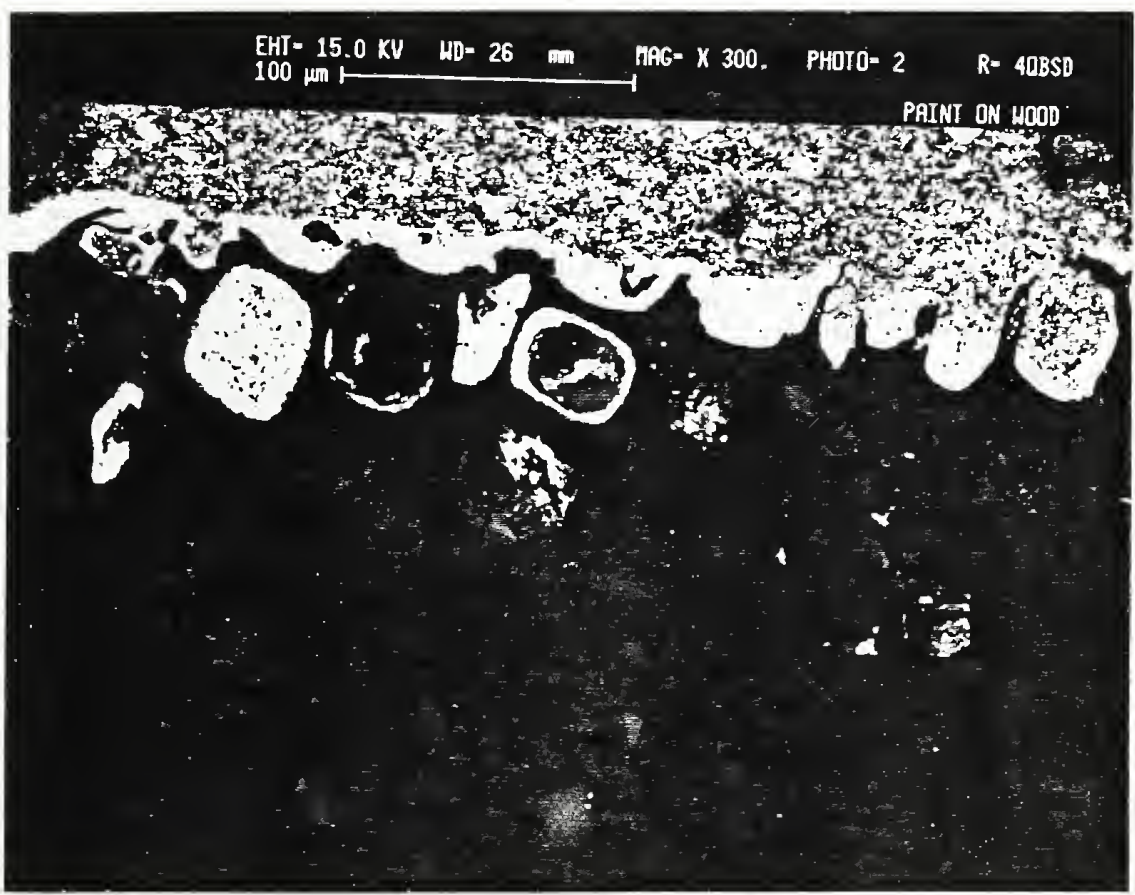

Figure 3. Scanning electron micrograph of a section through a paint film on wood from a house in Baltimore.

a) Overall image showing lead pigments in the uppermost pores of the wood.

b) Enlargement of area shown in a). 


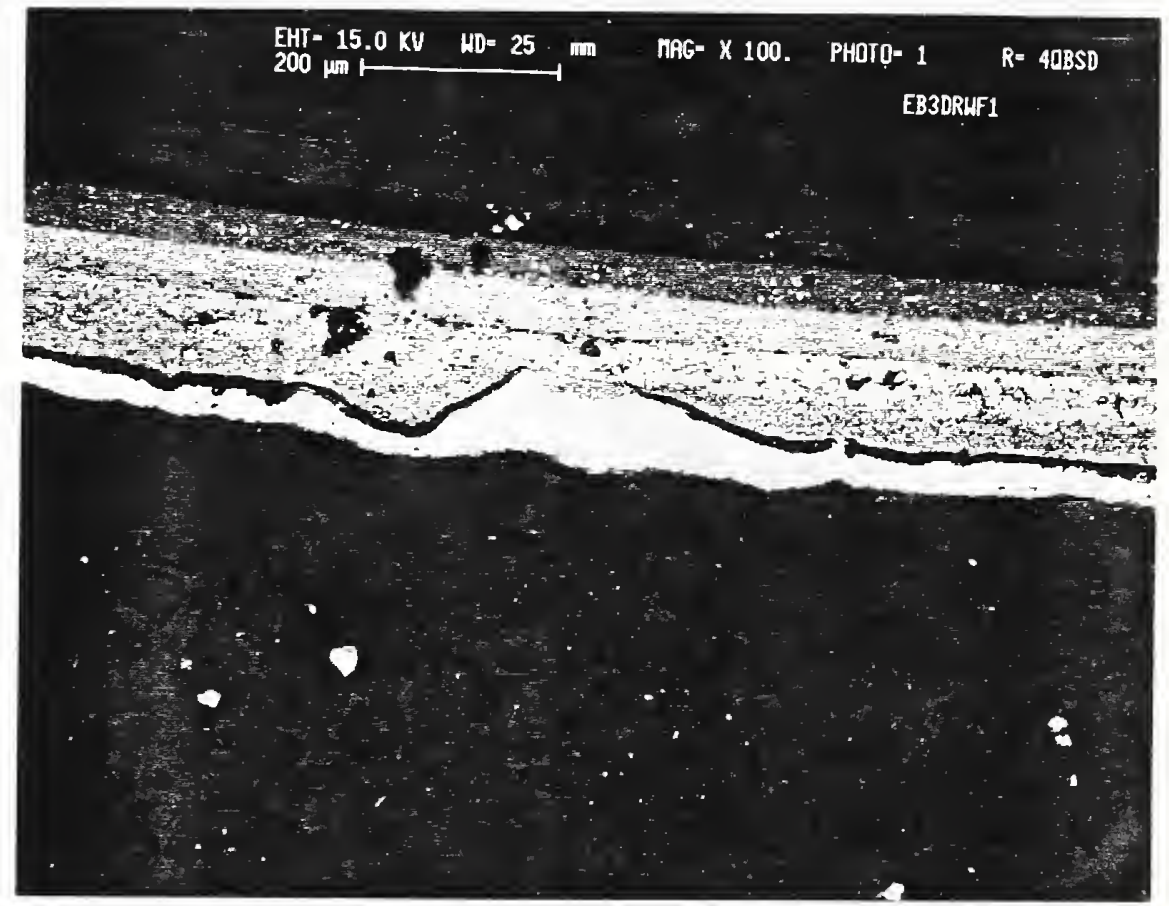

Figure 4. Scanning electron micrograph of a section through a paint film on wood over an apparent layer of varnish. 
a)

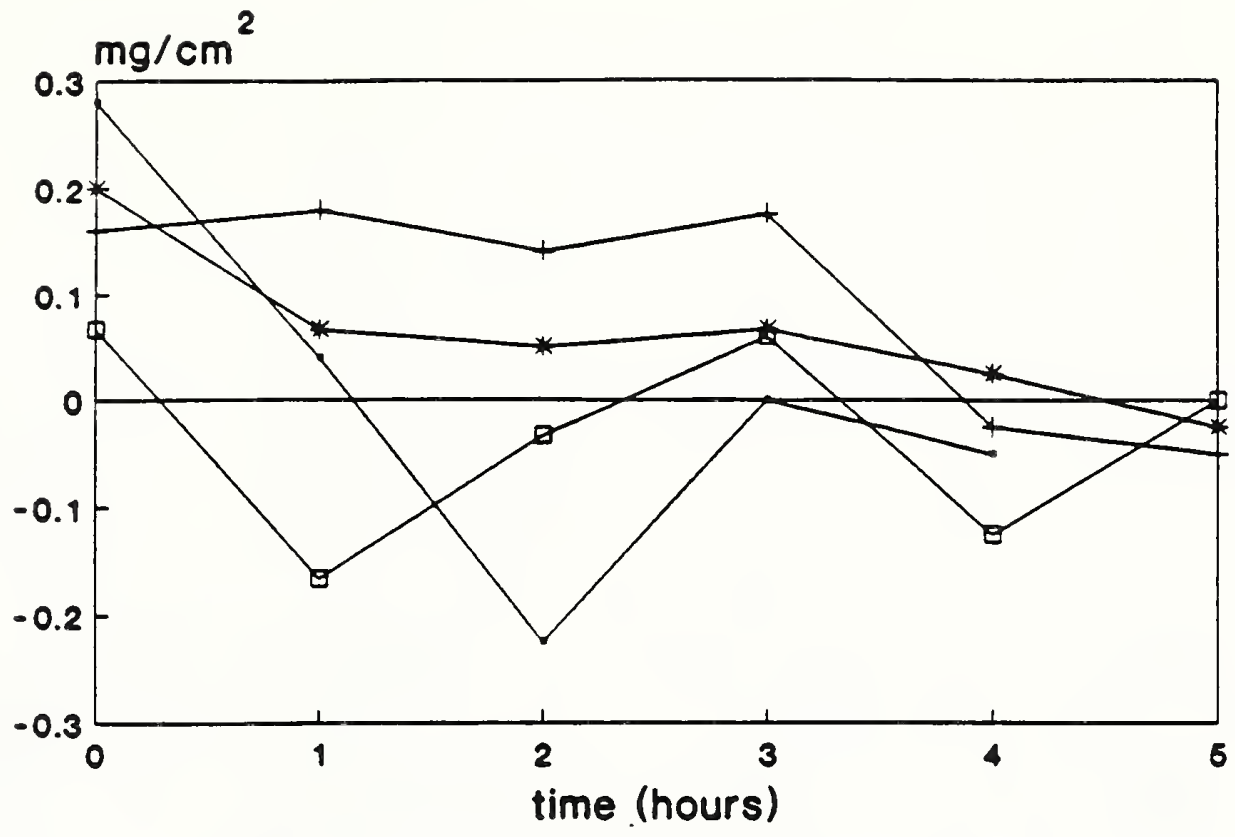

-Day $1 \rightarrow$ Day $2 \rightarrow$ Day $3 \rightarrow$ Day 4

b)

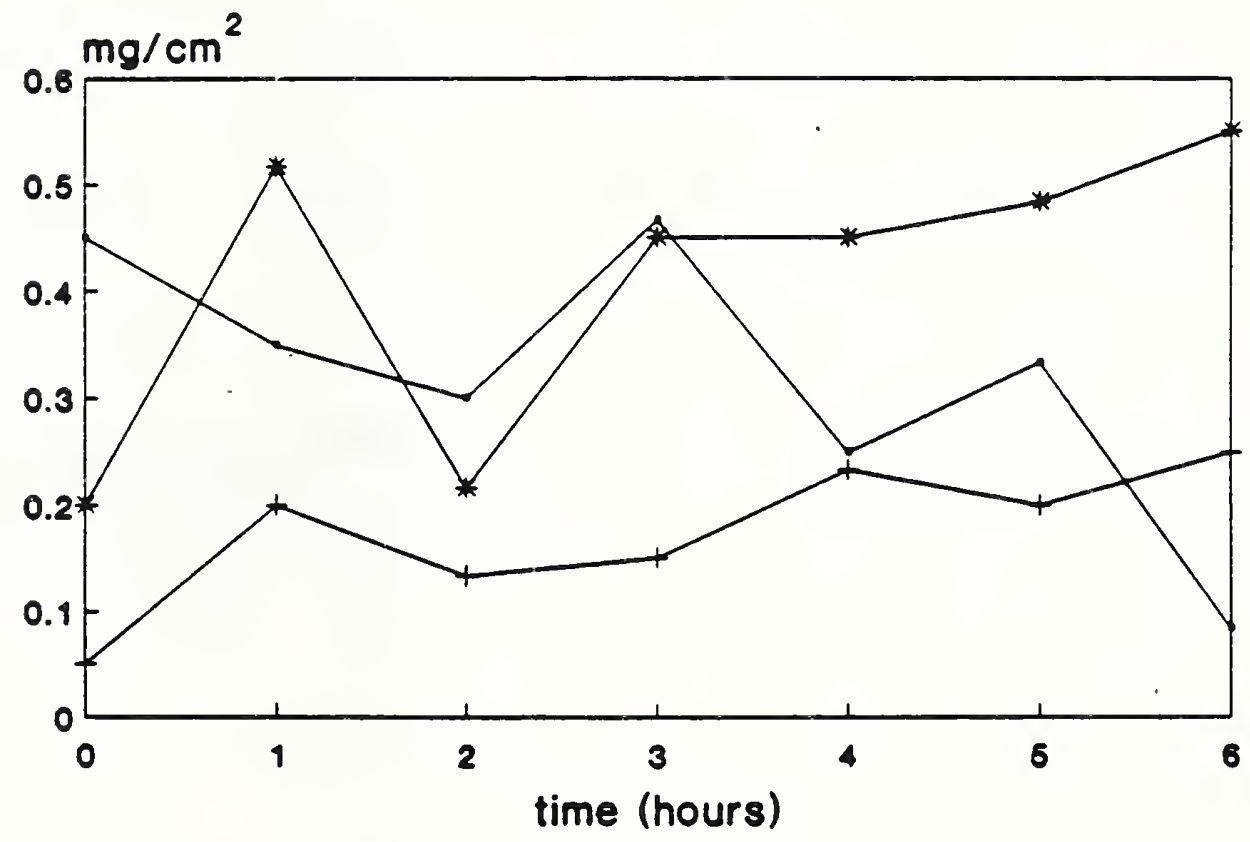

-Day $1+$ Day $2 \rightarrow$ Day 3

Figure 5. Typical results of drift measurement

a) XRF-A analyzer.

b) XRF-B analyzer. 


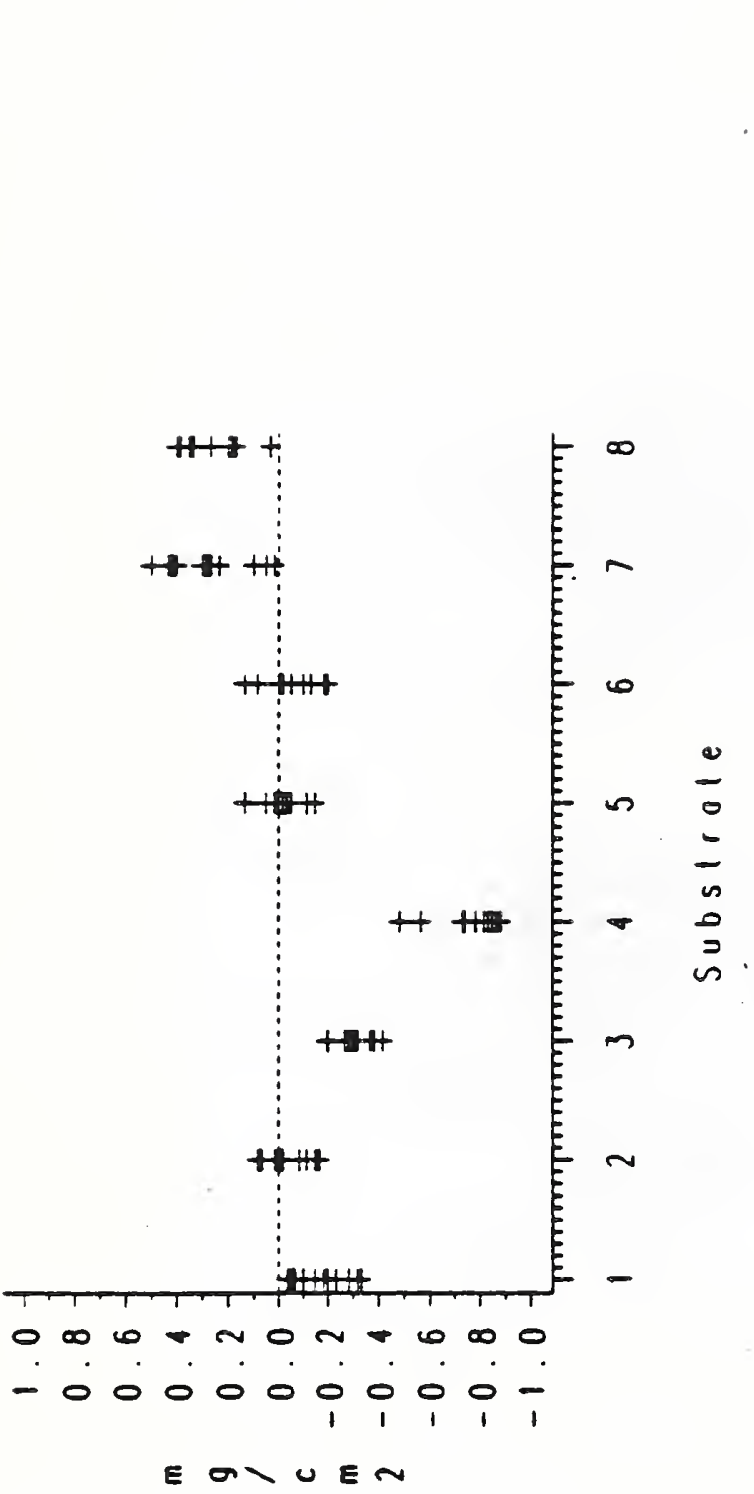

$\pi$

3 


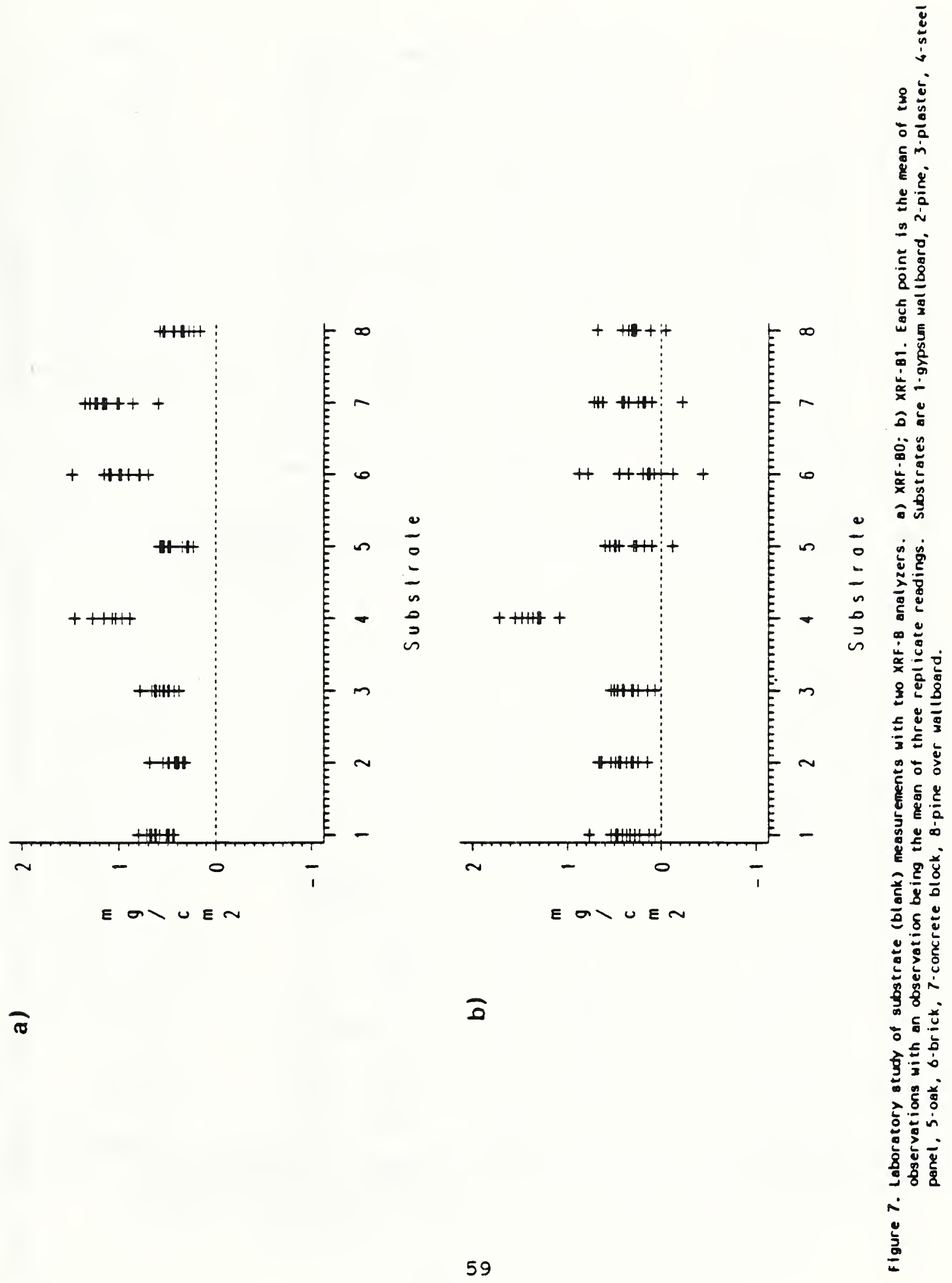




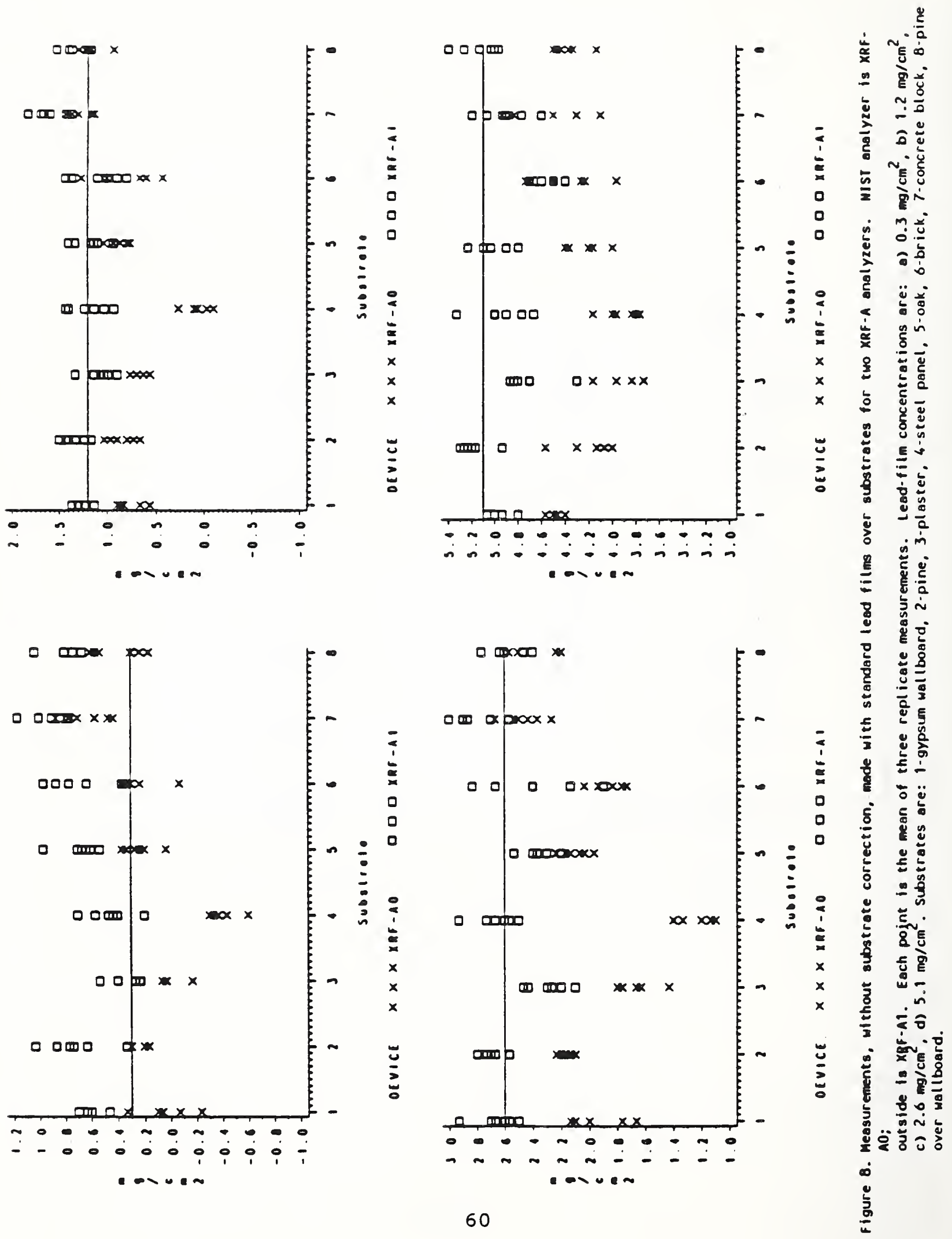



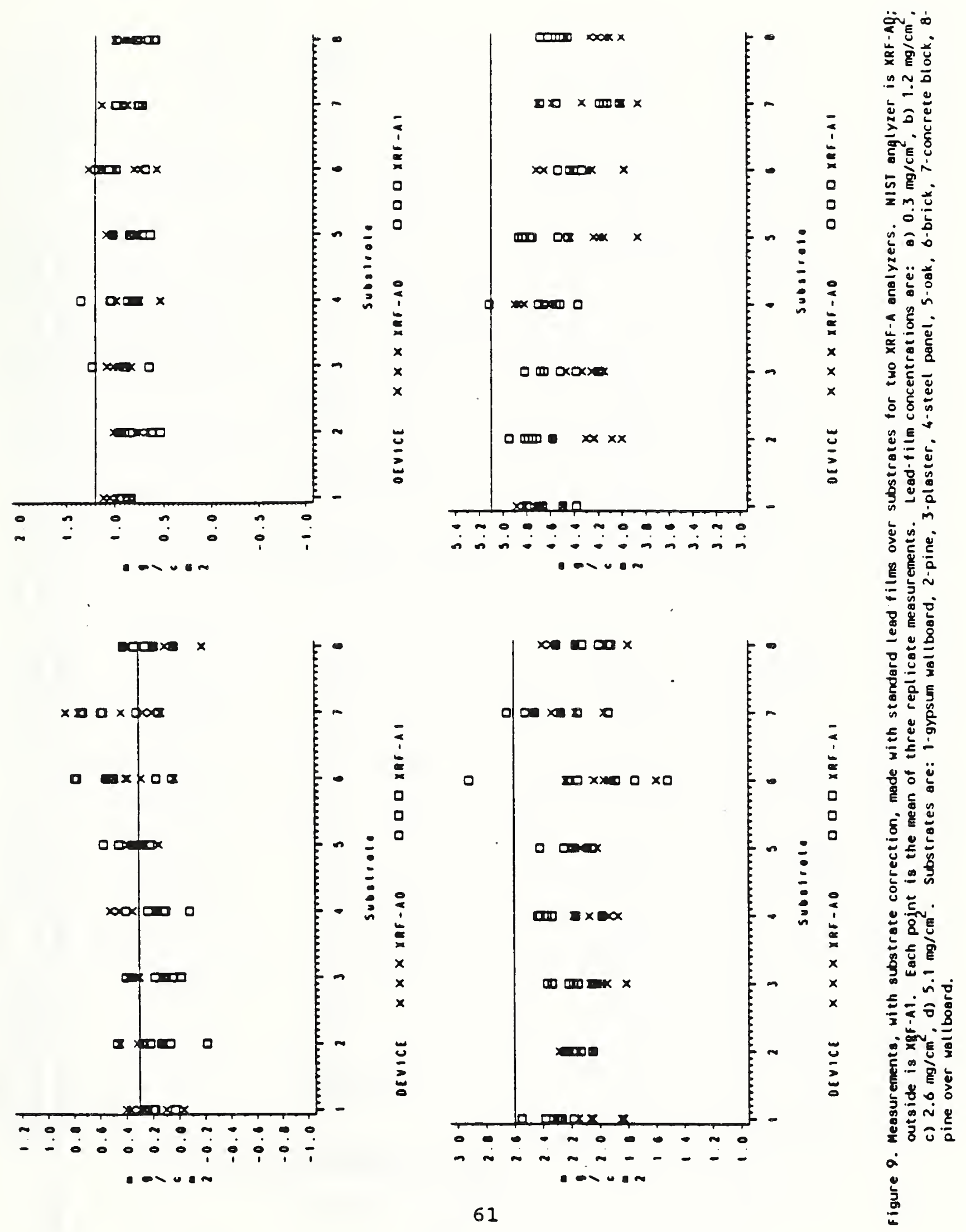

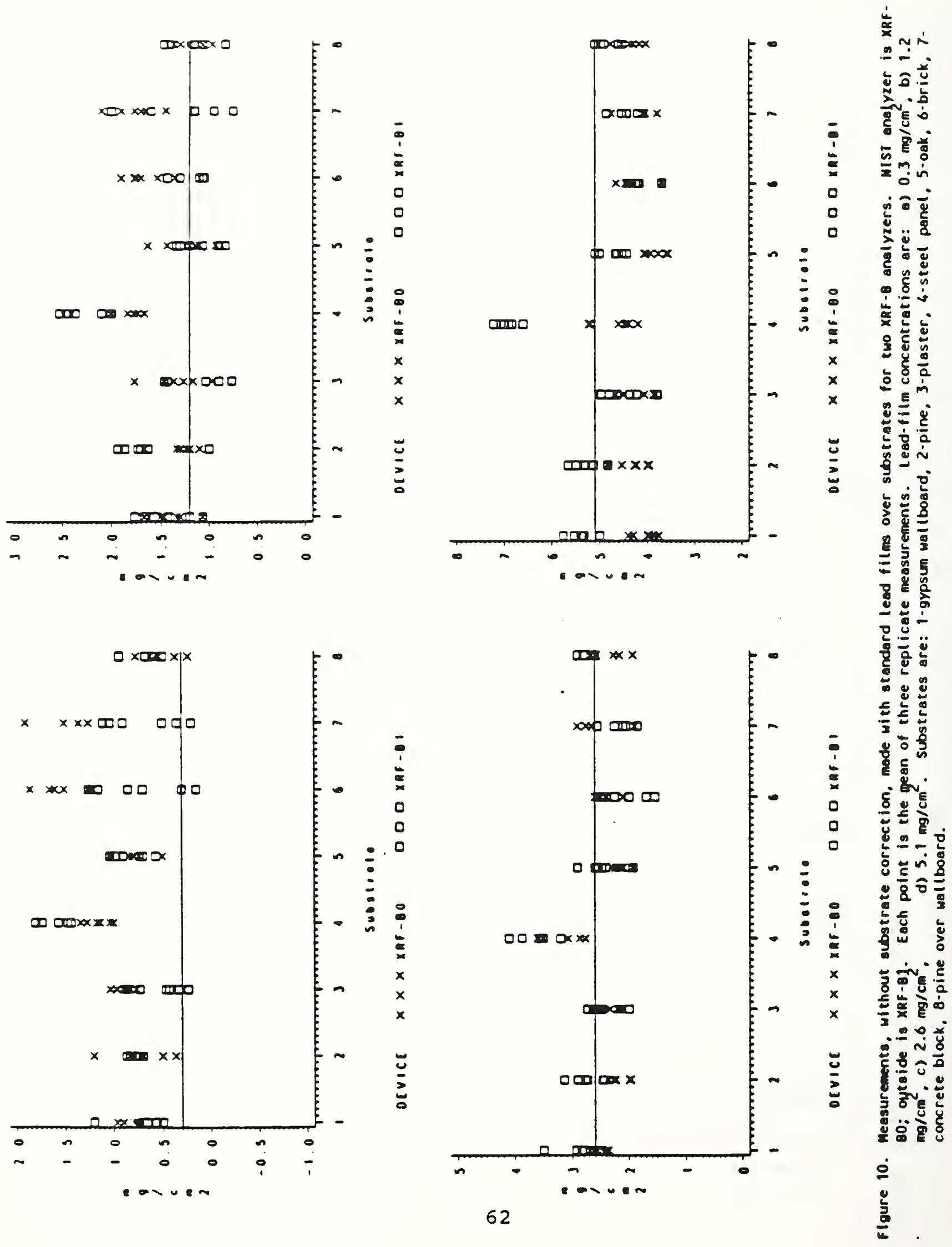

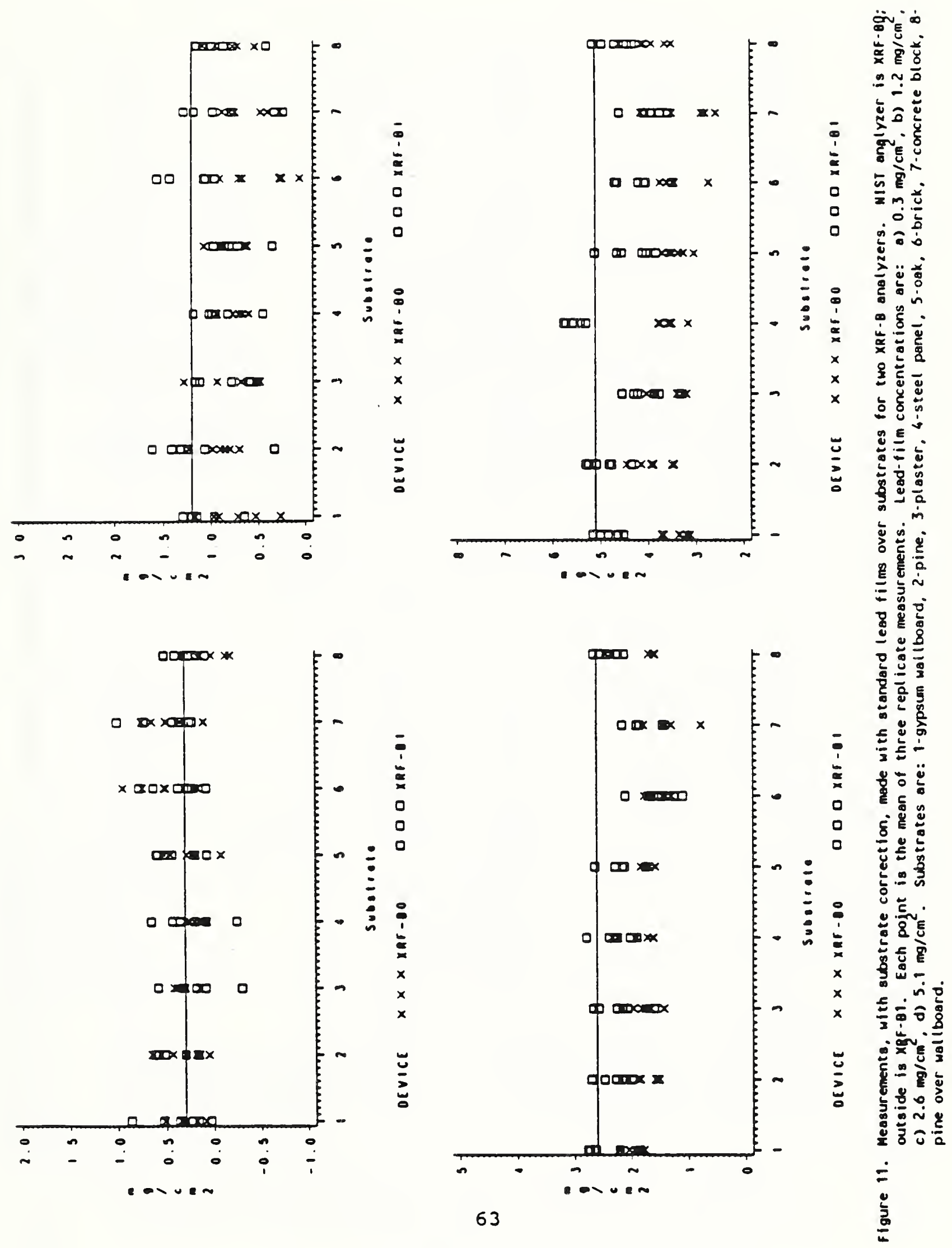


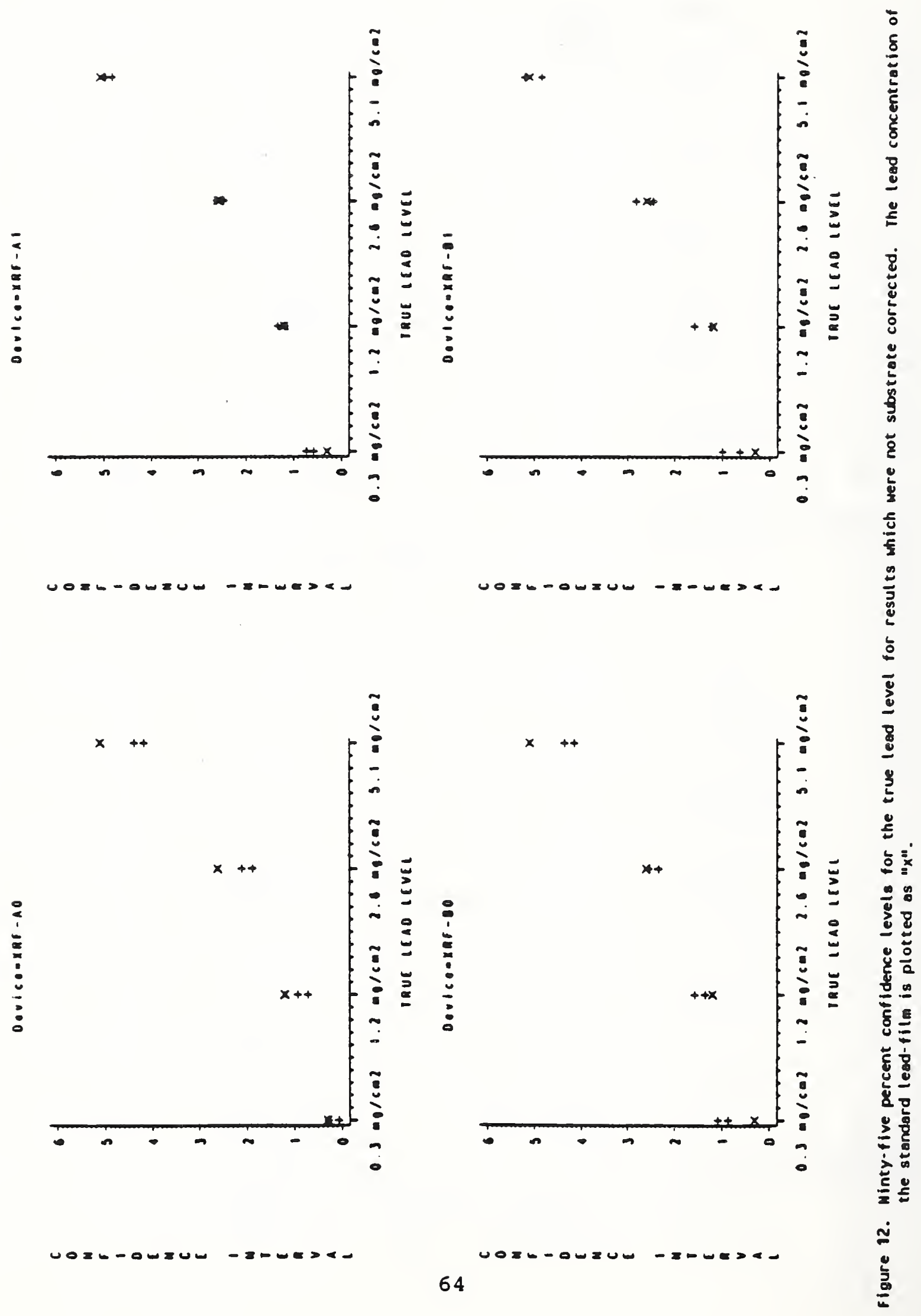




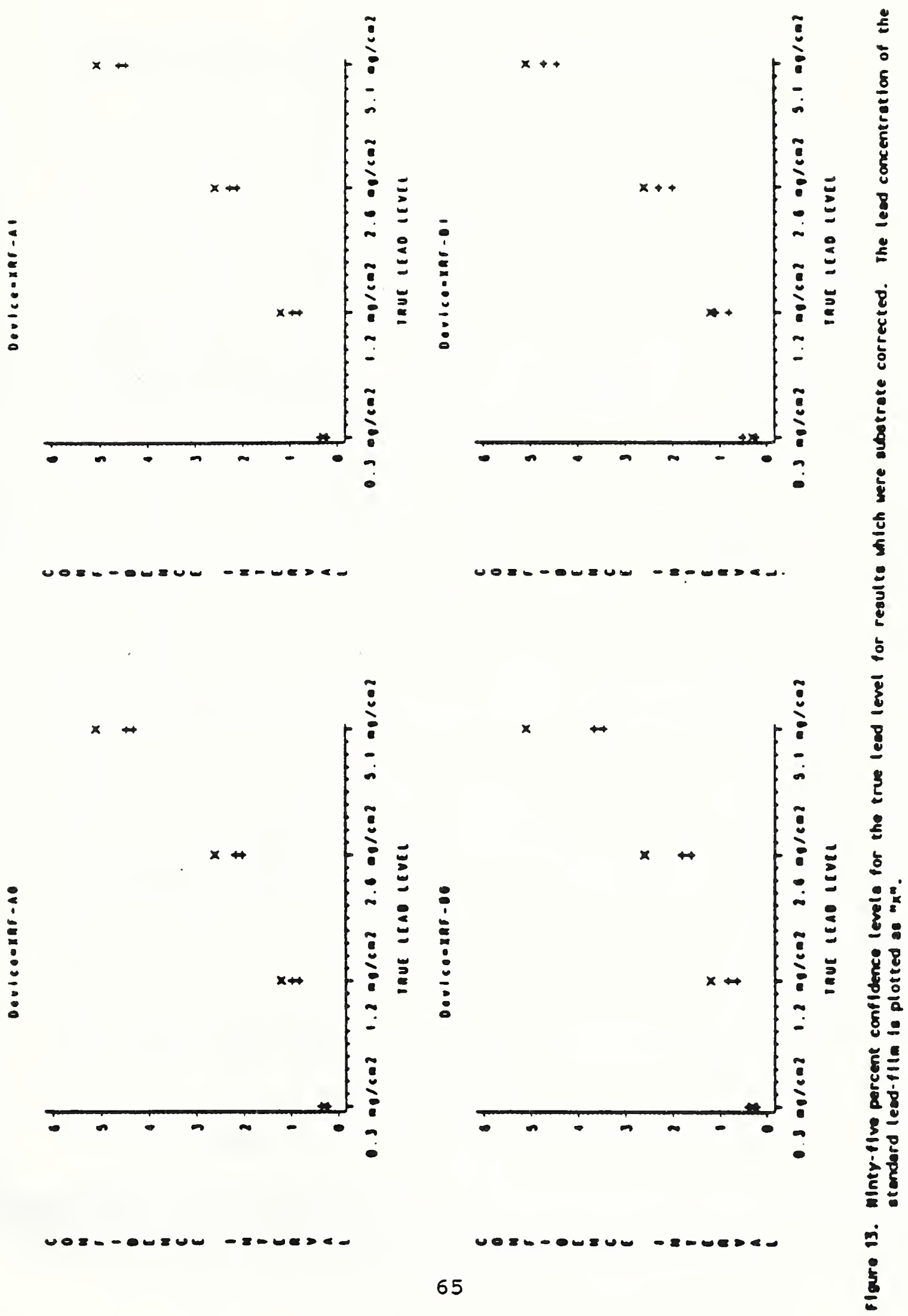



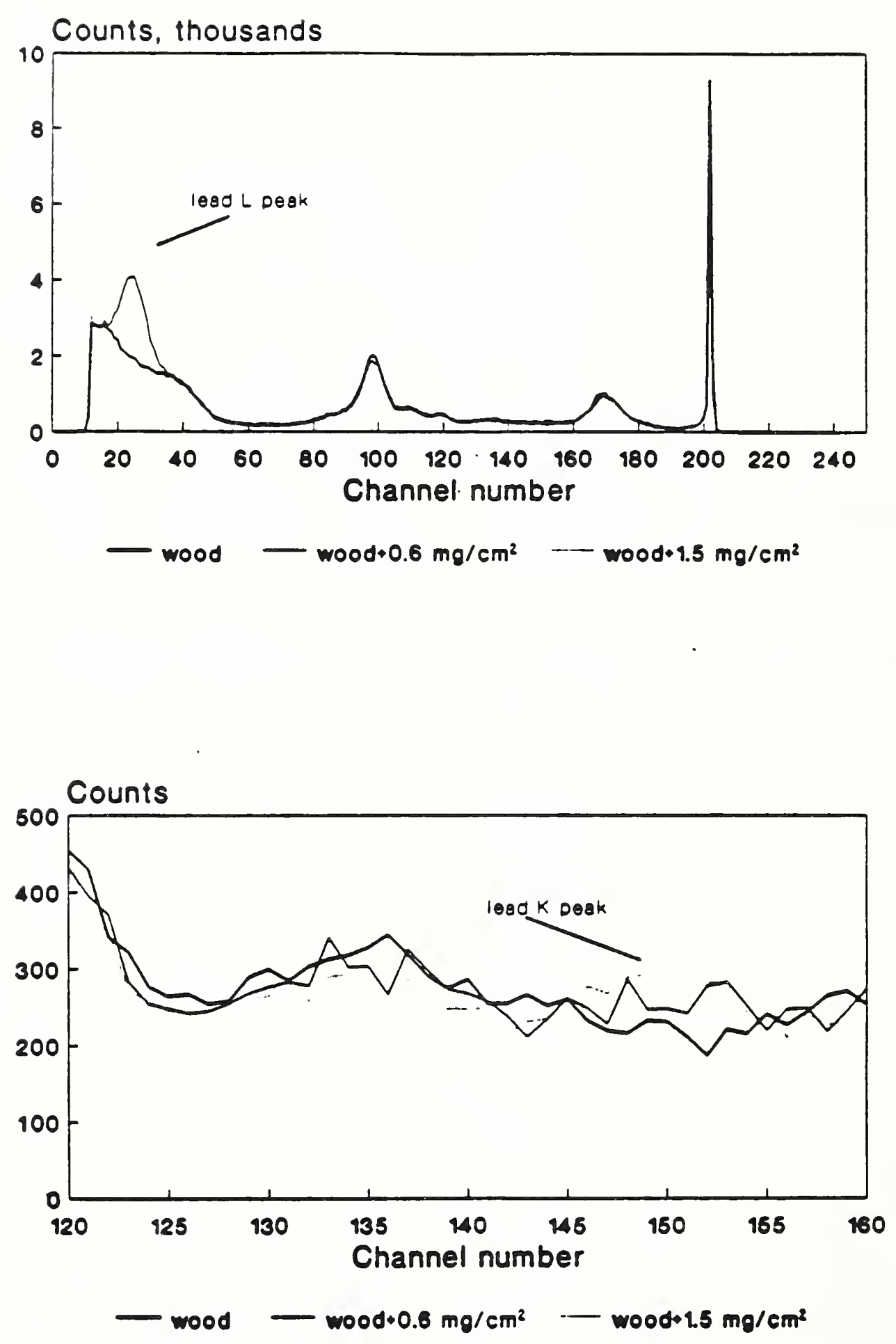

Figure 14. Spectra obtained using XRF-C of a bare wood substrate and of the substrate covered with lead-containing paint ellms on paper. 

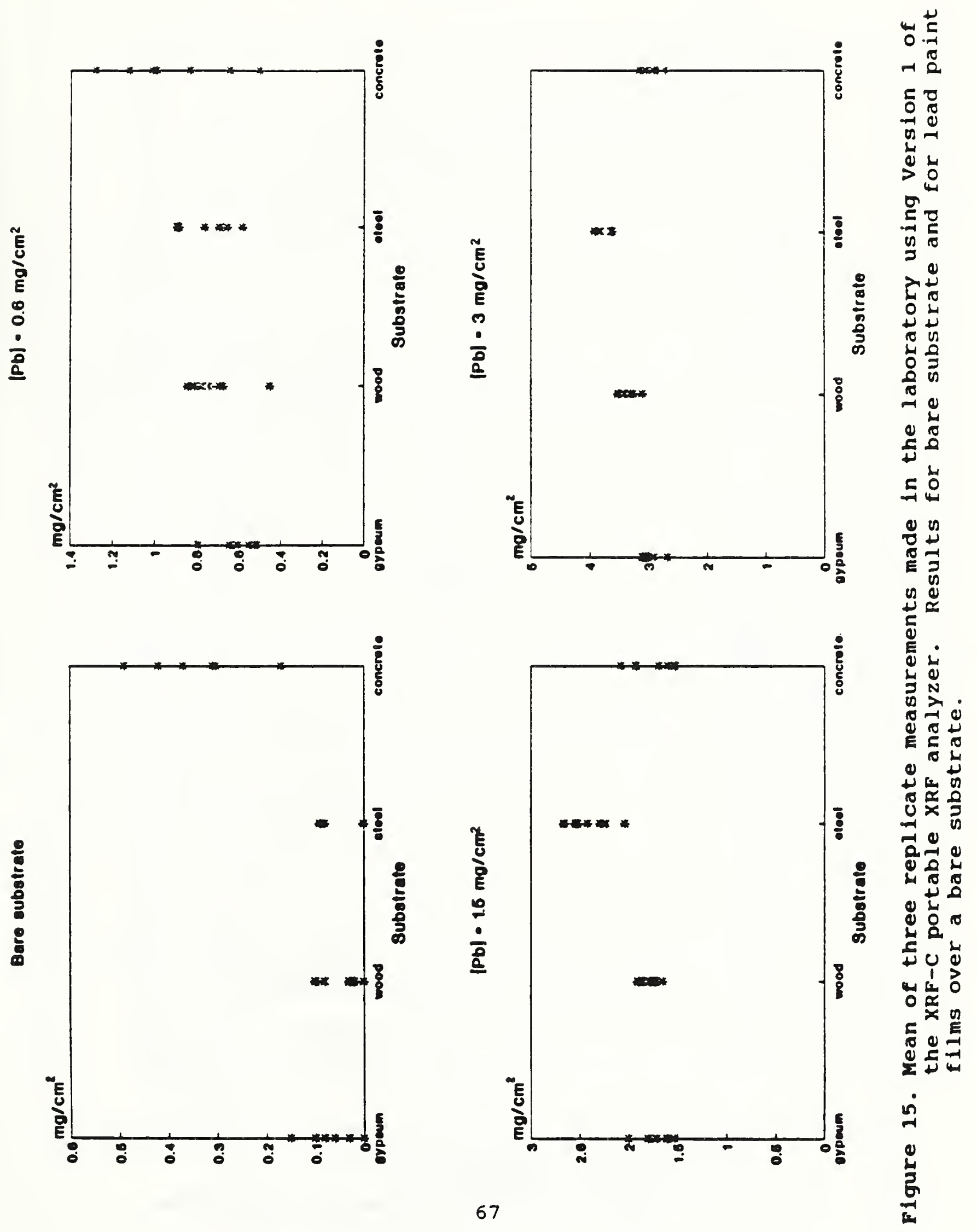
a)

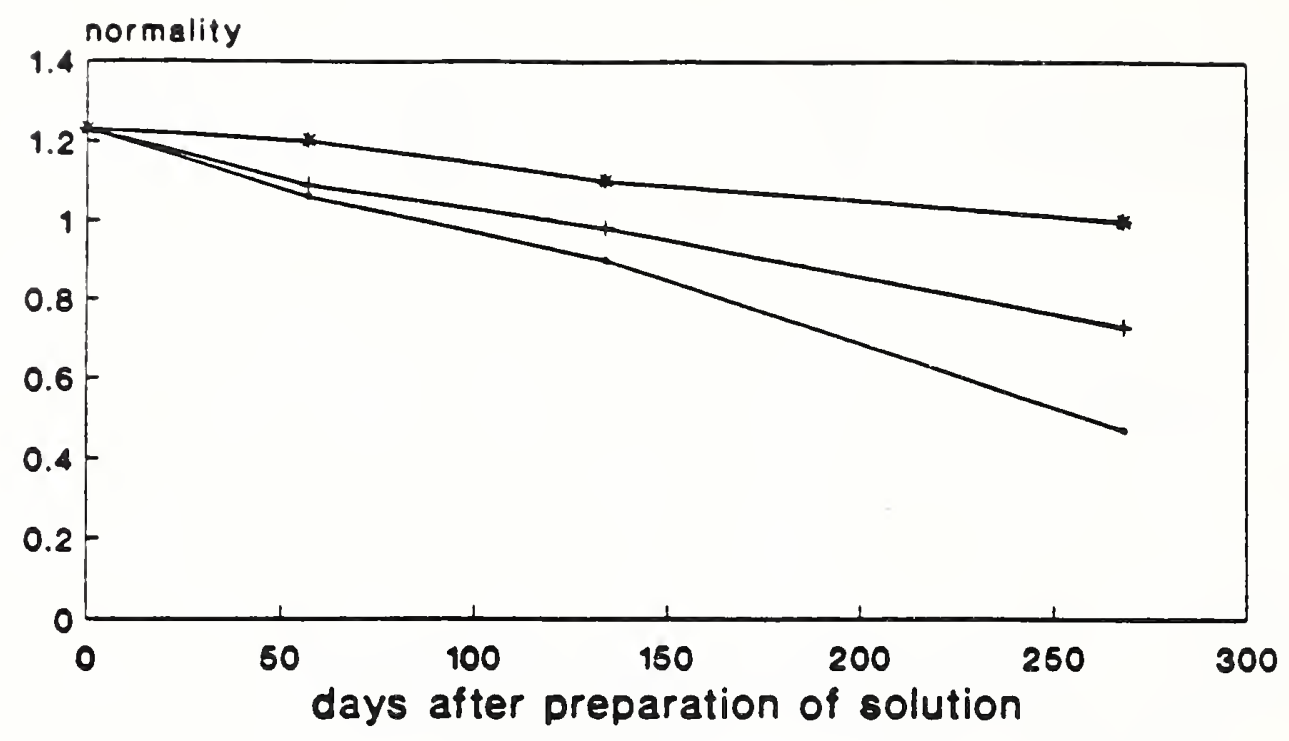

$-35 C+20 C \div 8 \mathrm{C}$

unthickened

b)

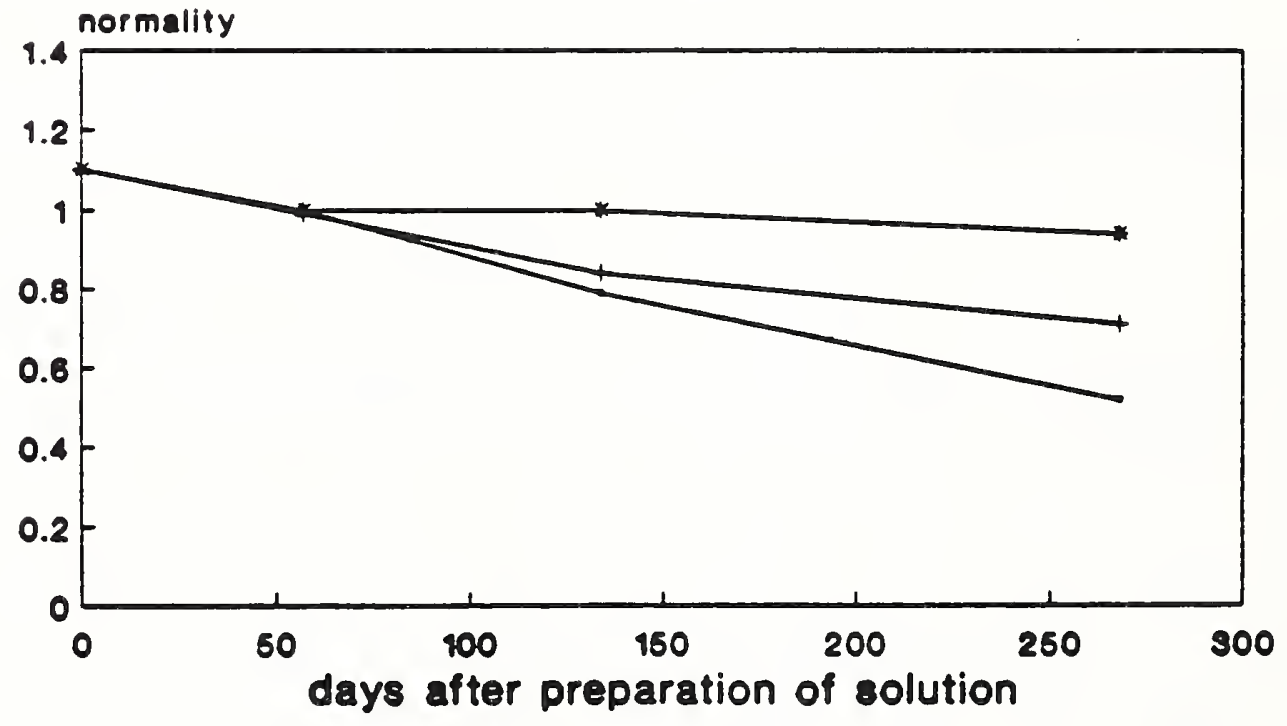

$-350+20 C \rightarrow 8 C$

Figure 16. Results of Vind et al. [9] stability studies for sodium sulfide solutions.

a) Unthickened solution.

b) Solution thickened with methyl cellulose. 


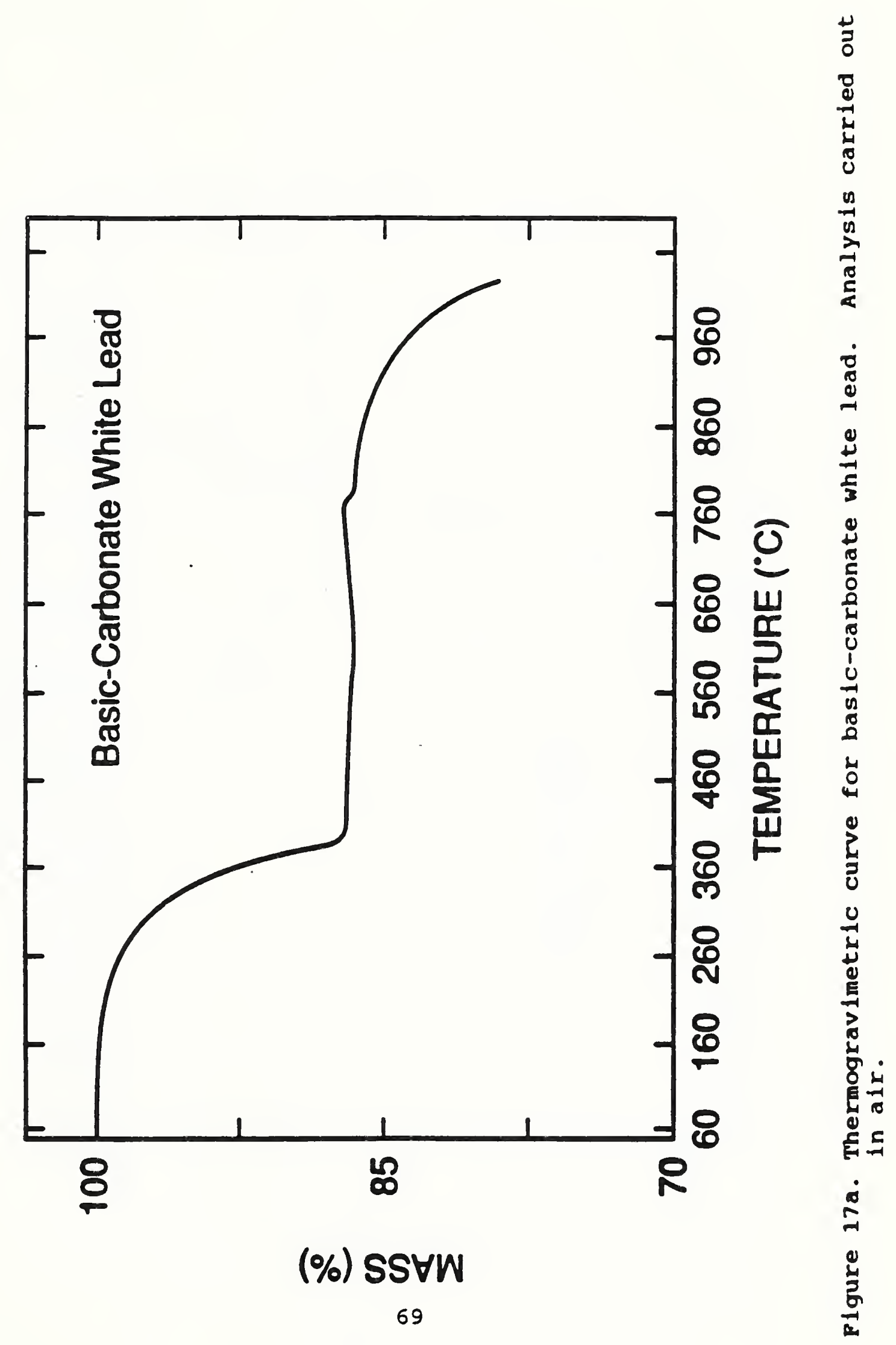




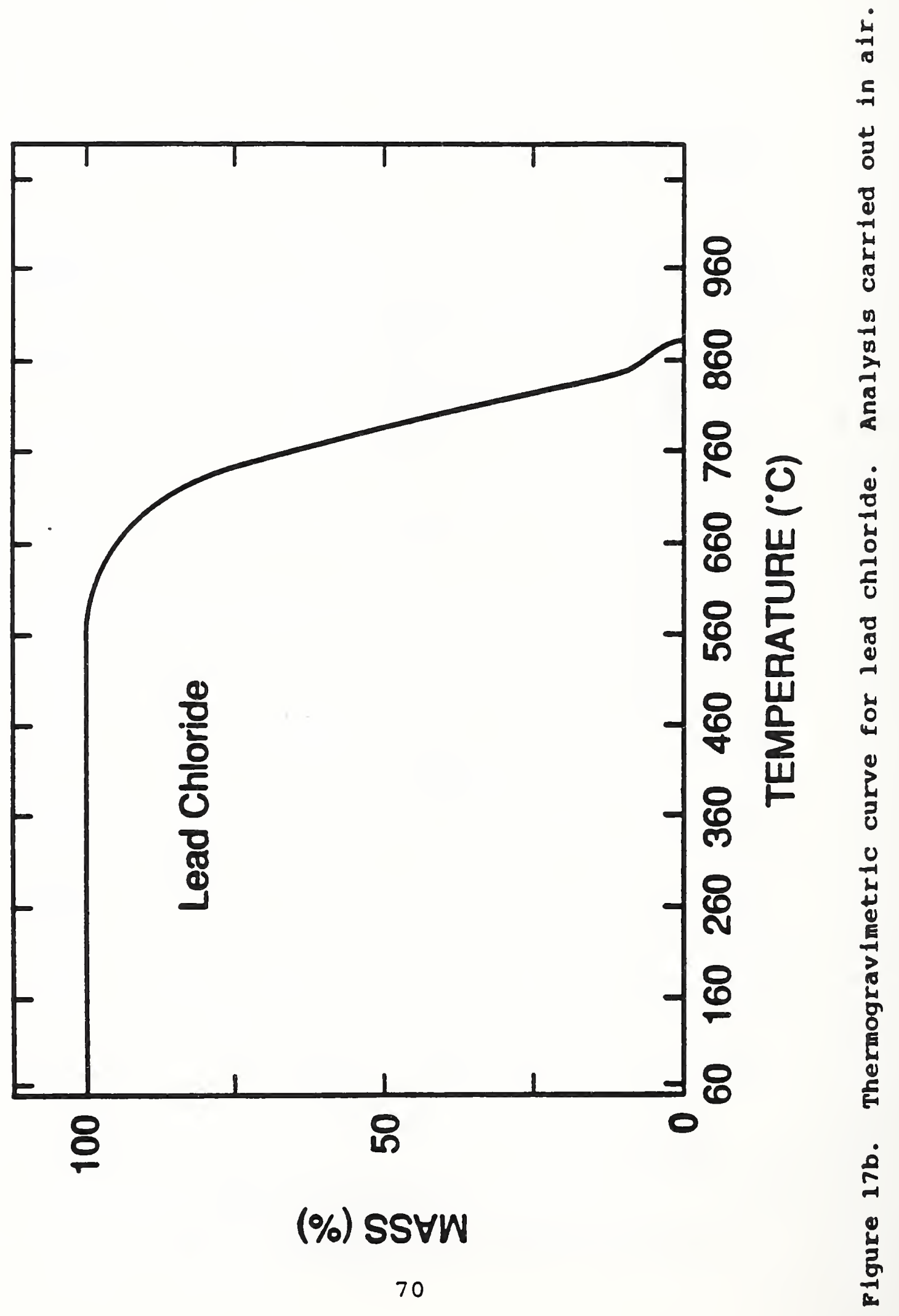




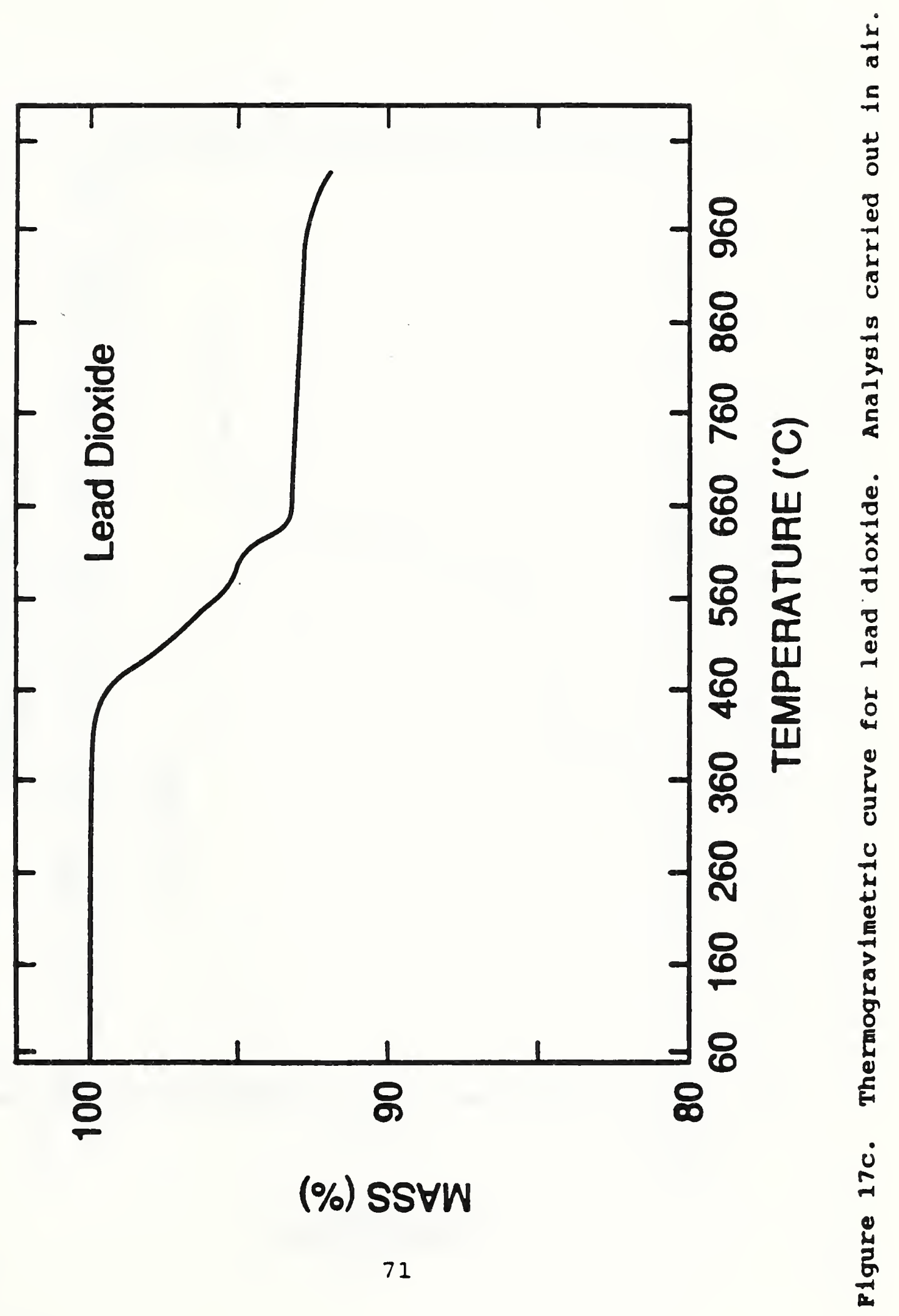




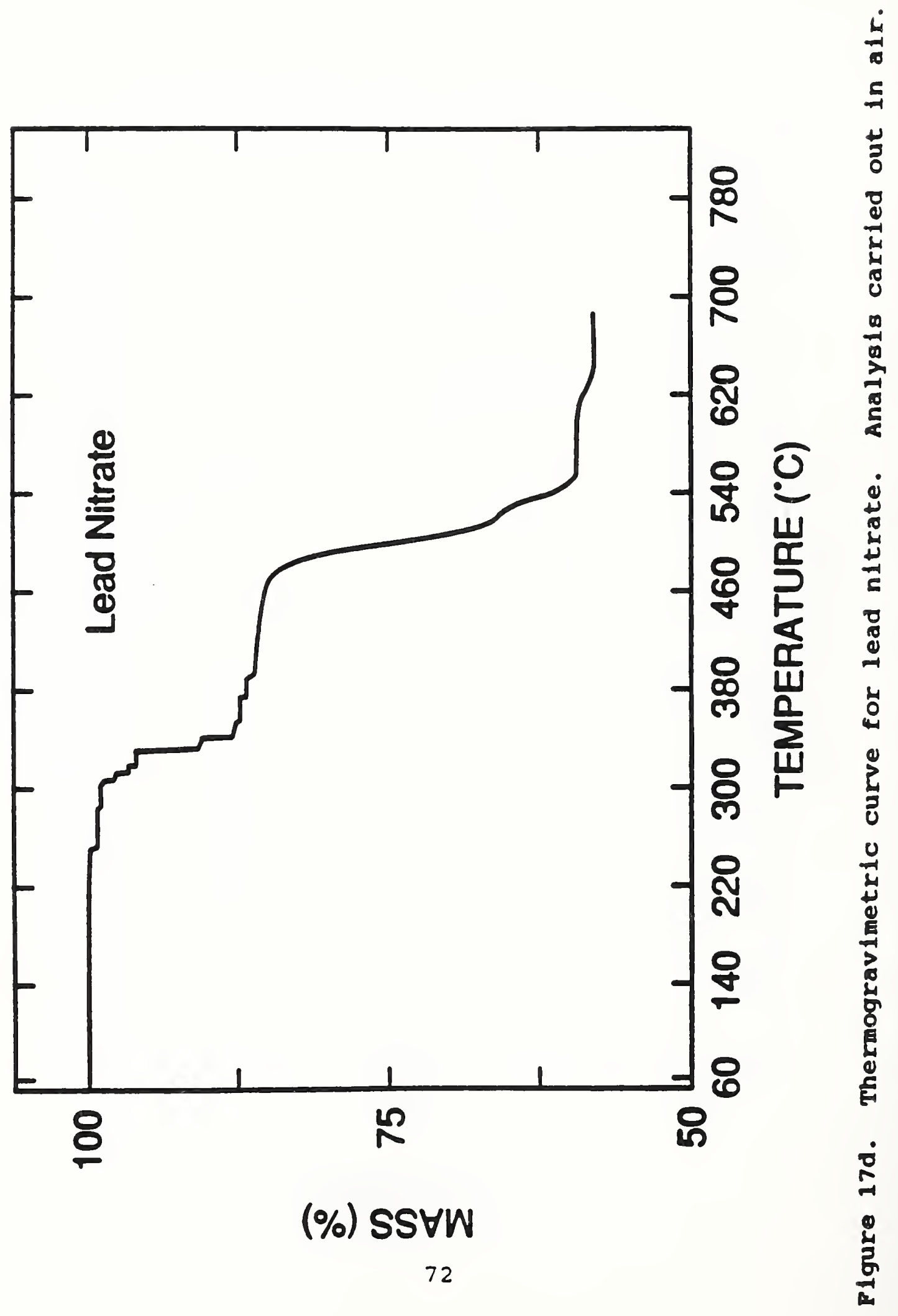




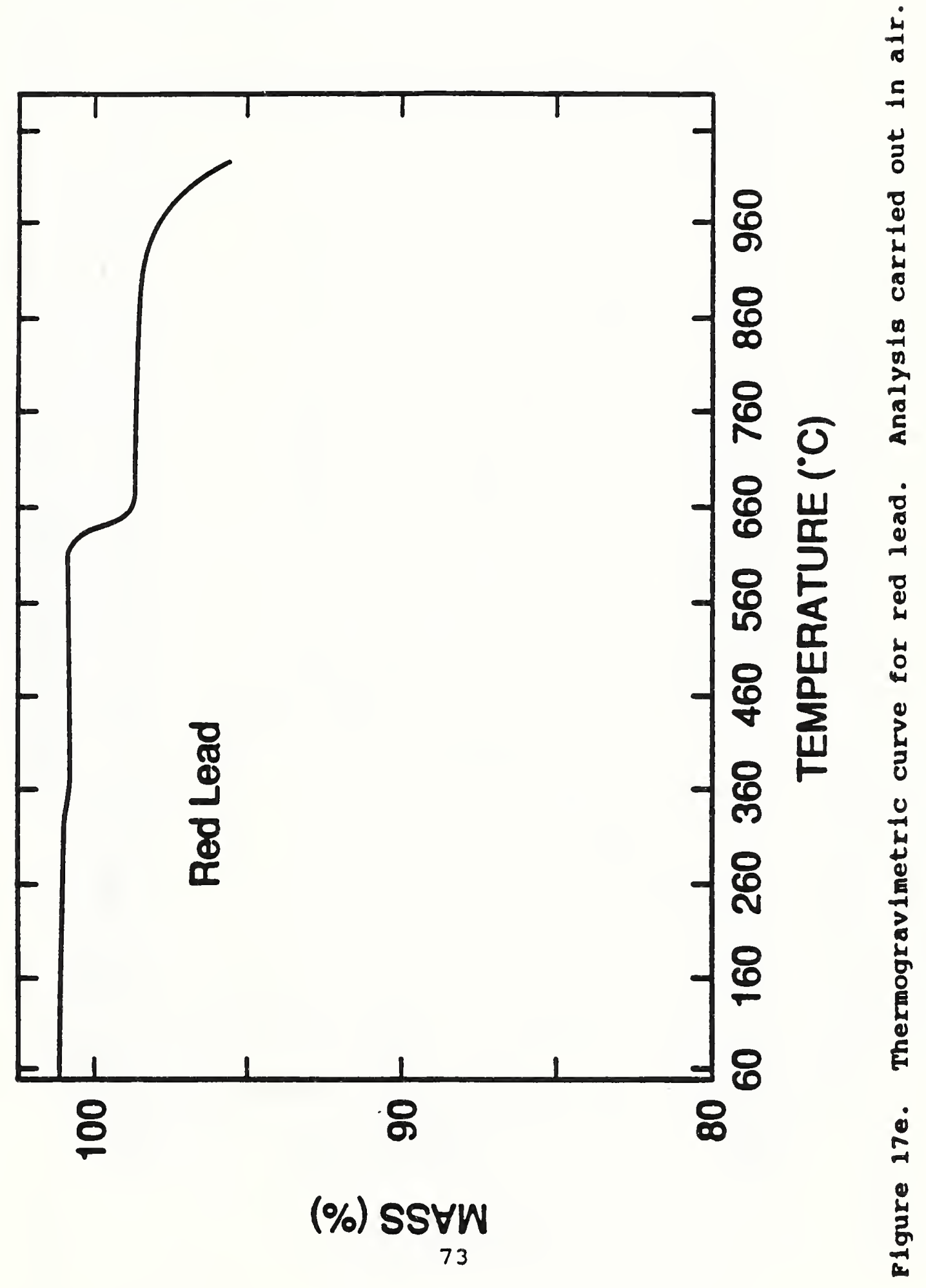




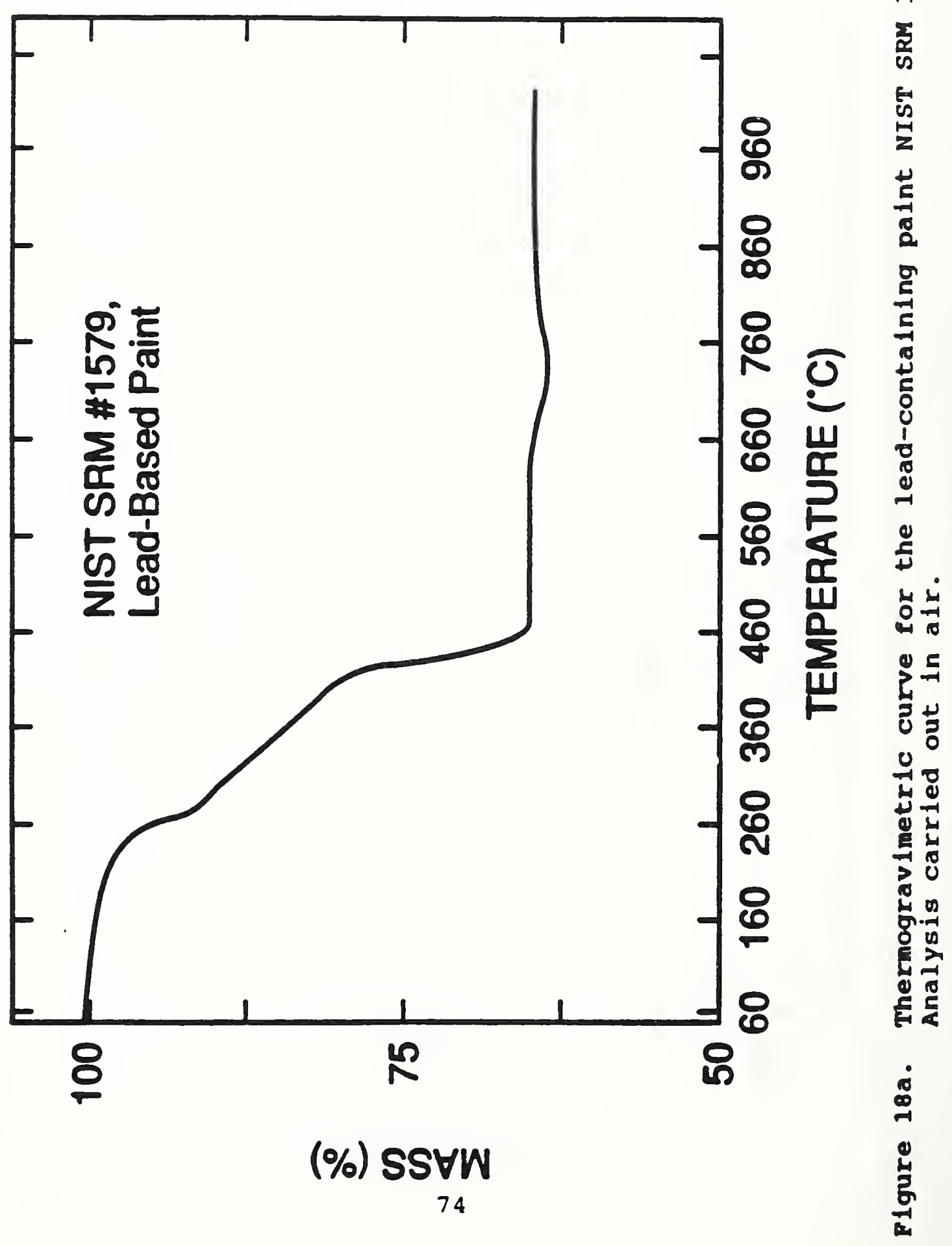




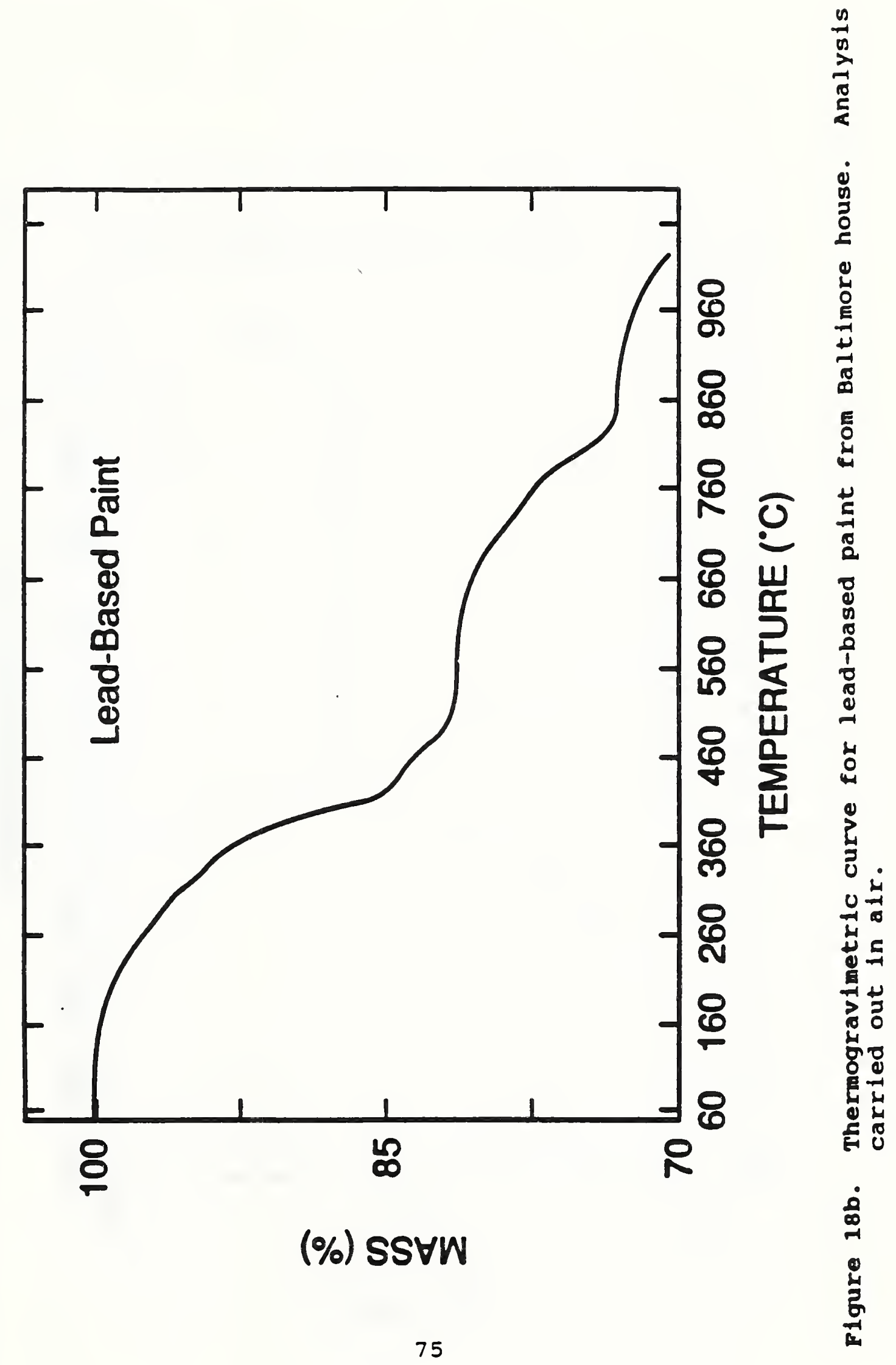




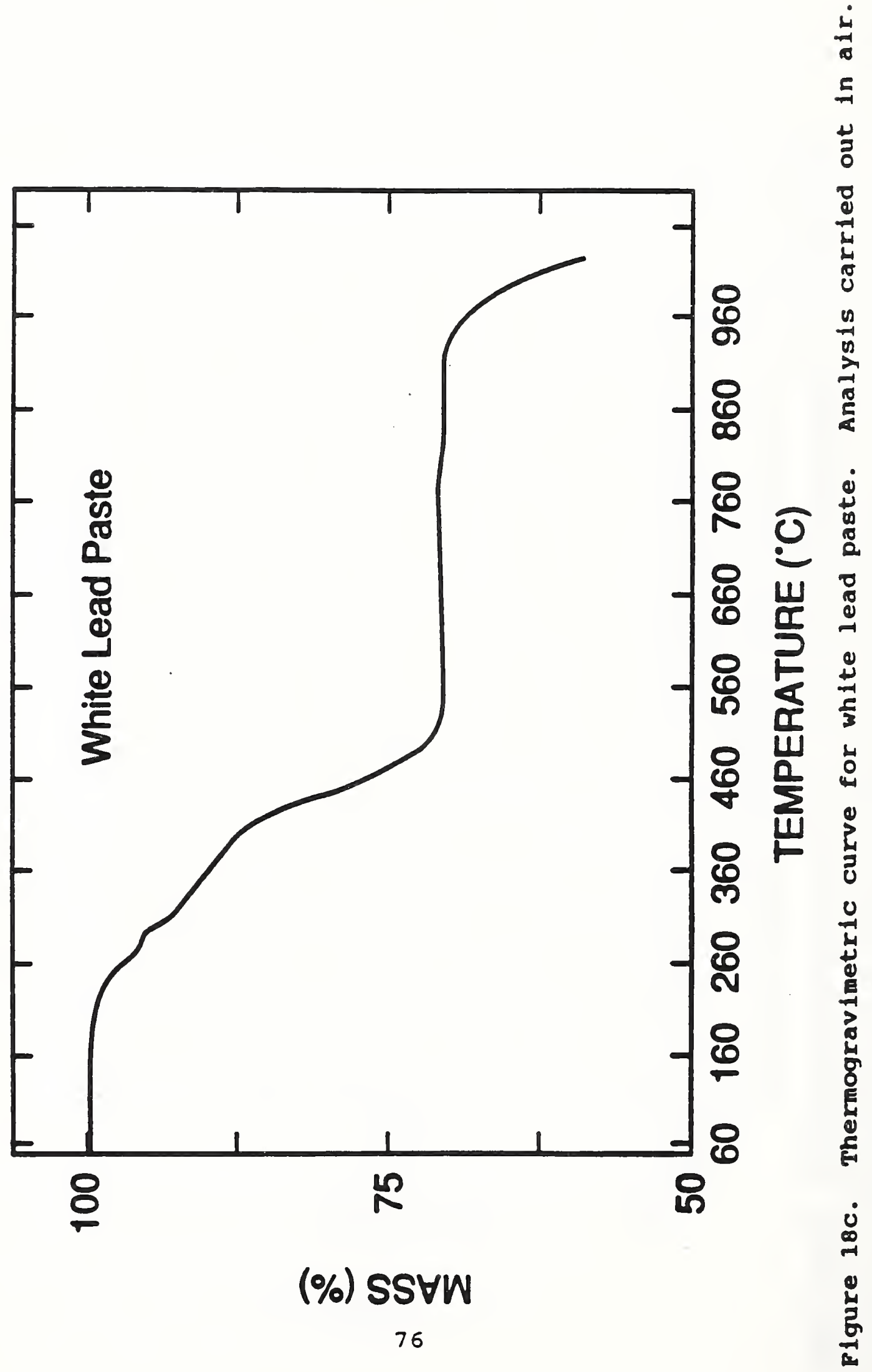




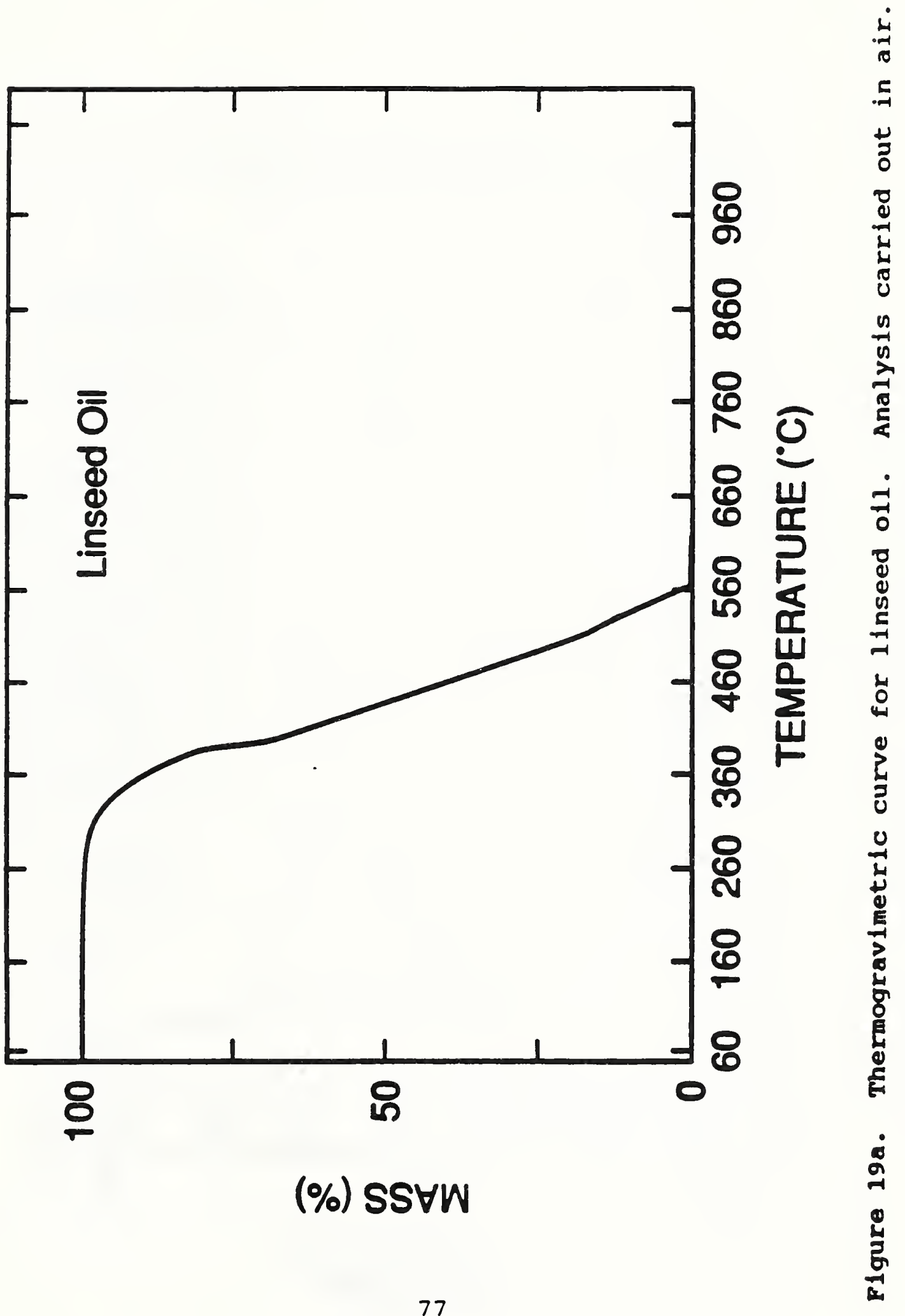




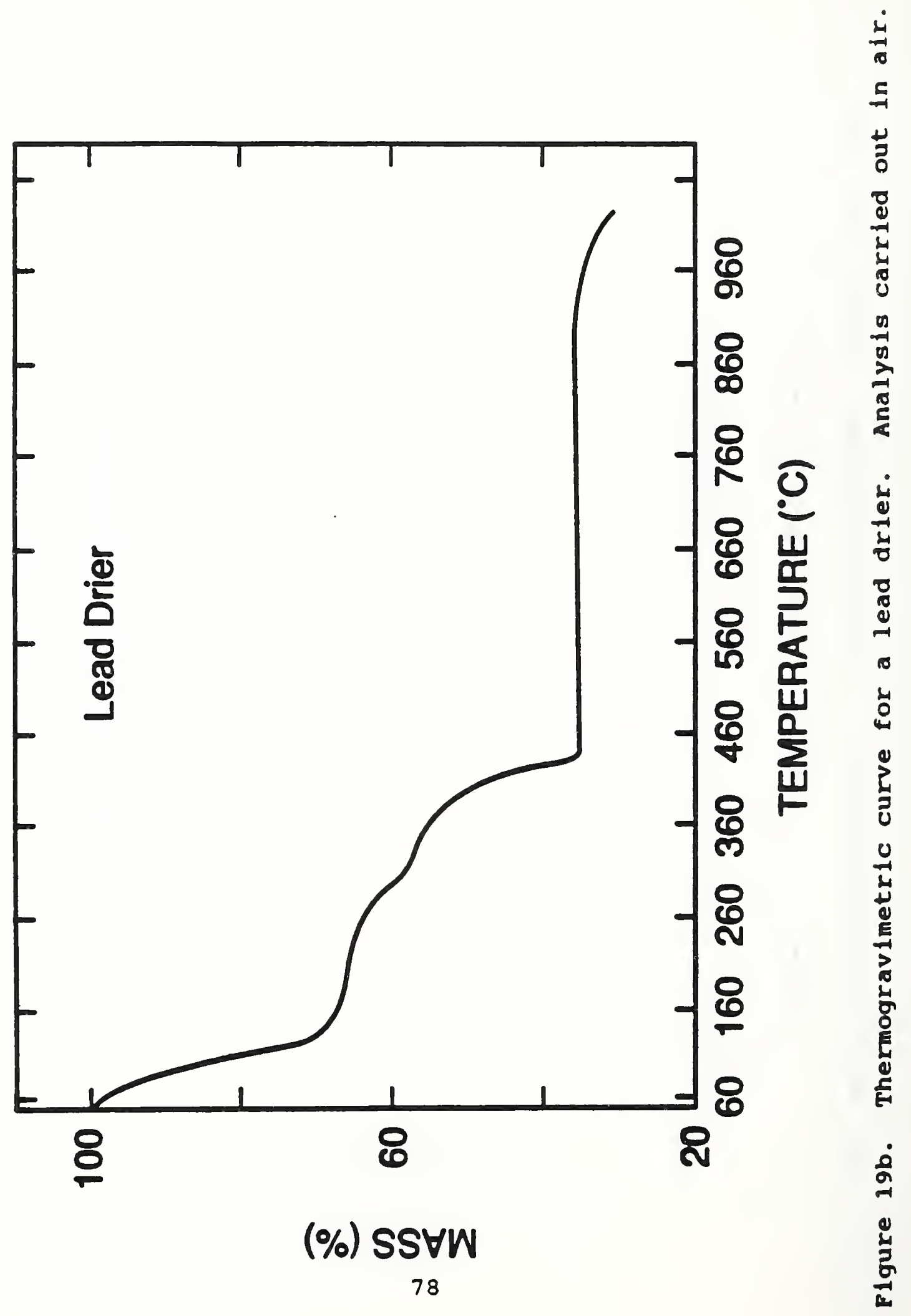




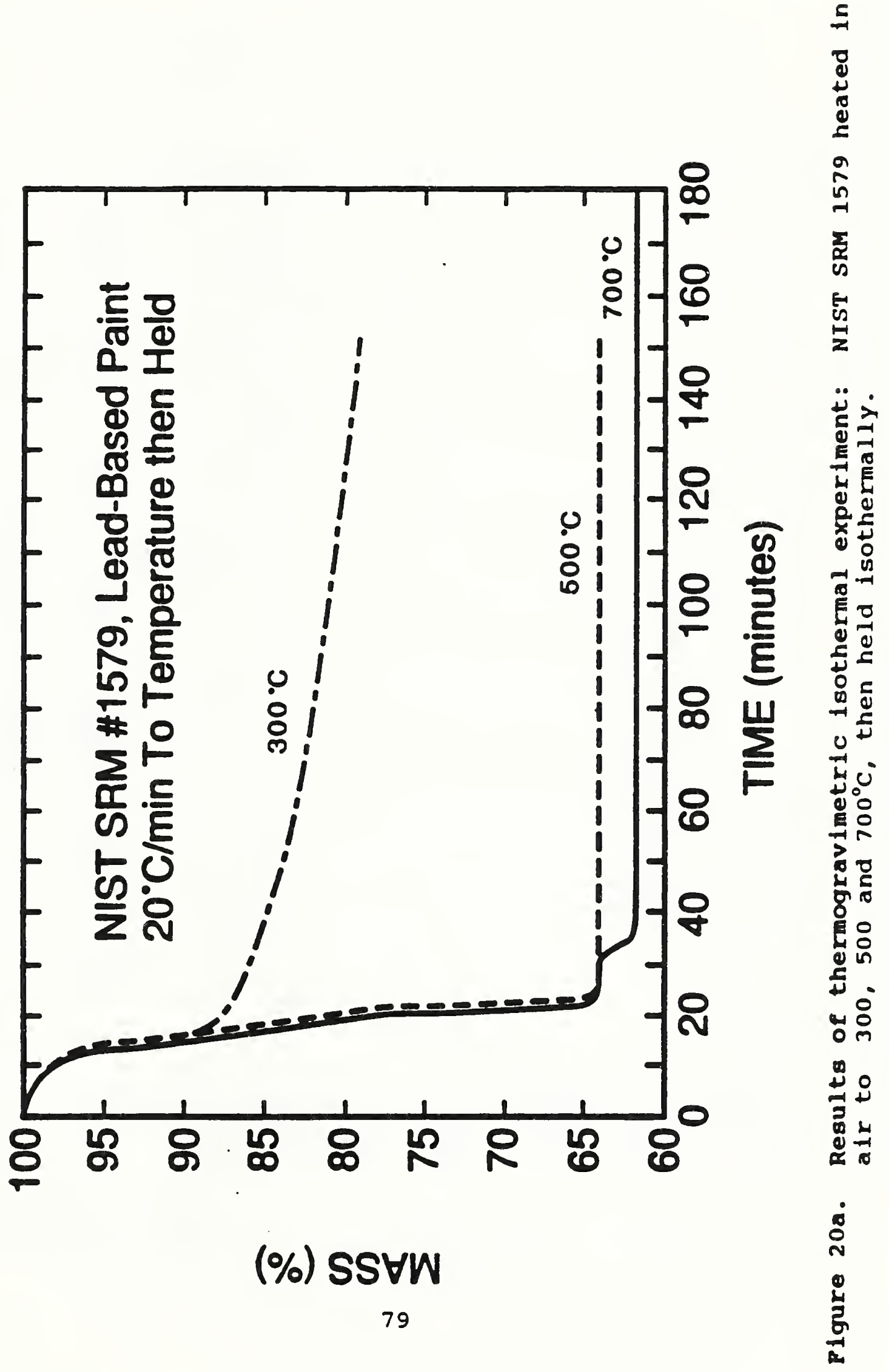




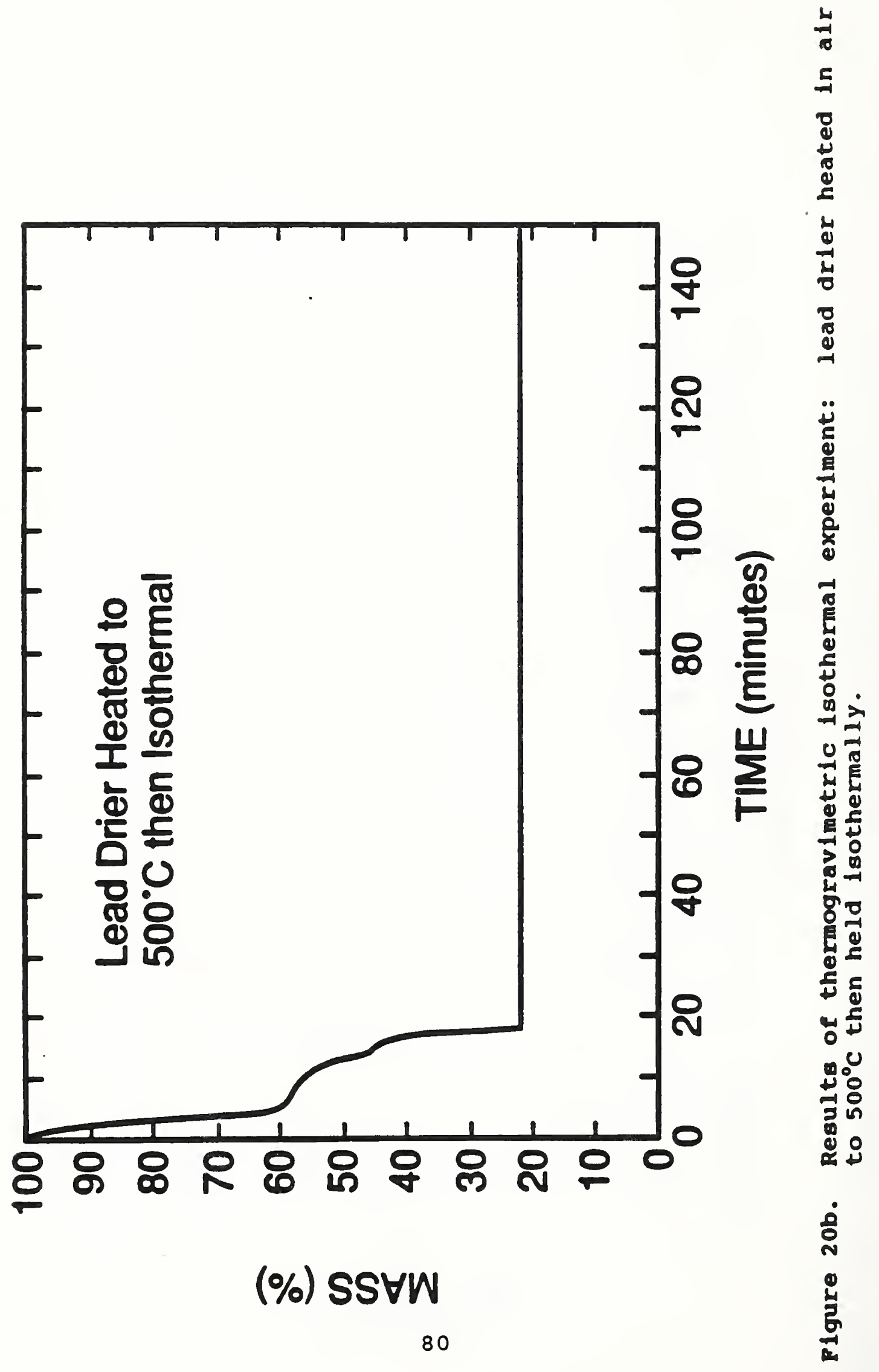



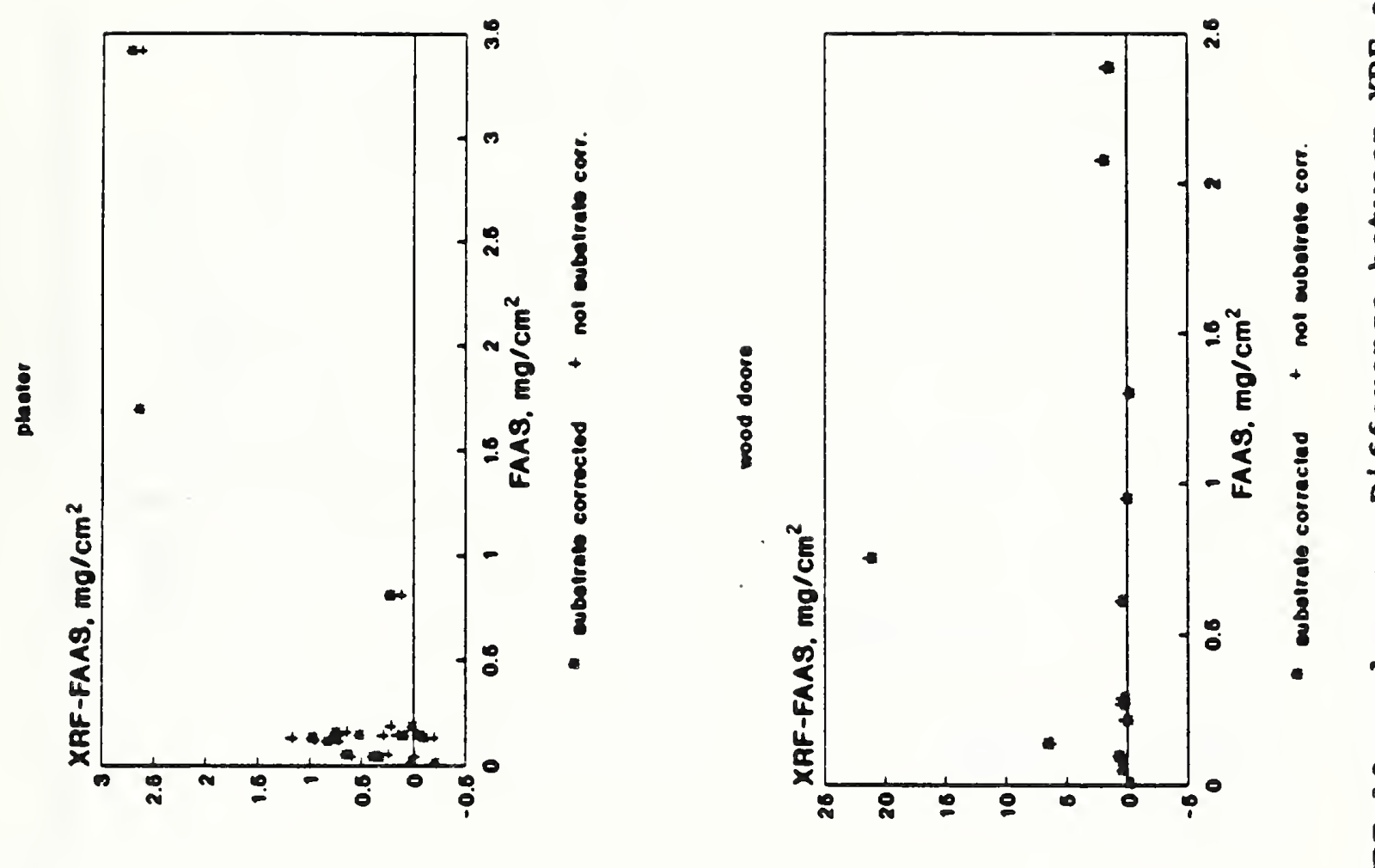

อ

岩

0



우

$\underline{c}$

ن

들

$\div 0$
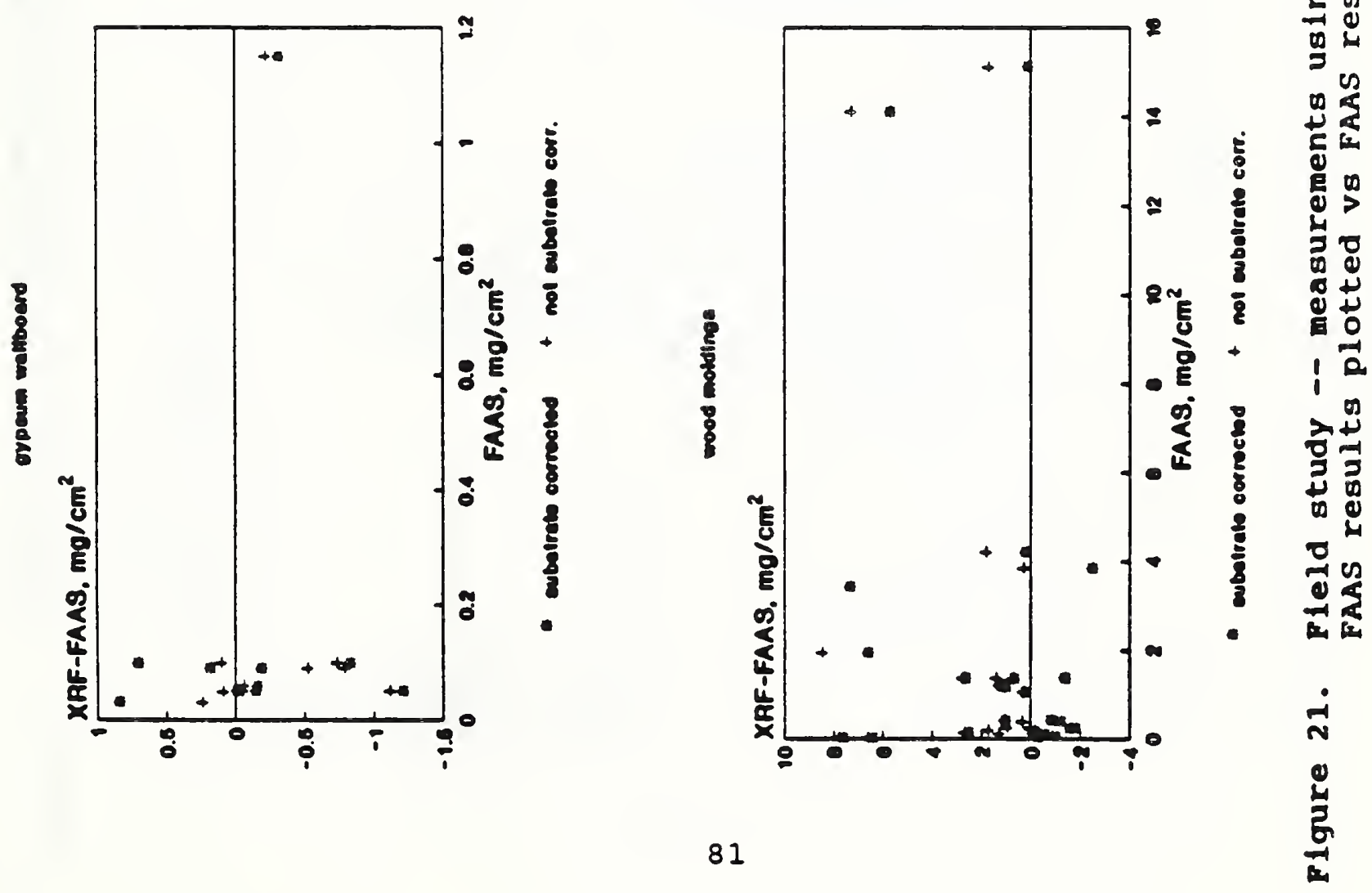

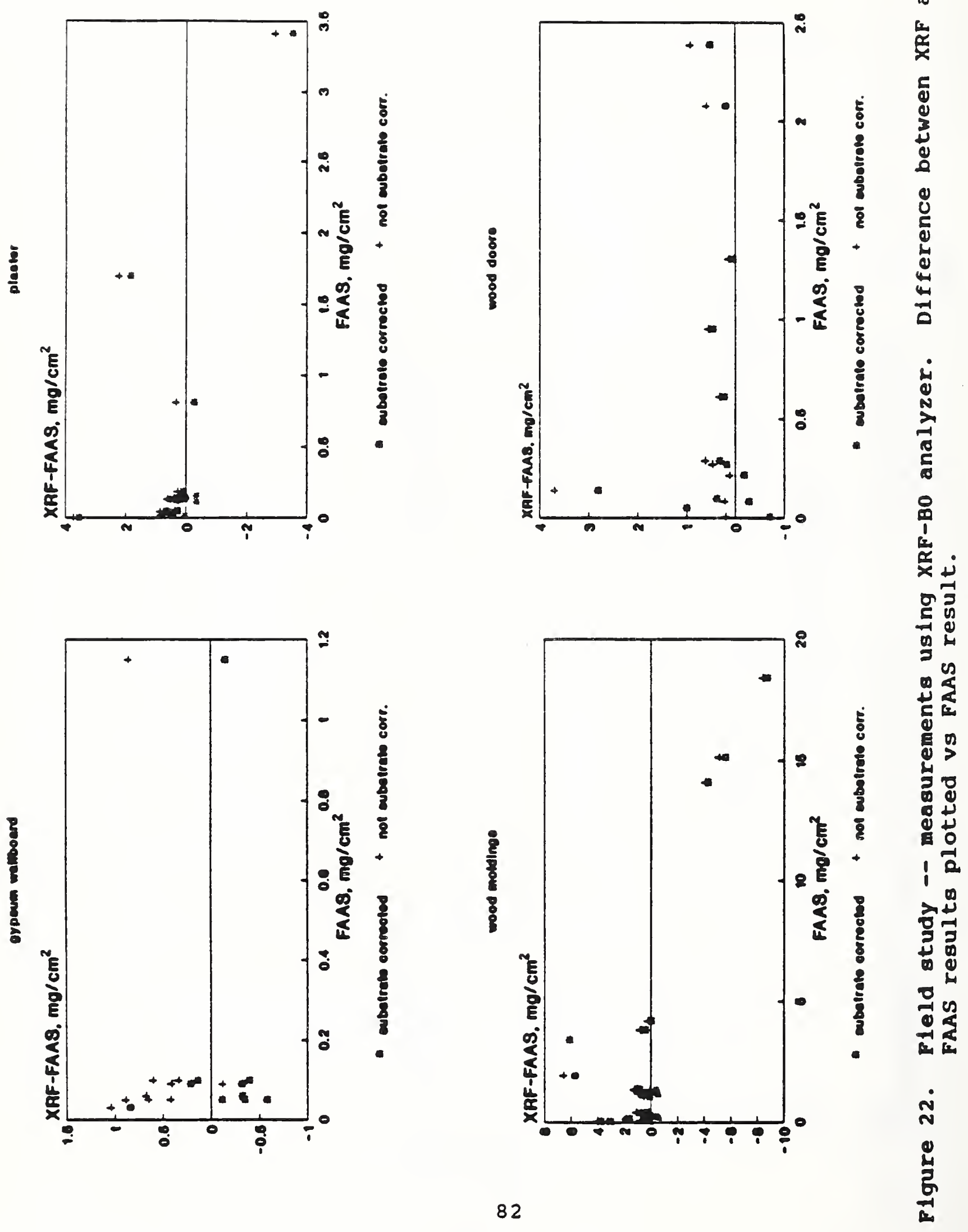


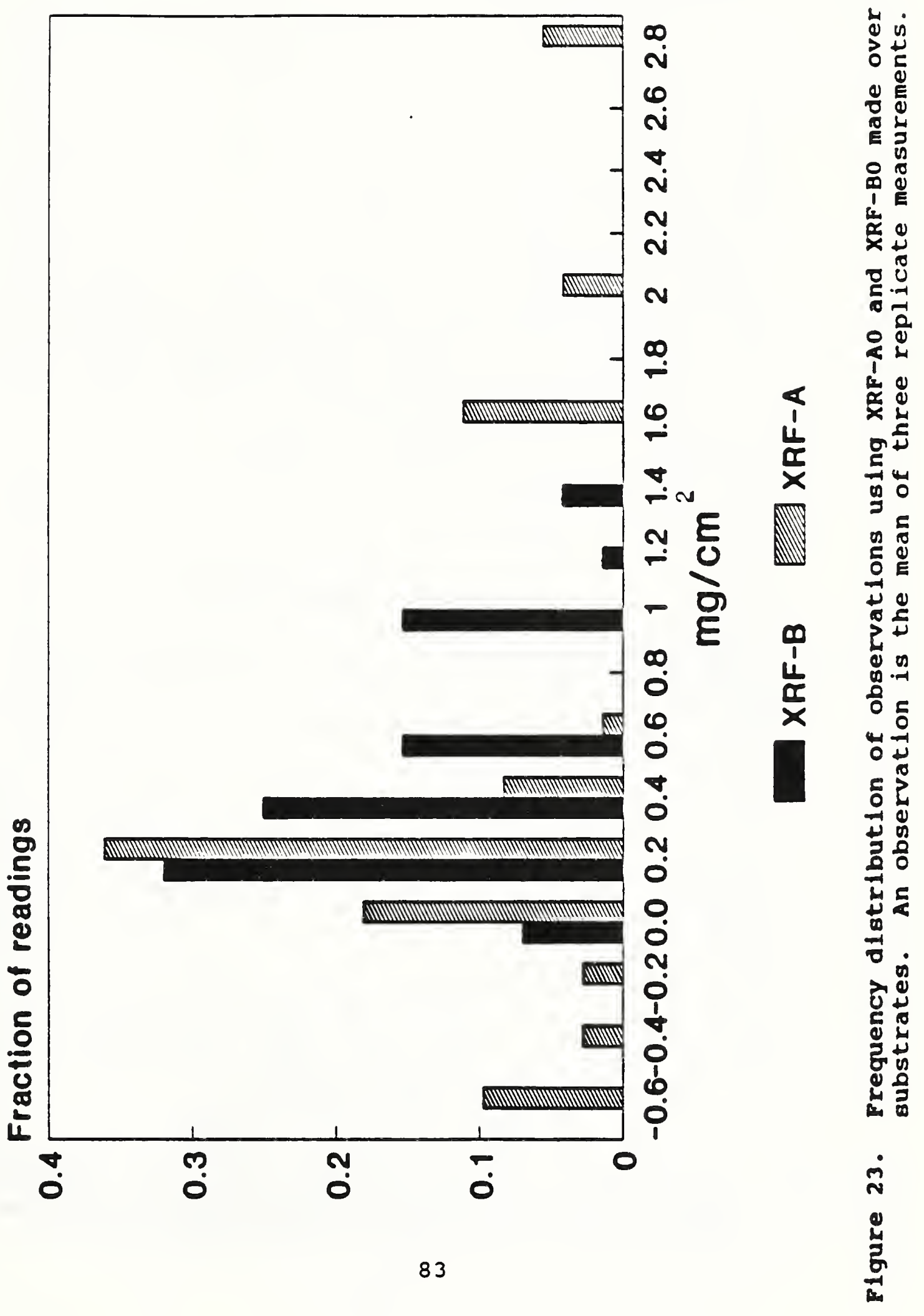


XRF-C1, without substrate correction

a) XRF-FAAS, $\mathrm{mg} / \mathrm{cm}^{2}$

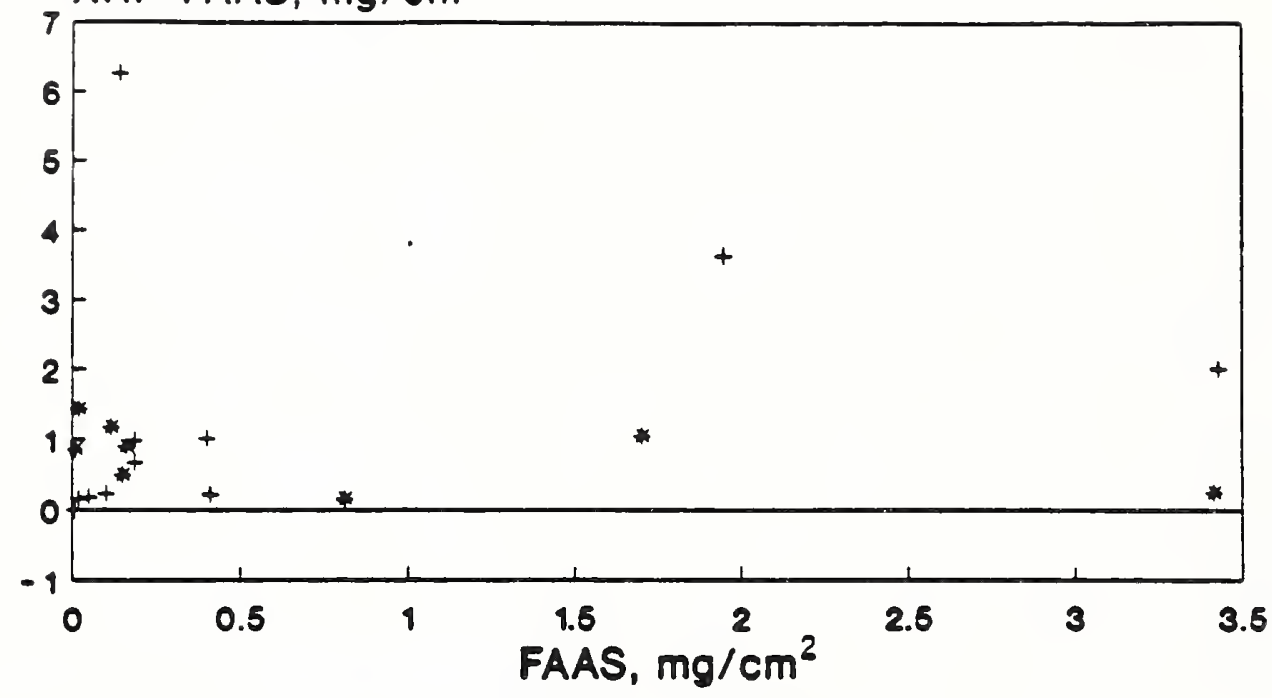

- plester + mood

XRF-C2, without eubetrate correction

b)

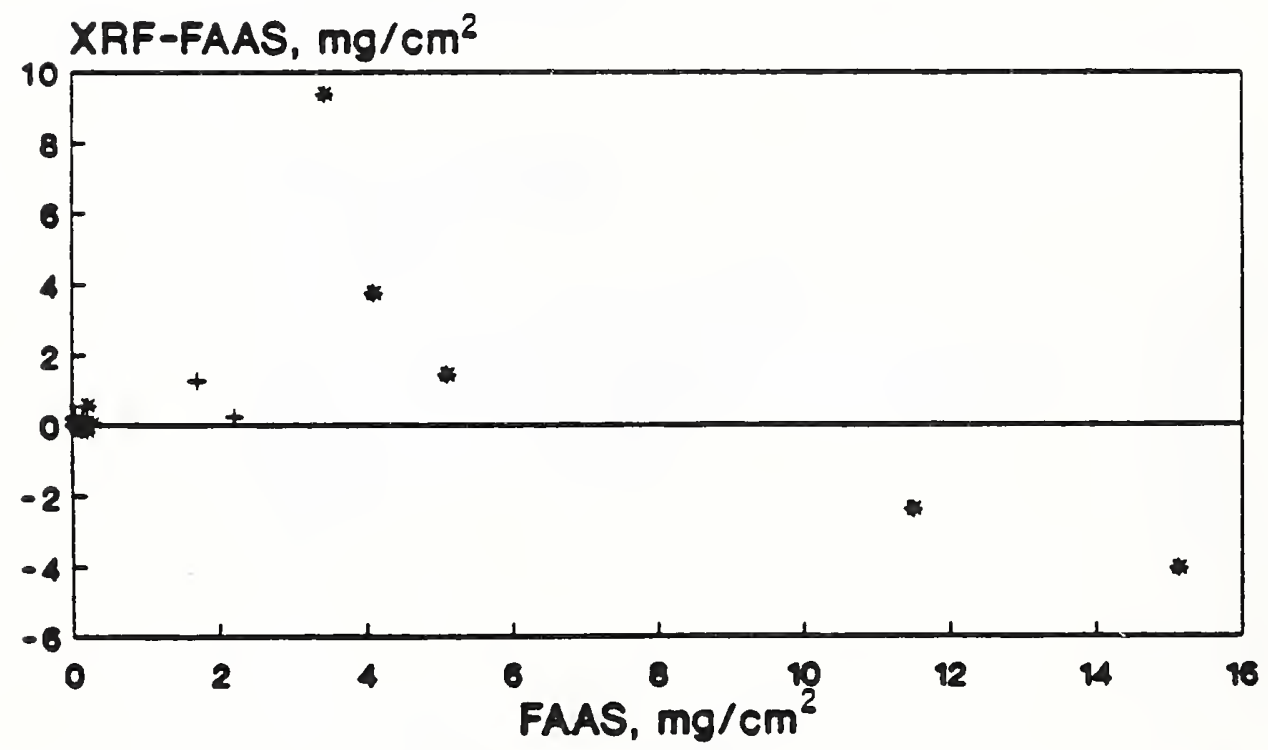

- motal + plaeter * wood

Figure 24. Field study -- measurements using XRF-C instrument. Difference between XRF and FAAS results plotted vs FAAS result. a) version 1 ; b) Version 2 . 


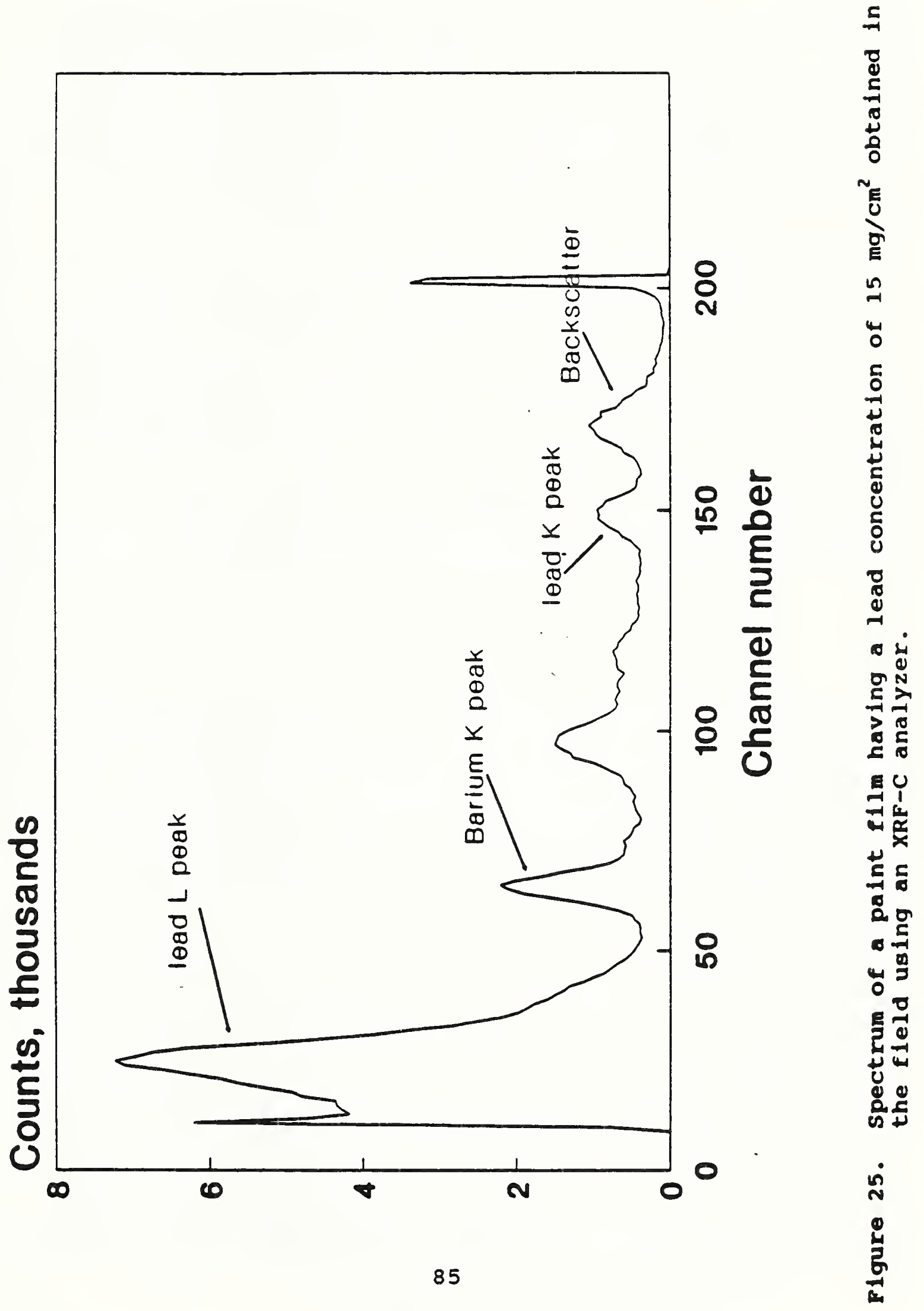


APPENDIX 


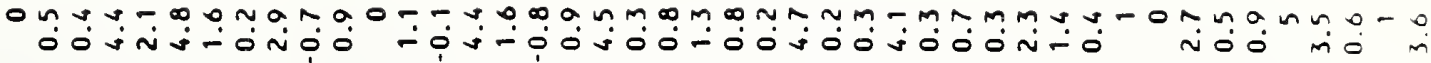

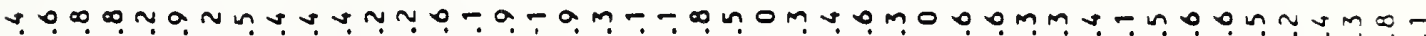

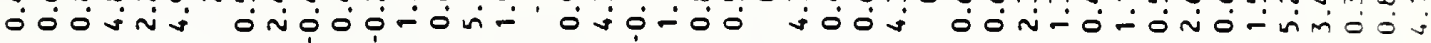
บn 000

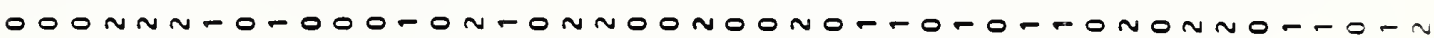

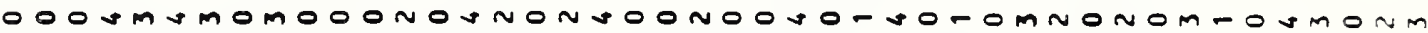
N

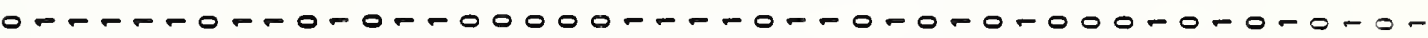

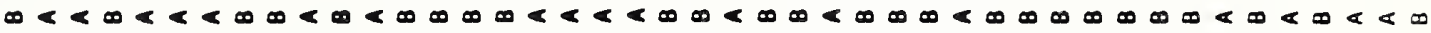

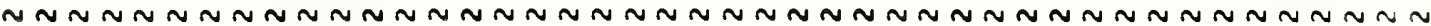
ڤ̆$\approx$ 彳ִm ex

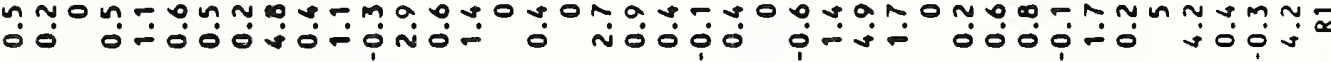

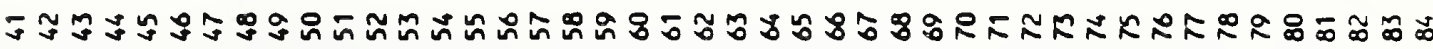

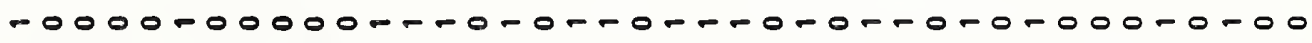

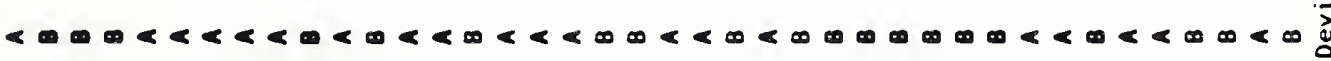




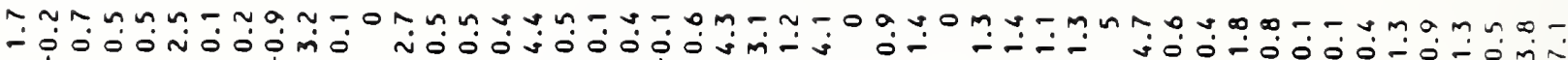
隹

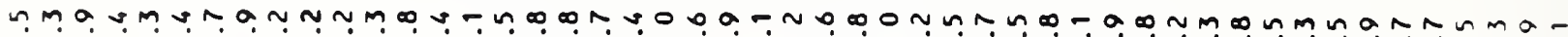

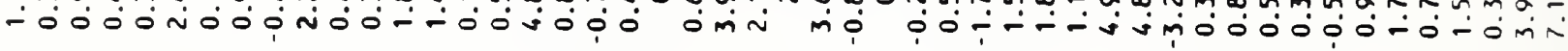

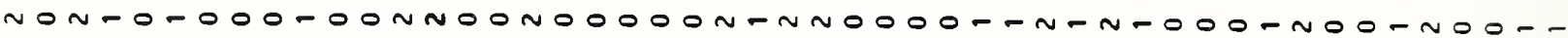
non-

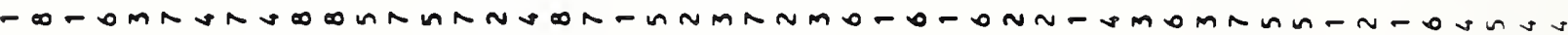

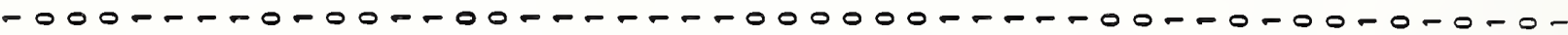

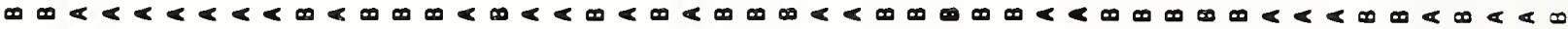

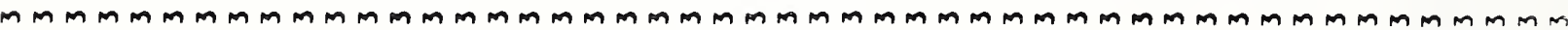

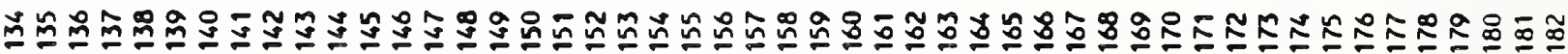

ப́m זํ.

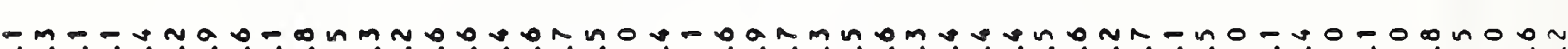

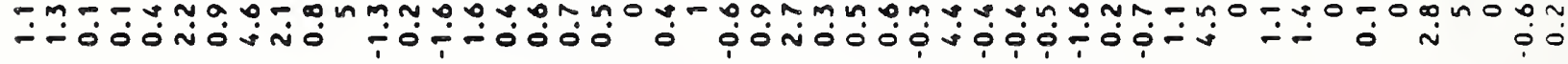

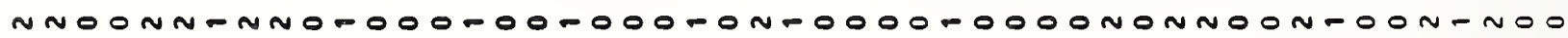
- noo-mnn N

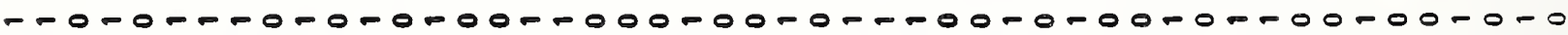

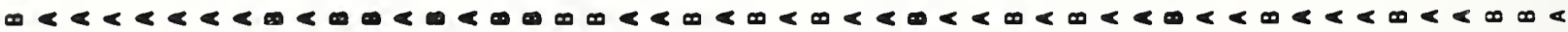

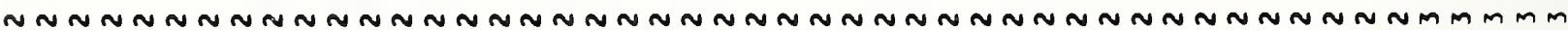

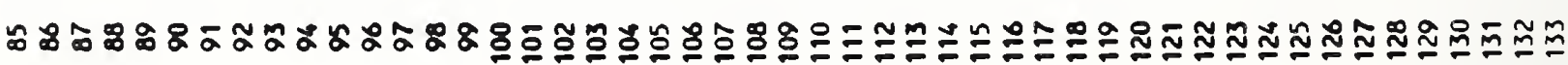




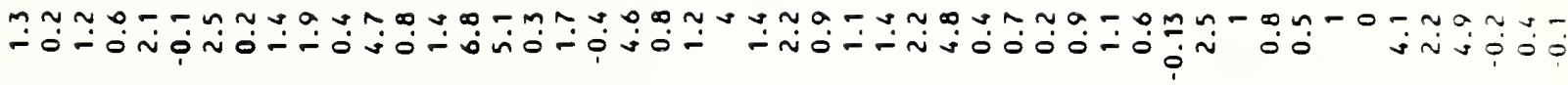
ว

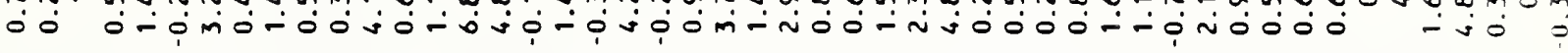

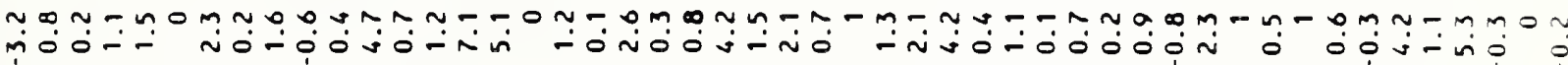

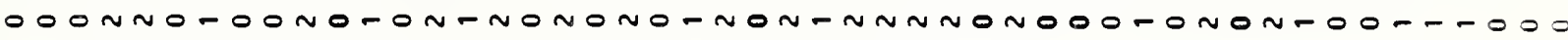

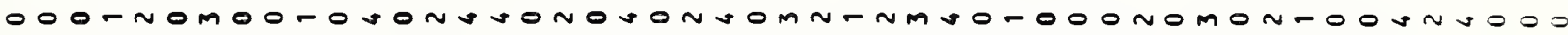
om $\sim$ M -

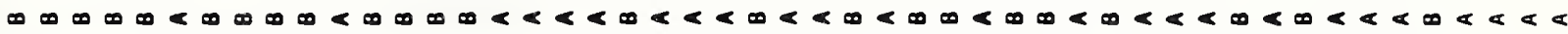

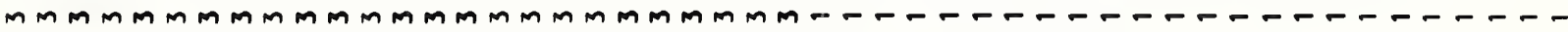

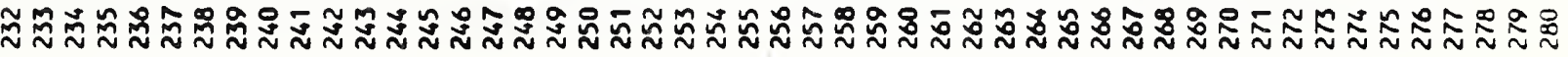

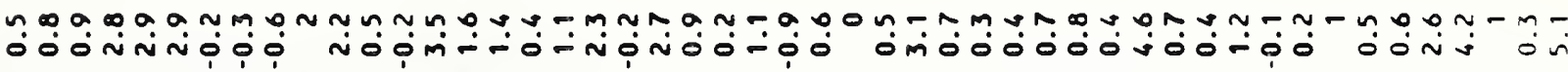

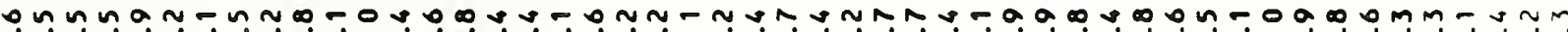

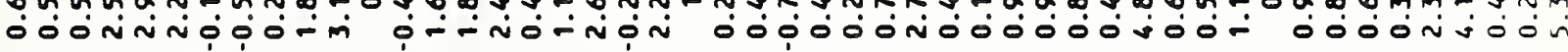
á -

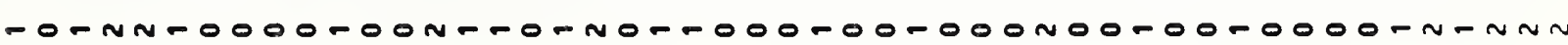

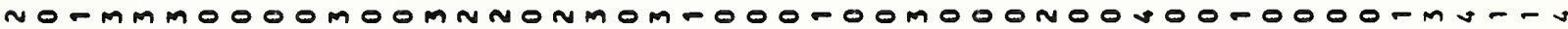

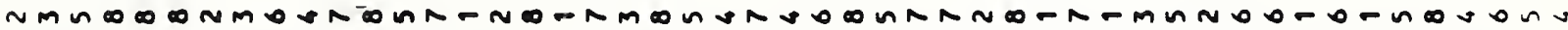

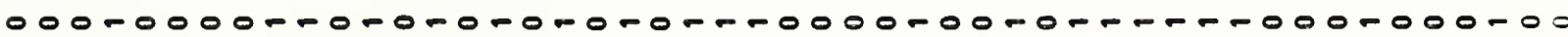

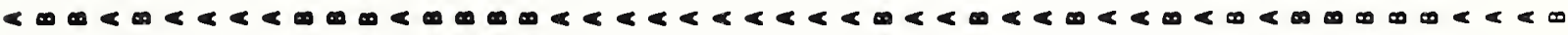

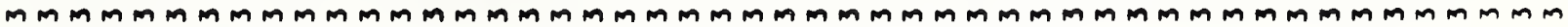

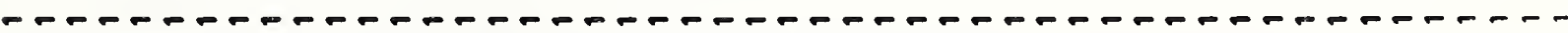

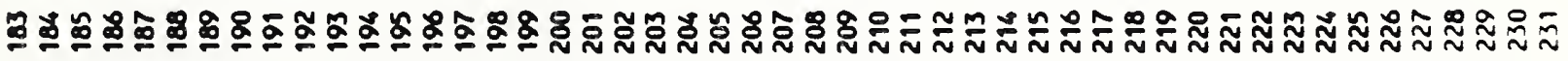




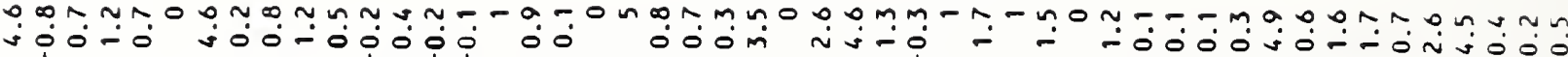
n ч

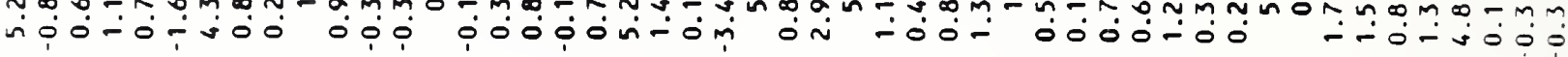

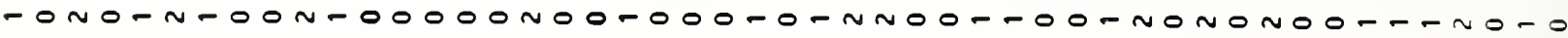

ho-o-na

A

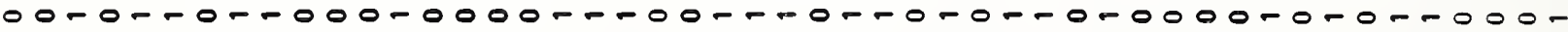

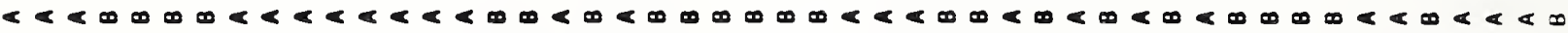

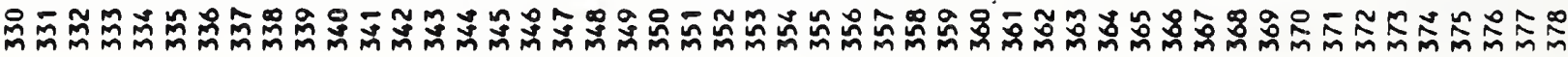

0 0 n n

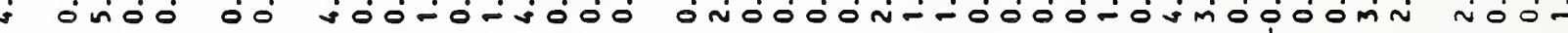

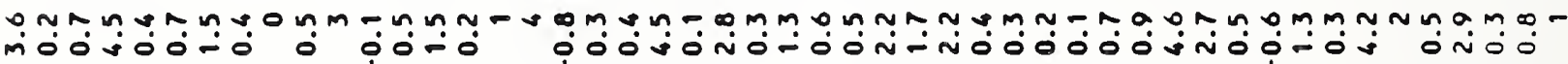

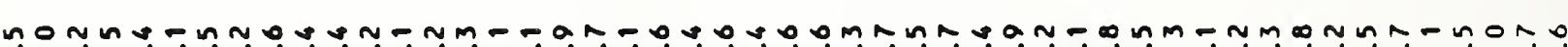
пำ

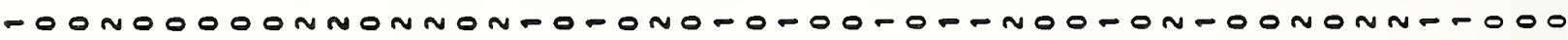

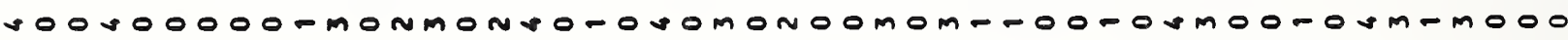

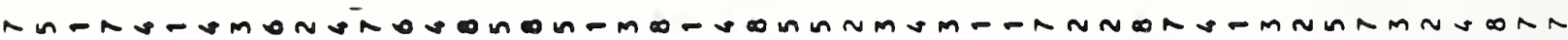

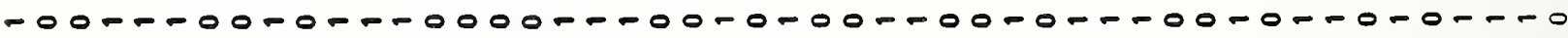

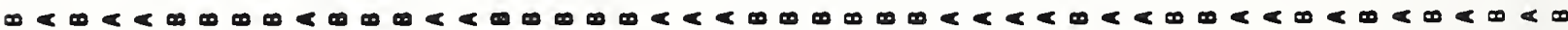
-

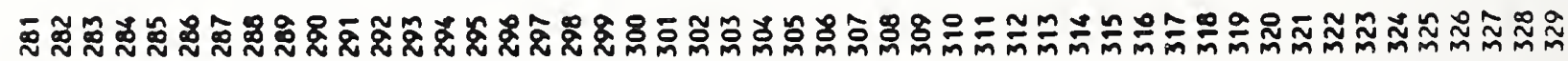




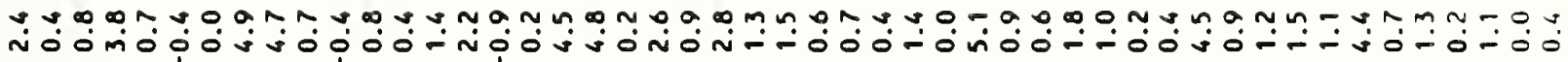
ñ

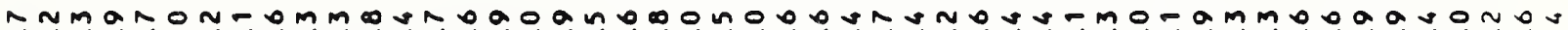
-í- $\dot{0}$ in

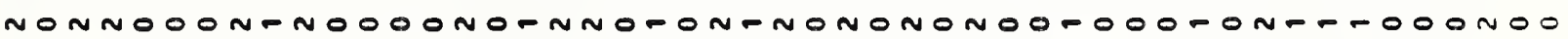

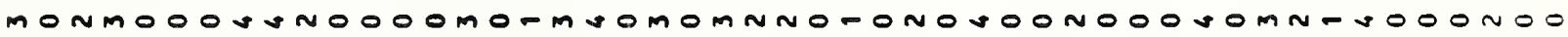

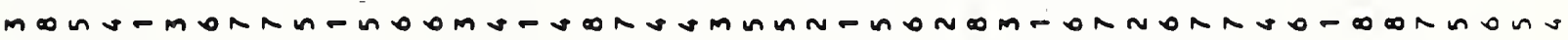

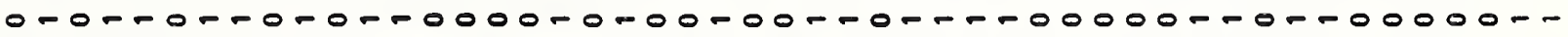

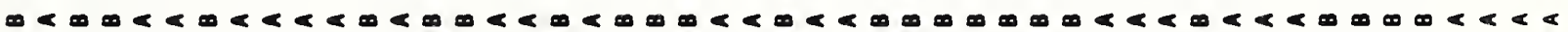

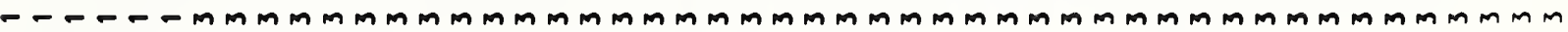

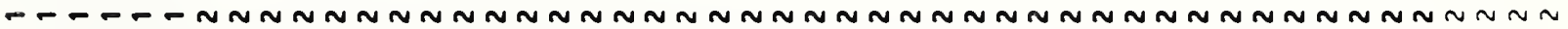

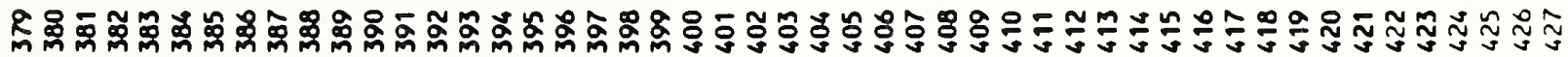


Tables A2 and A3. Raw data from ASTM round-robin experiment

Columns in the table are the following:

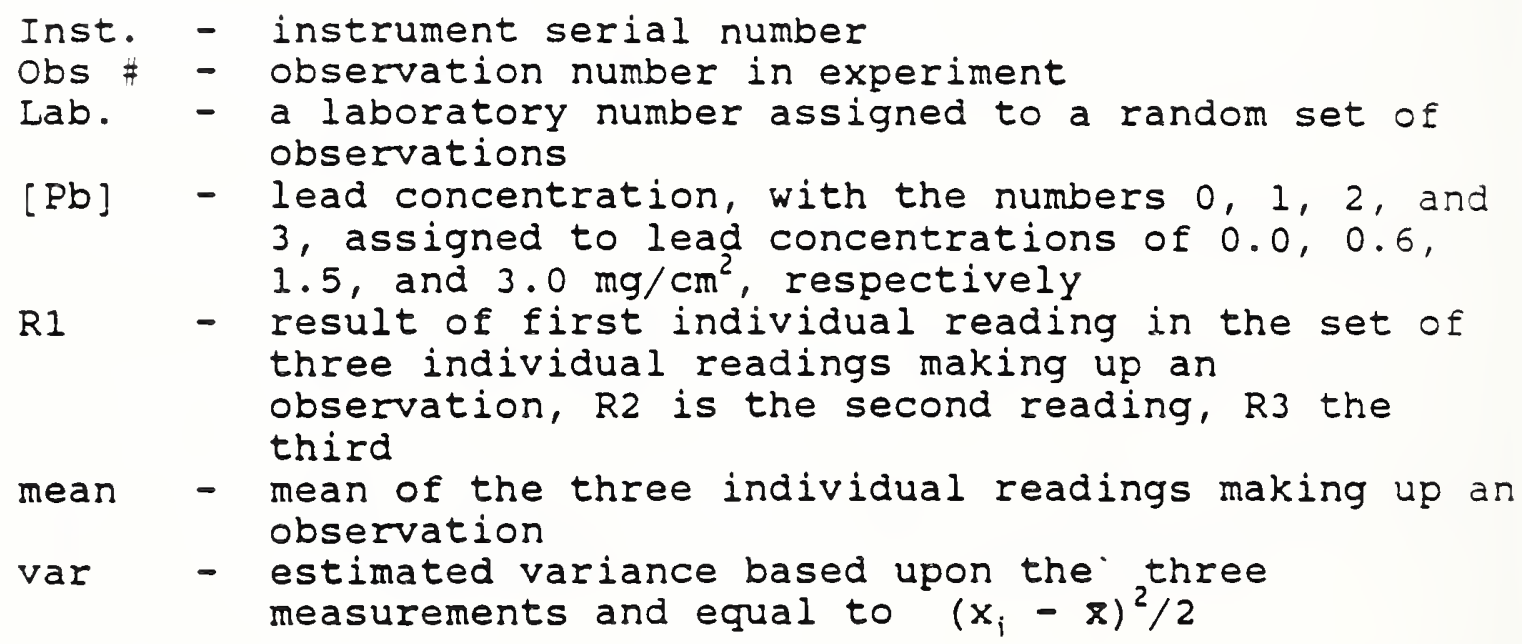




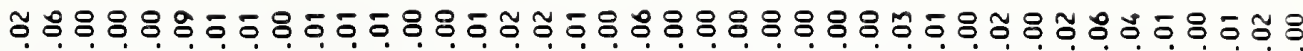

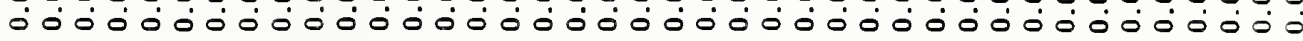

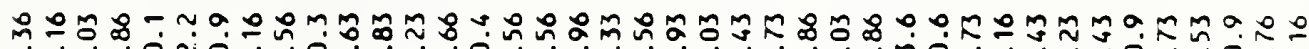

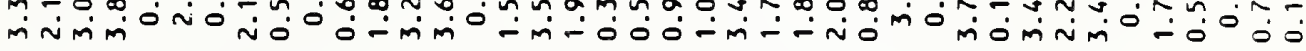
m-

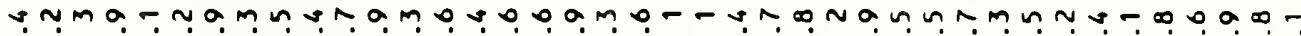

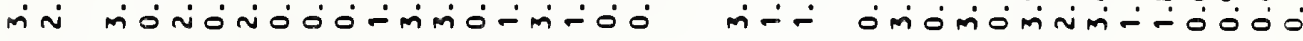

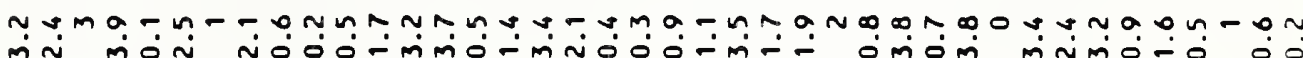

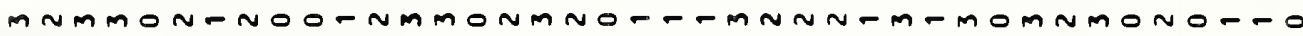

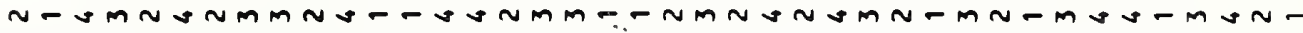
$M M M M M M M M M M M M M M M M M M M M M M M M M M M M M M M M M M M M M M M M$

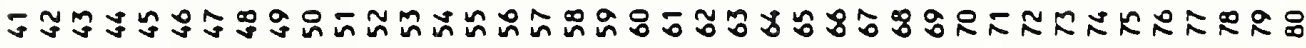

i.

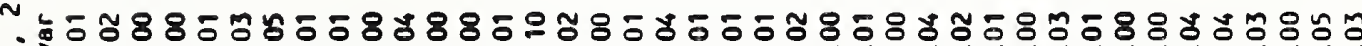

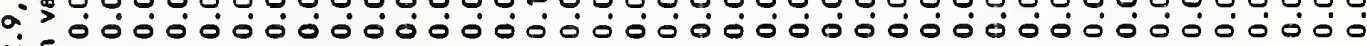
鹿 o ^ क - -

N na

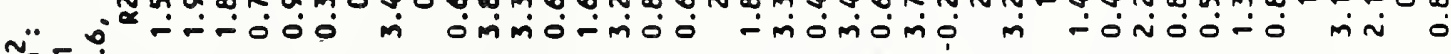
E $0^{j}$ -

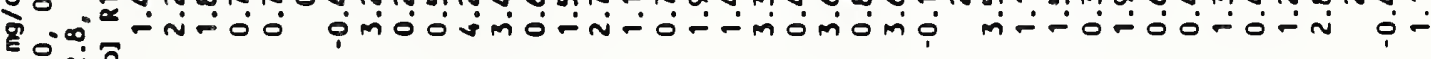

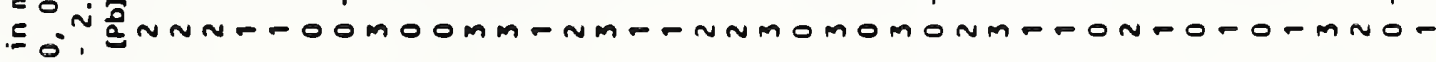
हु 要 $0^{\circ}$

: $=0$ mmmmmmmmmmmmmmmmmmmmmmmmmmmmmmmmmmmmmmm

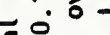

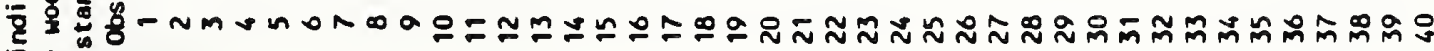
- 


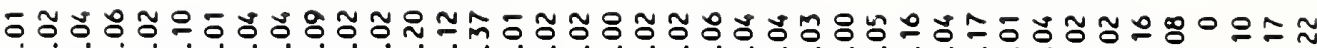

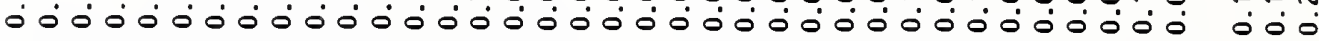

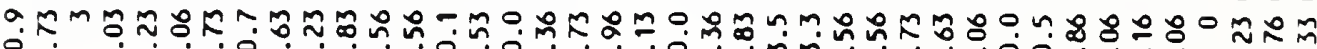
- m-0-0 -mó丶0்

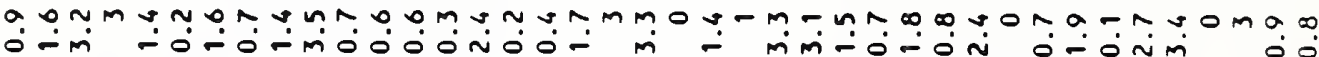

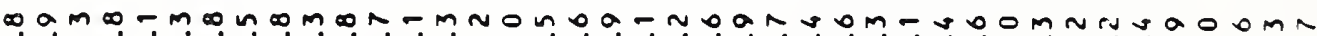

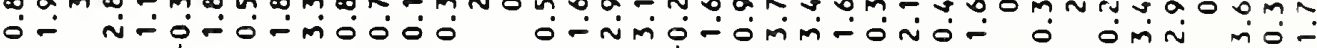

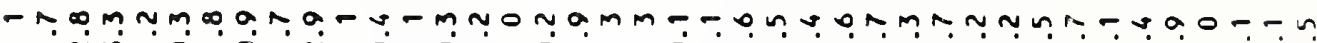

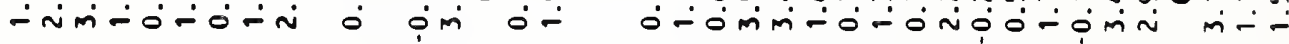
- Nmm-ONONM-- - ONO-NMmONOMMN-N-NO-NOMmOMO-

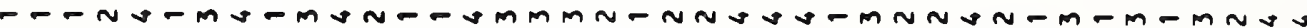

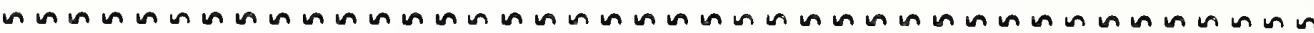

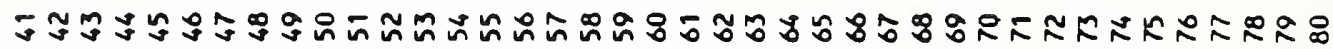

$-\tilde{m}$

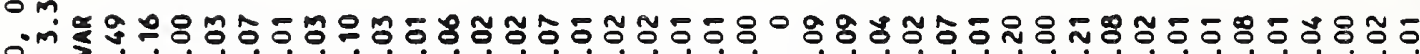

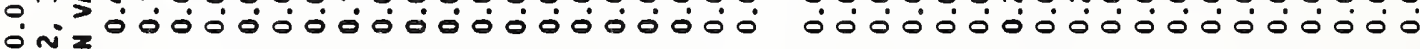
-m

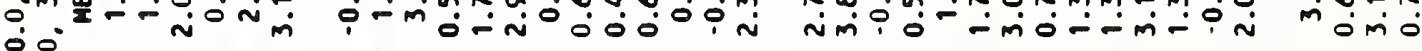

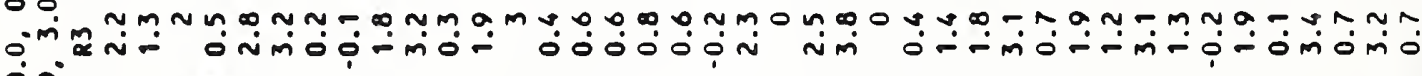
$\circ 0^{\circ}$

$e^{2}$

- - N N Eั0

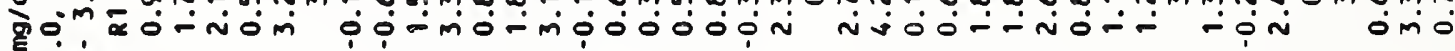
E. gån-NN-MmOONMONMO-- - ONOMMOONNM-RNMNONOM-M(

绳

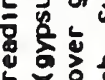

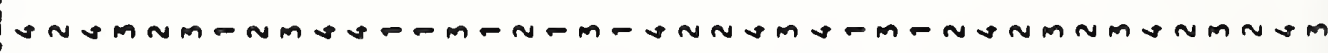

凹 -

马.

흔

$\geq 808$

ไี 


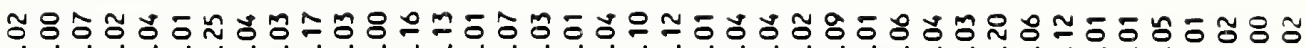

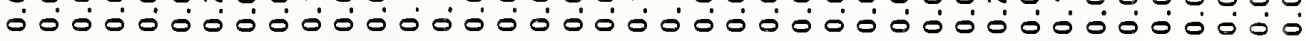

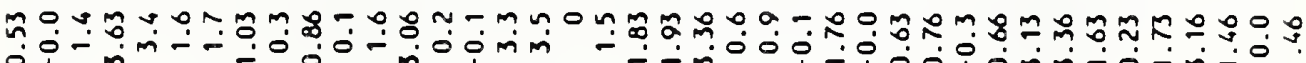
$01 m$ - 0 m im

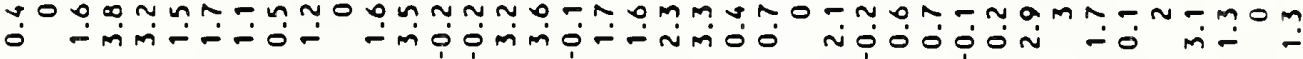

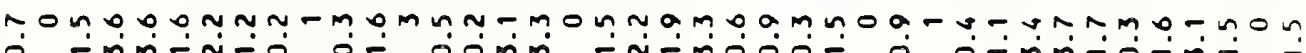

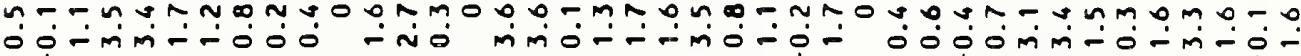

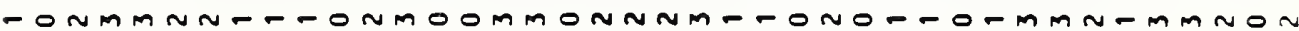

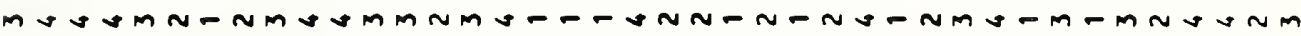

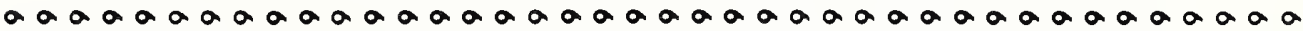

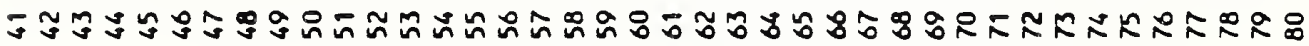

$\ddot{\dot{n}} \dot{0} \dot{0}$

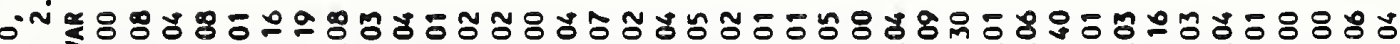

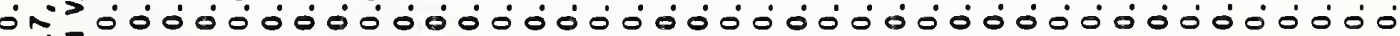
రN miñ

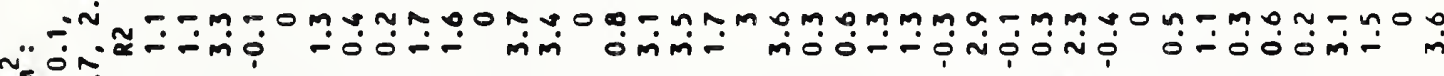
E

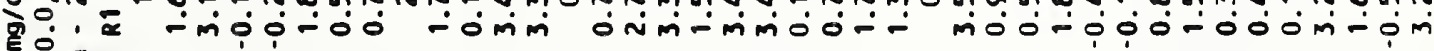

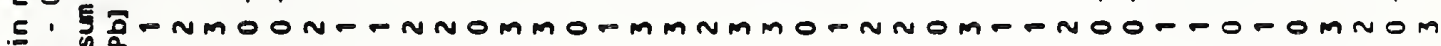

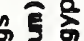

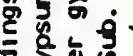
要言

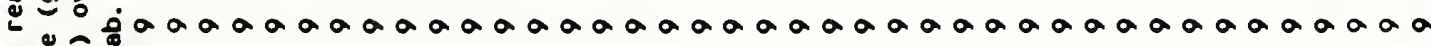
ธ

원 


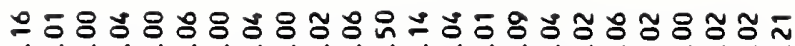

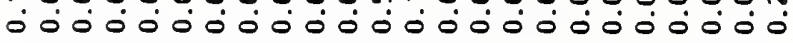

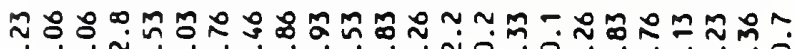

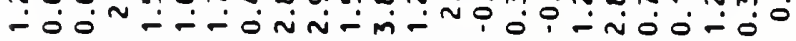
茂 0 

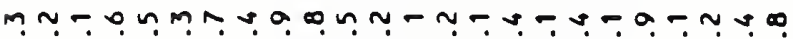

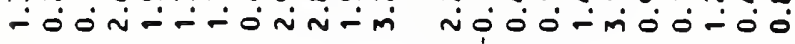
- O OMNON-MmNm-NO-ONM-ON-0

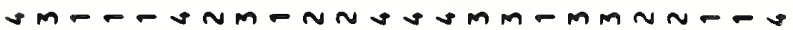

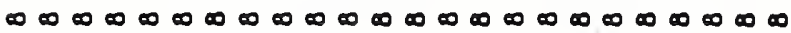

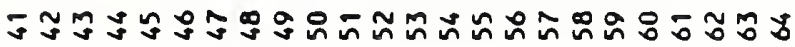

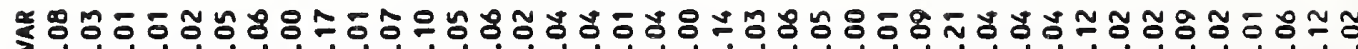
ojojojojojojojojojojojojojojojojojojojo

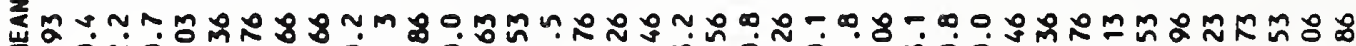

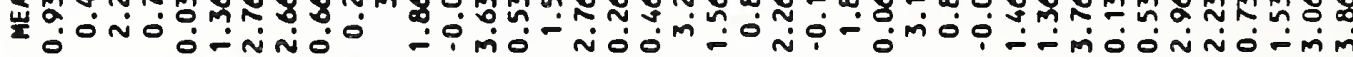

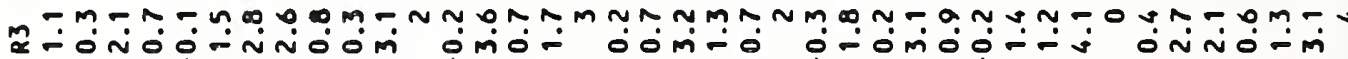
omm

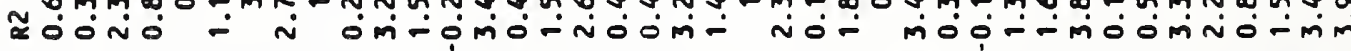

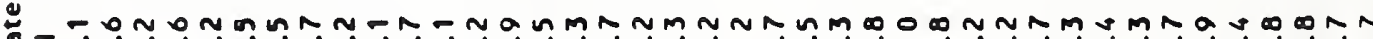

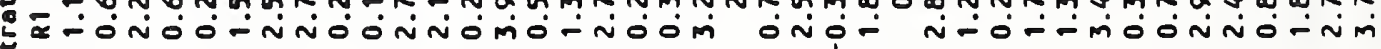

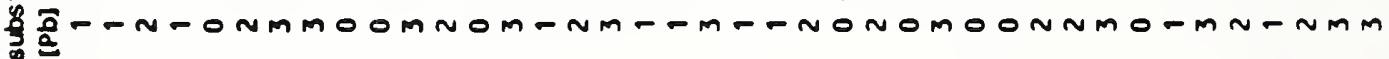
บั 马े

迥 


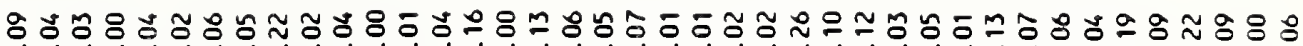

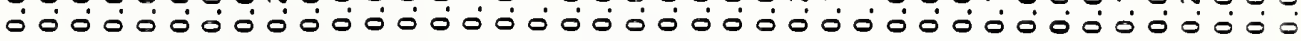
ติ - 0 -mi-omm o. -

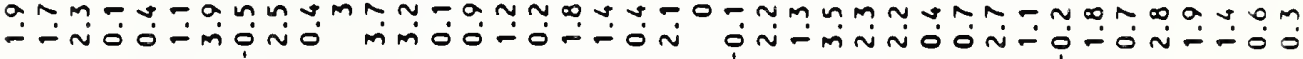

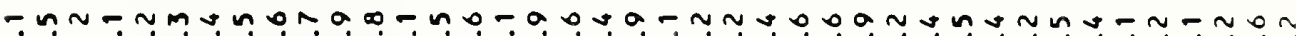

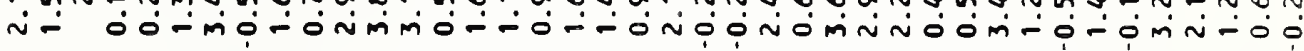
nmm N v o-

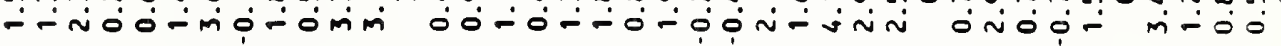

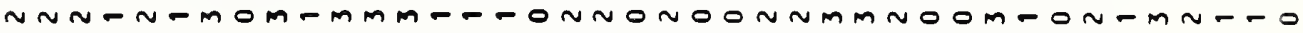

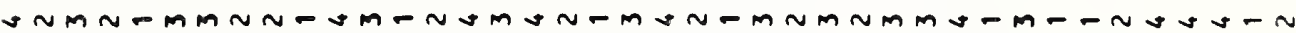

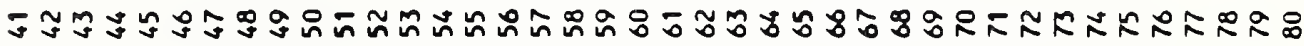

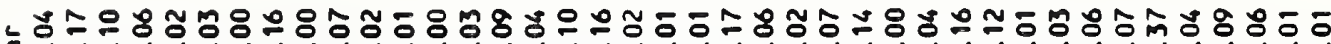

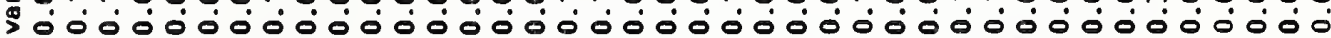

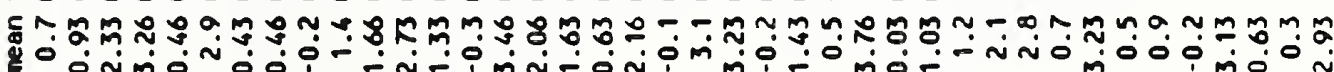

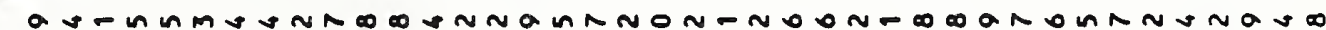

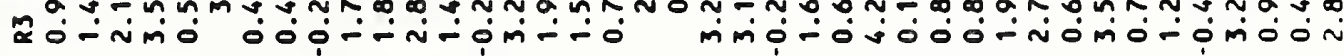

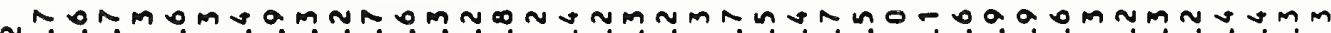

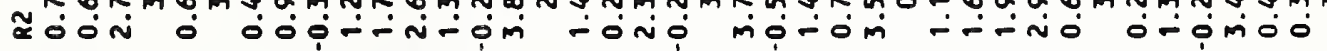

Z

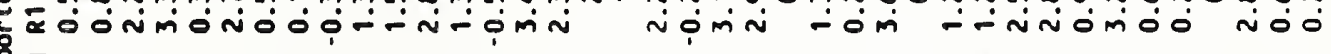
gE- - NMOM-OONNM-OMNNONOMMONOM-R-NM-MO-OMO-M $\leq$ 


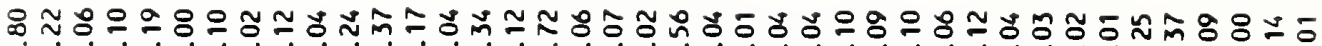

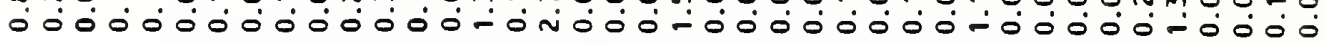
ज̧ - mam : - Non- 0 onmino- 0ด̆

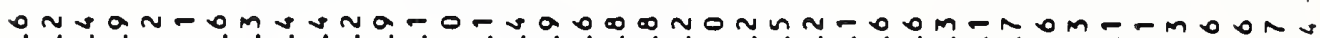

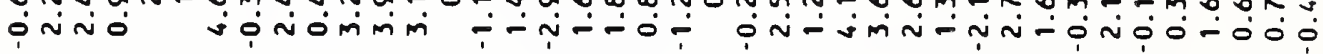

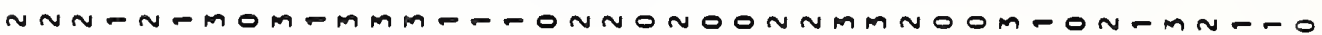

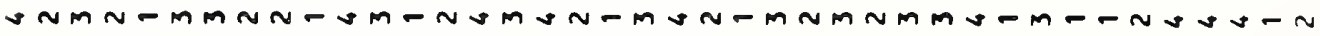

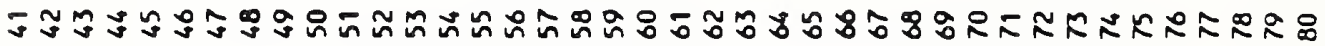

$\infty$

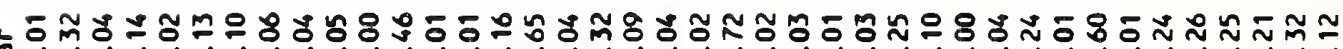
m

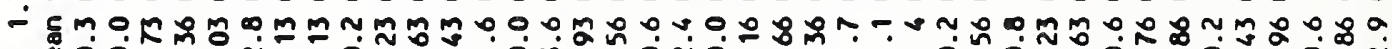
ه

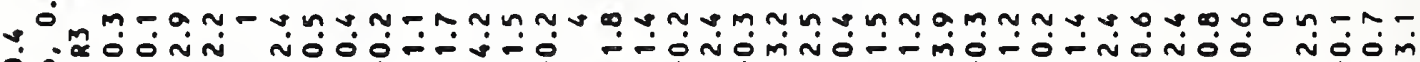

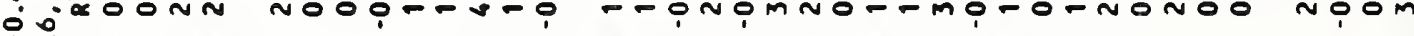

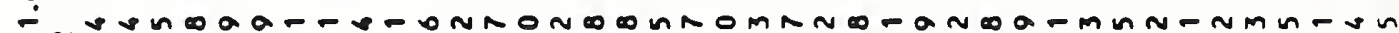

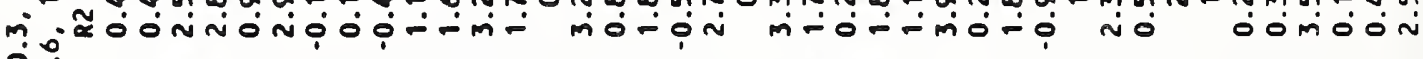
ह

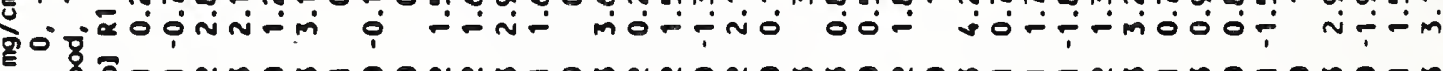
EO 0 a

总官

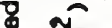

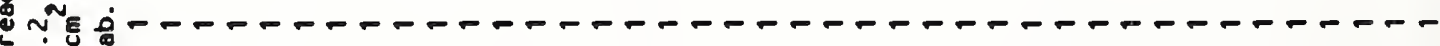
恿 in

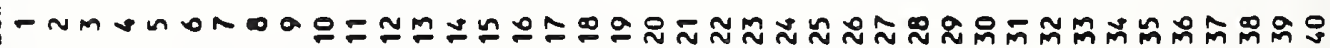




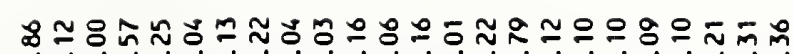
ல்

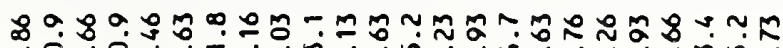

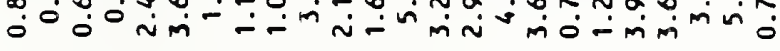

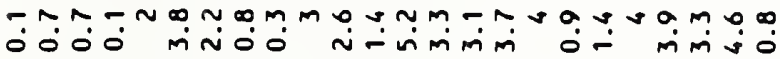

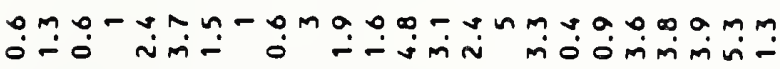

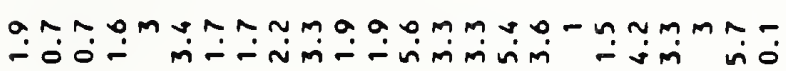
$-\sigma-N M-\sigma N M-M M M M-O M M M M N$

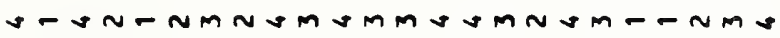

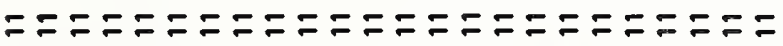

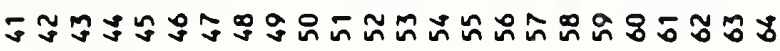

$\ddot{\circ}$

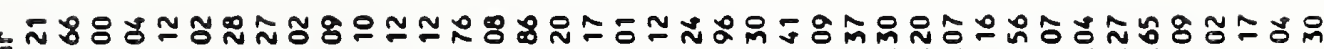

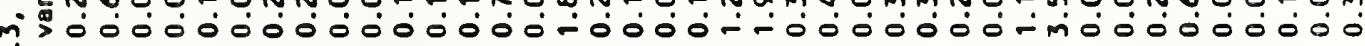

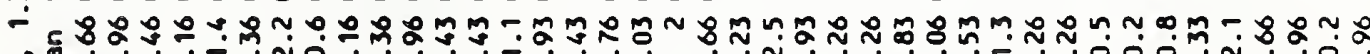
v

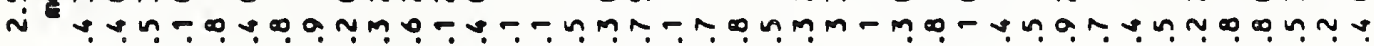

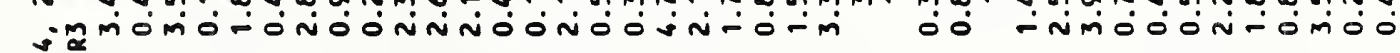

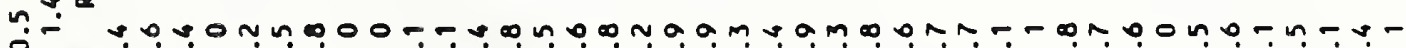

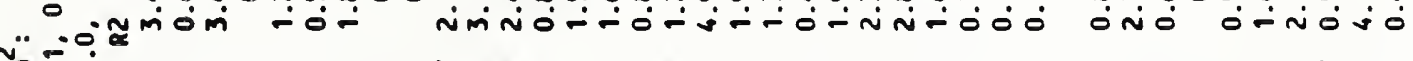
हु-

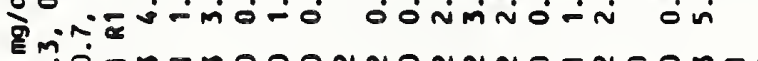
Eo am-MOOONNONNNO-nOOM-NONNNO-NOONMOO-n--MO$0 \cdot 0^{\circ}$

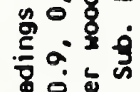

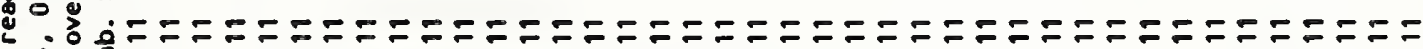
-

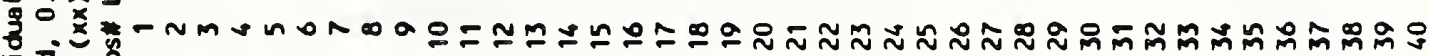




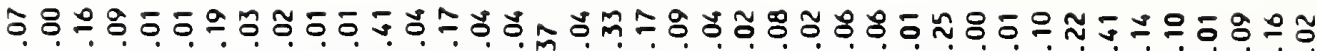

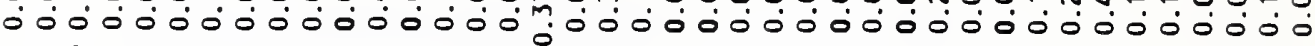

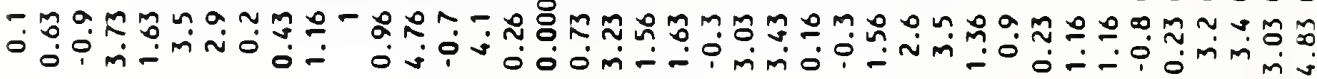

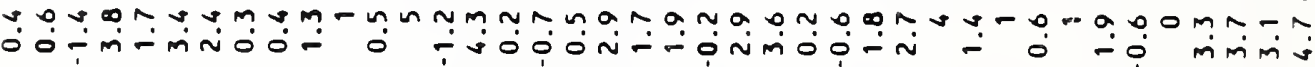

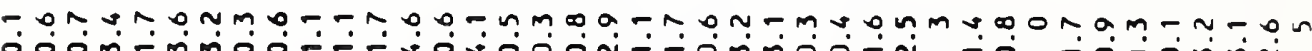

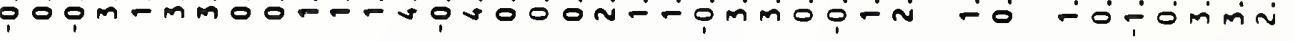

on

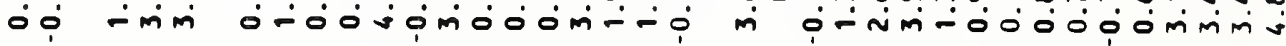
- OOMNMNO-N--MOMO-OMNNONM-ONNMNO- - OONMMM

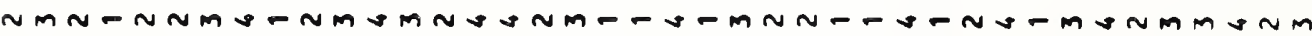

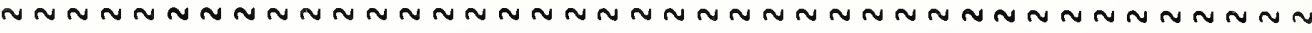

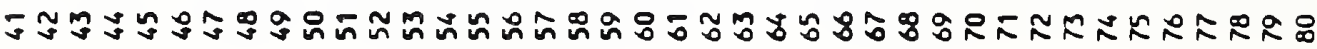

$\stackrel{\infty}{\circ}$

ㄴ. 8 ำ

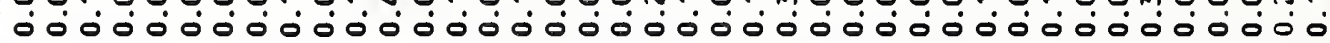

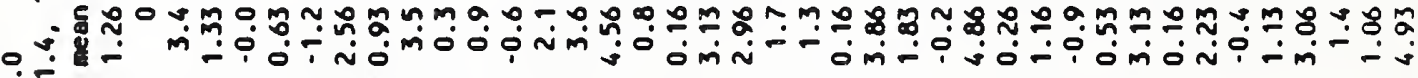

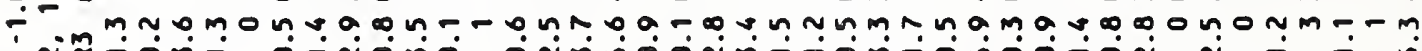

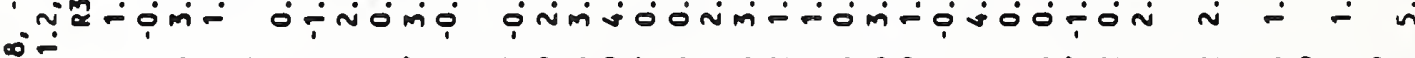

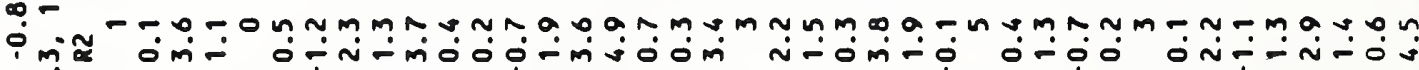

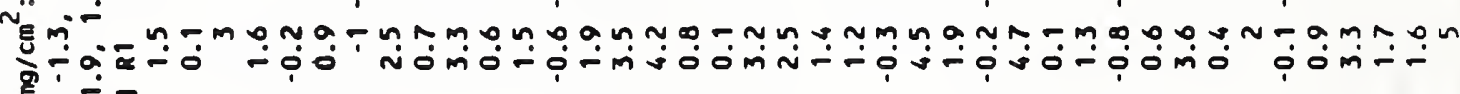
E .

象早

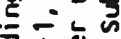

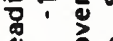

:

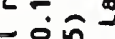

㕝: 380 


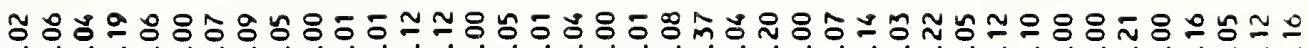

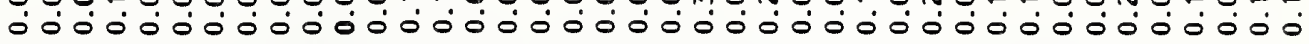

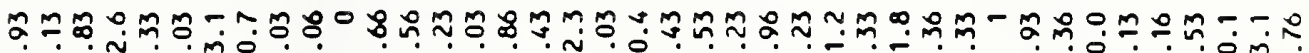
-

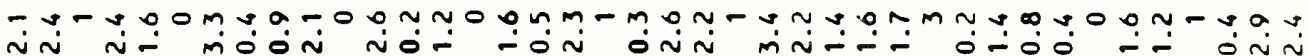

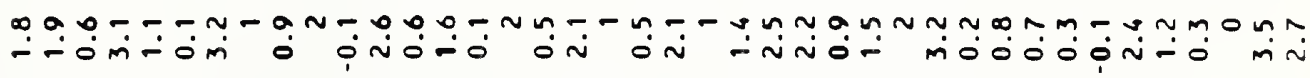

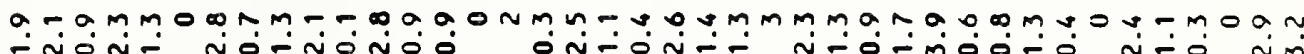

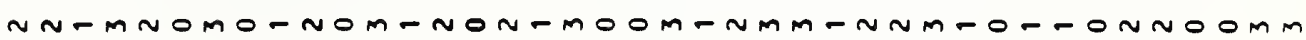

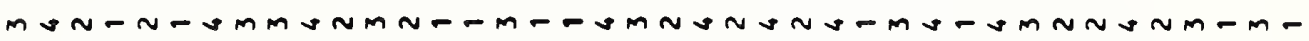

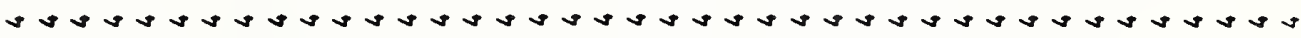

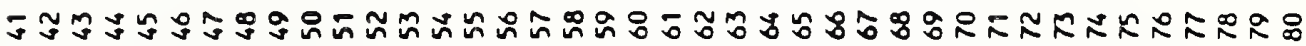

$\because$

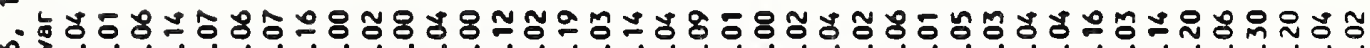

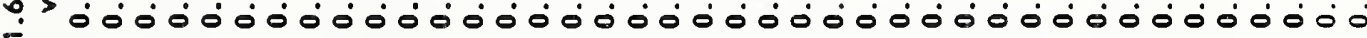
- Сัง

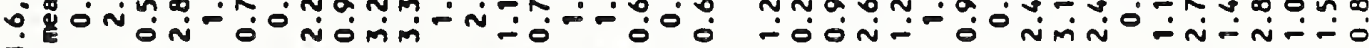
ๆ ๆ

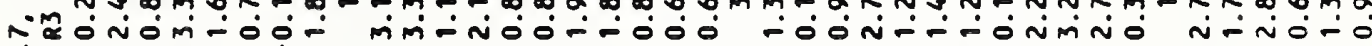

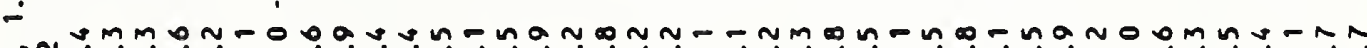

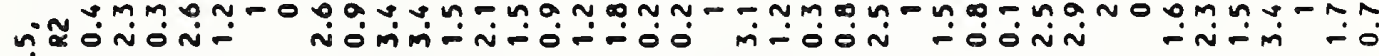
$\sim_{E}$ -

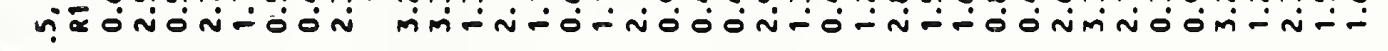

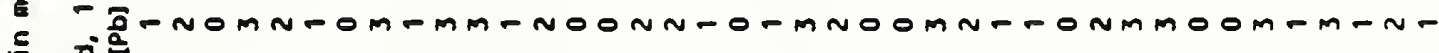
E. $\leq \dot{8}$ 


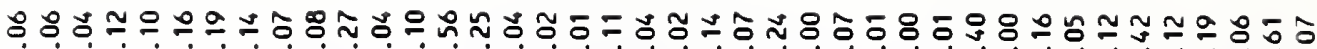

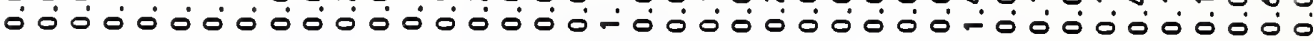

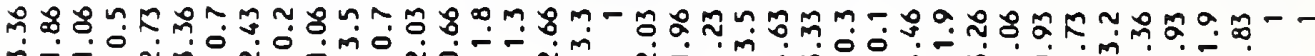
mंo m--0

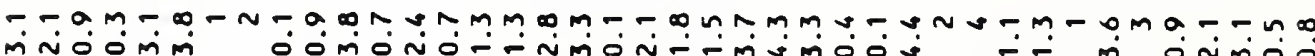

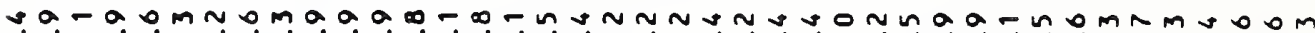

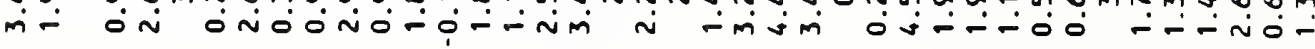

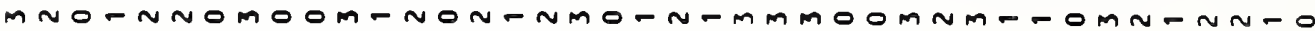

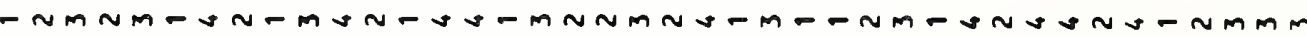

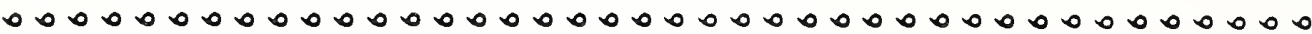

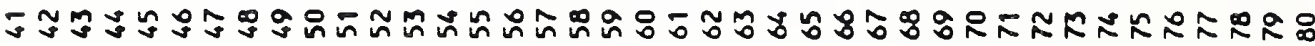

$\infty$

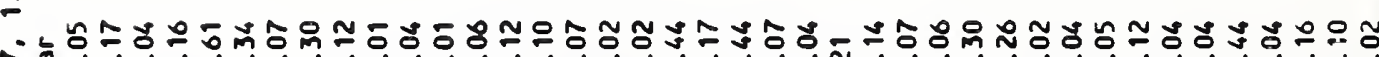

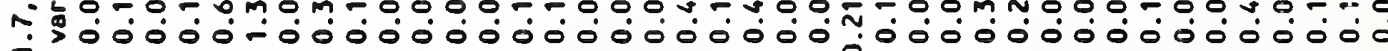

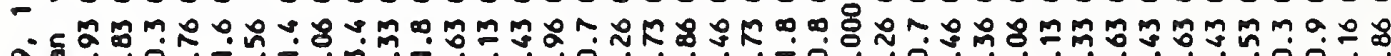
o̊

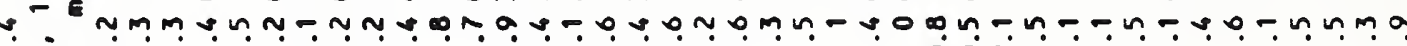

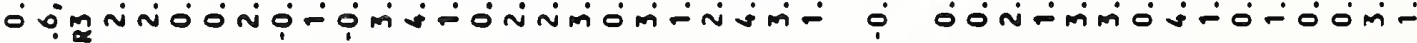
$\because \infty$ -

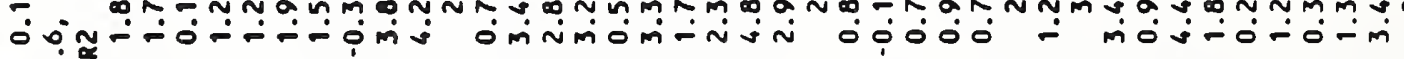
En

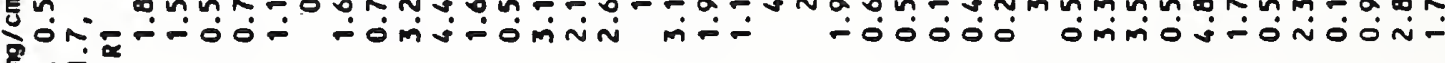
E-T-NOONO-OMMN-MNM-M-NMMNOOO-ON-MN-MNO-O-M$\therefore \dot{8}: \frac{a}{2}$

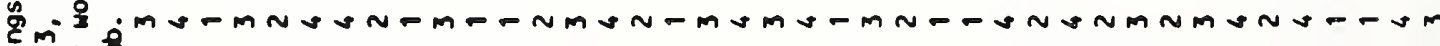

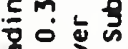

in 000000000000000000000000000000000000000000 - 0 กิด

马ㄷー $\frac{8}{8} 80$ 
Table A4. Raw data from laboratory experiments conducted with version 1 of Manufacturer C's instrument

\begin{tabular}{|c|c|c|c|c|c|c|c|c|}
\hline $\cos ^{1}$ & Oper & Substrate & {$[P b]$} & Paint & Thick & R1 & $R 2$ & R3 \\
\hline 1 & 1 & 3 & 2 & 2 & 1 & 2.48 & 2.76 & 2.4 \\
\hline 2 & 1 & 2 & 0 & 1 & 1 & 0 & 0 & 0 \\
\hline 3 & 1 & 4 & 0 & 2 & 2 & 0 & 0 & 0.51 \\
\hline 6 & 1 & 4 & 4 & 2 & 1 & 2.99 & 3.29 & 3.12 \\
\hline 5 & 1 & 1 & 3 & 2 & 1 & 2.26 & 1.7 & 1.77 \\
\hline 6 & 1 & 1 & 3 & 2 & 2 & 2.36 & 1.95 & 2.01 \\
\hline 7 & 1 & 4 & 1 & 2 & 2 & 0.77 & 1.16 & 0 \\
\hline 8 & 1 & 2 & 0 & 1 & 2 & 0.08 & 0 & 0 \\
\hline 9 & 1 & 3 & 0 & 2 & 1 & 0 & 0 & 0.28 \\
\hline 10 & 1 & 2 & 3 & 2 & 1 & 2.58 & 3 & 2.71 \\
\hline 11 & 1 & 4 & 0 & 2 & 1 & 1 & 0.22 & 0.24 \\
\hline 12 & 1 & 1 & 4 & 2 & 1 & 2.86 & 3.1 & 3.1 \\
\hline 13 & 1 & 2 & 3 & 1 & 1 & 2.54 & 2.21 & 2.32 \\
\hline 16 & 1 & 1 & 1 & 1 & 2 & 0.75 & 0.73 & 0.89 \\
\hline 15 & 1 & 4 & 0 & 1 & 2 & 0.14 & 0.62 & 0.51 \\
\hline 16 & 1 & 1 & 1 & 2 & 2 & 0.59 & 0.67 & 0.36 \\
\hline 17 & 9 & 2 & 3 & 2 & 2 & $=1.96$ & 2.59 & 2.67 \\
\hline 18 & 1 & 3 & 1 & 2 & 1 & 1.05 & 1.02 & 0.56 \\
\hline 19 & 1 & 2 & 2 & 1 & 1 & 1.81 & 1.85 & 1.68 \\
\hline 20 & 1 & 3 & 1 & 1 & 1 & 0.67 & 0.79 & 1.19 \\
\hline 21 & 1 & 3 & 4 & 2 & 1 & 3.86 & 3.84 & 3.68 \\
\hline 22 & 1 & 4 & 2 & 1 & 2 & 1.42 & 1.71 & 1.7 \\
\hline 23 & 1 & 3 & 1 & 1 & 2 & 0.73 & 1.03 & 0.52 \\
\hline 24 & 1 & 1 & 0 & 1 & 2 & 0 & 0 & 0.1 \\
\hline 25 & 1 & 4 & 4 & 1 & 2 & 2.26 & 2.95 & 2.91 \\
\hline 26 & 1 & 3 & 4 & 2 & 2 & 3.6 & $3 . \pi 5$ & 3.76 \\
\hline 27 & 1 & 3 & 0 & 1 & 2 & 0 & 0 & 0 \\
\hline 28 & 1 & 2 & 4 & 2 & 2 & 3.02 & 3.28 & 3 \\
\hline 29 & 1 & 3 & 2 & 2 & 2 & 2.64 & 1.81 & 1.87 \\
\hline 30 & 1 & 4 & 3 & 1 & 1 & 2.68 & 1.16 & 2.29 \\
\hline 31 & 1 & 1 & 0 & 2 & 2 & 0.19 & 0 & 0 \\
\hline 32 & 1 & 1 & 6 & 1 & 1 & 3 & 3.06 & 3.16 \\
\hline 33 & 1 & 2 & 0 & 2 & 1 & 0.03 & 0.21 & 0 \\
\hline 34 & 1 & 1 & 1 & 1 & 1 & 0.67 & 0.44 & 0.83 \\
\hline 35 & 1 & 1 & 1 & 2 & 1 & 0.4 & 0.71 & 0.45 \\
\hline 36 & 1 & 3 & 0 & 1 & 1 & 0 & 0 & 0 \\
\hline 37 & 1 & 1 & 2 & 1 & 1 & 1.49 & 1.62 & 1.73 \\
\hline 38 & 1 & 1 & 0 & 2 & 1 & 0.23 & 0 & 0 \\
\hline 39 & 1 & 2 & 0 & 2 & 2 & 0 & 0 & 0.01 \\
\hline 40 & 1 & 2 & 2 & 2 & 1 & 1.64 & 2 & 1.53 \\
\hline 41 & 1 & $?$ & 2 & 2 & 2 & 1.62 & 1.51 & 1.67 \\
\hline 42 & 1 & 1 & 2 & 1 & 2 & 1.37 & 1.45 & 1.98 \\
\hline 43 & 1 & 1 & 3 & 1 & 1 & 2.42 & 2.16 & 2.48 \\
\hline 44 & 1 & 2 & 3 & 1 & 2 & 2.59 & 2.26 & 2.2 \\
\hline 45 & 1 & 3 & 1 & 2 & 2 & 1.05 & 0.29 & 0.61 \\
\hline 46 & 1 & 3 & 0 & 2 & 2 & 0 & 0 & 0 \\
\hline 47 & 1 & 3 & 3 & 1 & 2 & 2.3 & 3.25 & 2.78 \\
\hline 68 & 1 & 1 & 4 & 2 & 2 & 3.08 & 2.85 & 3.01 \\
\hline 49 & 1 & 4 & 2 & 2 & 1 & 1.61 & 1.48 & 1.47 \\
\hline 50 & 1 & 4 & 1 & 1 & 2 & 0.86 & 1.65 & 0.66 \\
\hline 51 & 1 & 3 & 3 & 2 & 1 & 3.3 & 2.61 & 3.22 \\
\hline 52 & 1 & 1 & 4 & 1 & 2 & 2.65 & 3.16 & 2.99 \\
\hline 53 & 1 & 2 & 1 & 2 & 1 & 0.6 & 0.84 & 0.86 \\
\hline 54 & 1 & 4 & 3 & 2 & 2 & 1.88 & 1.56 & 2.21 \\
\hline 55 & 1 & 2 & 4 & 1 & 2 & 3.46 & 3.4 & 3.48 \\
\hline 56 & 1 & 1 & 3 & 1 & 2 & 2.19 & 2.33 & 2.16 \\
\hline 57 & 1 & 4 & 2 & 1 & 1 & 1.38 & 1.57 & 1.85 \\
\hline 58 & 1 & 4 & 4 & 2 & 2 & 2.33 & 3.06 & 3.12 \\
\hline 59 & 1 & 2 & 1 & 1 & 1 & 0.82 & 0.47 & 0.73 \\
\hline 60 & 1 & 4 & 4 & 1 & 1 & 3.11 & 3.09 & 2.85 \\
\hline
\end{tabular}




\begin{tabular}{|c|c|c|c|c|c|c|c|c|}
\hline 61 & 1 & 2 & 1 & 2 & 2 & 0.59 & 1.03 & 0.65 \\
\hline 62 & 1 & 1 & 2 & 2 & 1 & 1.97 & 1.79 & 1.64 \\
\hline 63 & 1 & 6 & 3 & 1 & 2 & 2.17 & 2.52 & 2.62 \\
\hline 64 & 1 & 3 & 2 & 1 & 2 & 2.23 & 2.24 & 2.24 \\
\hline 65 & 1 & 3 & 4 & 1 & 2 & 3.61 & 3.56 & 3.6 \\
\hline$\infty 6$ & 1 & 2 & 2 & 1 & 2 & 2.01 & 1.57 & 1.98 \\
\hline 67 & 1 & 3 & 3 & 1 & 1 & 2.97 & 2.97 & 2.59 \\
\hline 68 & 1 & 4 & 1 & 1 & 1 & 1.15 & 1.39 & 0.84 \\
\hline 69 & 1 & 2 & 4 & 2 & 1 & 3 & 3.37 & 3.4 \\
\hline 70 & 1 & 3 & 2 & 1 & 1 & 2.2 & 2.31 & 2.75 \\
\hline 79 & 1 & 4 & 1 & 2 & 1 & 1.63 & 1.32 & 0.89 \\
\hline 72 & 9 & 4 & 3 & 2 & 1 & 2.24 & 2.28 & 2.05 \\
\hline 73 & 1 & 2 & 1 & 1 & 2 & 0.77 & 0.84 & 0.92 \\
\hline 74 & 1 & 3 & 3 & 2 & 2 & 2.92 & 2.7 & 2.38 \\
\hline 75 & 1 & 4 & 2 & 2 & 2 & 1.71 & 1.46 & 1.64 \\
\hline 76 & 1 & 1 & 0 & 1 & 1 & 0 & 0 & 0 \\
\hline$\pi 7$ & 1 & 2 & 6 & 1 & 1 & 3.67 & 3.24 & 3.34 \\
\hline 78 & 1 & 2 & 2 & 2 & 2 & 1.94 & 1.86 & 1.59 \\
\hline 79 & 1 & 3 & 4 & 1 & 1 & 3.71 & 3.74 & 4.07 \\
\hline 80 & 1 & 4 & 0 & 1 & 1 & 0.52 & 0.59 & 0 \\
\hline 81 & 1 & 1 & 3 & 2 & 1 & 2.03 & 1.77 & 1.9 \\
\hline 82 & 1 & 3 & 2 & 2 & 2 & 2.06 & 2.48 & 2.35 \\
\hline 83 & 1 & 1 & 2 & 2 & 2 & 1.74 & 9.65 & 1.76 \\
\hline 84 & 1 & 4 & 1 & 1 & 2 & 0.67 & 0.92 & 0.89 \\
\hline 85 & 1 & 3 & 3 & 2 & 1 & 2.6 & 2.99 & 3.18 \\
\hline 86 & 1 & 2 & 3 & 1 & 1 & 2.04 & 2.3 & 2.35 \\
\hline 87 & 1 & 1 & 0 & 1 & 1 & 0.49 & 0.04 & 0 \\
\hline 88 & 1 & 3 & 3 & 2 & 2 & 3.27 & 2.85 & 3.04 \\
\hline 89 & 1 & 1 & 4 & 2 & 1 & 2.65 & 3.36 & 3.16 \\
\hline 90 & 1 & 2 & 4 & 1 & 2 & 3.45 & 3.52 & 3.01 \\
\hline 91 & 1 & 1 & 1 & 1 & 2 & 0.67 & 0.48 & 0.65 \\
\hline 92 & 1 & 3 & 1 & 1 & 1 & 0.66 & 0.92 & 1.09 \\
\hline 93 & 1 & 6 & 0 & 2 & 1 & 0.38 & 0.08 & 0.49 \\
\hline 94 & 1 & 2 & 1 & 1 & 1 & 1.11 & 0.75 & 0.57 \\
\hline 95 & 1 & 3 & 2 & 2 & 1 & 2.61 & 2.36 & 2.6 \\
\hline 96 & 1 & 2 & 2 & 1 & 2 & 1.85 & 1.9 & 1.79 \\
\hline 97 & 1 & 3 & 2 & 1 & 2 & 2.35 & 2.04 & 2.06 \\
\hline 98 & 1 & 3 & 3 & 1 & 1 & 3.12 & 2.94 & 2.37 \\
\hline 99 & 1 & 3 & 0 & 1 & 2 & 0 & 0 & 0 \\
\hline 100 & 1 & 2 & 2 & 2 & 1 & 9.5 & 1.55 & 1.92 \\
\hline 101 & 1 & 4 & 3 & 2 & 1 & 2.06 & 2.06 & 2.42 \\
\hline 102 & 1 & 1 & 0 & 1 & 2 & 0.06 & 0.13 & 0.12 \\
\hline 103 & 1 & 3 & 1 & 2 & 1 & 0.47 & 0.54 & 0.73 \\
\hline 104 & 1 & 2 & 9 & 2 & 9 & 0.65 & 0.78 & 0.64 \\
\hline 105 & 1 & 1 & 4 & 1 & 2 & 3.26 & 3.06 & 2.82 \\
\hline 106 & 1 & 2 & 1 & 2 & 2 & 0.61 & 0.88 & 0.73 \\
\hline 107 & 1 & 2 & 4 & 1 & 1 & 3.56 & 3.18 & 3.71 \\
\hline 108 & 1 & 1 & 3 & 2 & 2 & 2.23 & 1.76 & 2.37 \\
\hline 109 & 1 & 1 & 1 & 1 & 1 & 0.28 & 0.6 & 0.79 \\
\hline 110 & 1 & 3 & 4 & 2 & 2 & 3.62 & 3.84 & 3.75 \\
\hline 111 & 1 & 4 & 3 & 2 & 2 & 1.86 & 1.89 & 1.91 \\
\hline 112 & 1 & 3 & 2 & 1 & 1 & 2.66 & 2.54 & 2.78 \\
\hline 113 & 1 & 1 & 3 & 1 & 1 & 2.1 & 1.94 & 2.12 \\
\hline 194 & 1 & 3 & 0 & 2 & 1 & 0.24 & 0 & 0 \\
\hline 115 & 9 & 4 & 2 & 1 & 2 & 2.3 & 1.62 & 1.85 \\
\hline 116 & 1 & 4 & 4 & 1 & 2 & 3.01 & 2.51 & 3.09 \\
\hline 197 & 1 & 2 & 2 & 2 & 2 & 2 & 1.56 & 2.15 \\
\hline 118 & 1 & 2 & 3 & 1 & 2 & 2.28 & 2.33 & 2.51 \\
\hline 119 & 1 & 3 & 0 & 2 & 2 & 0.18 & 0 & 0.27 \\
\hline 120 & 1 & 2 & 3 & 2 & 2 & 2.69 & $2 . \pi 7$ & 2.14 \\
\hline 121 & 1 & 4 & 0 & 9 & 1 & 0.65 & 0 & 0.26 \\
\hline 122 & 1 & 2 & 0 & 1 & 2 & 0 & 0.29 & 0 \\
\hline 123 & 1 & 3 & 4 & 1 & 2 & 3.54 & 3.56 & 3.81 \\
\hline 124 & 1 & 2 & 4 & 2 & 2 & 3.7 & 3.03 & 3.42 \\
\hline 125 & 1 & 4 & 0 & 1 & 2 & 0.92 & 0.32 & 0.26 \\
\hline
\end{tabular}




$\begin{array}{llllllrrr}126 & 1 & 4 & 2 & 2 & 2 & 1.71 & 2.74 & 1.81 \\ 127 & 1 & 2 & 4 & 2 & 1 & 3.5 & 3.05 & 3.72 \\ 128 & 1 & 1 & 2 & 1 & 1 & 2.38 & 1.72 & 1.92 \\ 129 & 1 & 3 & 4 & 1 & 1 & 4.24 & 3.57 & 3.98 \\ 130 & 1 & 1 & 2 & 2 & 1 & 1.71 & 1.42 & 1.48 \\ 131 & 1 & 3 & 0 & 1 & 1 & 0 & 0 & 0 \\ 132 & 1 & 1 & 2 & 1 & 2 & 1.59 & 1.6 & 1.45 \\ 133 & 1 & 4 & 4 & 2 & 1 & 2.77 & 3.05 & 3 \\ 134 & 1 & 1 & 0 & 2 & 2 & 0 & 0 & 0.43 \\ 135 & 1 & 1 & 4 & 1 & 1 & 2.86 & 2.95 & 3.01 \\ 136 & 1 & 3 & 1 & 2 & 2 & 0.45 & 0.82 & 0.28 \\ 137 & 1 & 3 & 3 & 1 & 2 & 2.88 & 2.61 & 2.81 \\ 138 & 1 & 3 & 4 & 2 & 1 & 3.93 & 3.83 & 3.63 \\ 139 & 1 & 2 & 0 & 1 & 1 & 0 & 0.06 & 0 \\ 140 & 1 & 1 & 1 & 2 & 2 & 0.48 & 0.25 & 0.87 \\ 141 & 1 & 2 & 3 & 2 & 1 & 2.37 & 2.43 & 2.38 \\ 142 & 1 & 1 & 3 & 1 & 2 & 2.08 & 2.44 & 2.56 \\ 143 & 1 & 4 & 0 & 2 & 2 & 0.07 & 0.45 & 0.14 \\ 144 & 1 & 2 & 1 & 1 & 2 & 0.28 & 0.57 & 0.51 \\ 145 & 1 & 4 & 1 & 1 & 1 & 0.2 & 0.57 & 0.72 \\ 146 & 1 & 4 & 2 & 1 & 1 & 1.32 & 2.59 & 1.89 \\ 147 & 1 & 2 & 0 & 2 & 2 & 0.04 & 0 & 0.17 \\ 148 & 1 & 4 & 1 & 2 & 2 & 0.87 & 0.92 & 0.82 \\ 149 & 1 & 4 & 3 & 1 & 1 & 2.3 & 2.2 & 2.21 \\ 150 & 1 & 1 & 4 & 2 & 2 & 1.93 & 3.06 & 3.02 \\ 151 & 1 & 4 & 3 & 1 & 2 & 2.16 & 2.14 & 3.04 \\ 152 & 1 & 2 & 2 & 1 & 1 & 1.83 & 1.58 & 1.82 \\ 153 & 1 & 4 & 1 & 2 & 1 & 1.06 & 1.18 & 0.8 \\ 154 & 1 & 3 & 1 & 1 & 2 & 0.51 & 1.23 & 0.34 \\ 155 & 1 & 4 & 2 & 2 & 1 & 1.06 & 2.38 & 1.64 \\ 156 & 1 & 1 & 0 & 2 & 1 & 0 & 0 & 0 \\ 157 & 1 & 4 & 4 & 1 & 1 & 2.52 & 2.69 & 3.3 \\ 158 & 1 & 2 & 0 & 2 & 1 & 0 & 0 & 0.23 \\ 159 & 1 & 1 & 1 & 2 & 1 & 0.52 & 0.64 & 0.37 \\ 160 & 1 & 4 & 4 & 2 & 2 & 2.49 & 2.9 & 3.02\end{array}$

${ }^{1}$ Colum headings are as follows: obs - observation number; oper - operator number; [Pb] - lead concentration of paint film; paint - type of point film used in overlay, 1 = titatium containing, 2 = barium containing; thick - thickness of paint film in overtay, $1=0.05 \mathrm{~mm}, 2=0.5 \mathrm{~mm}$; and $R 1, R 2, R 3$ - replicate readings. 
Table A5. Field data taken with XRF-AO analyzer

\begin{tabular}{|c|c|c|c|c|c|c|c|c|c|c|c|c|c|c|c|}
\hline House & Room & surf. & sub. & inst. & - Bare & E RI & $R 2$ & R3 & Avg & sed. & Var. & $X R F=A A$ & Avg-Sub. & $\begin{array}{c}\text { XRF-SUL } \\
-A A\end{array}$ & b. \\
\hline$D \cdot B A$ & EX & ST & c & $A$ & 1.5 & 1.6 & 1.9 & 1.5 & 1.7 & 0.2 & 0.0 & 1.3 & 0.2 & .0 .2 & 0.36 \\
\hline$C .0 C$ & EX & $w 2$ & $C M$ & $A$ & 1.6 & 2.6 & 2.1 & 2.3 & 2.3 & 0.3 & 0.1 & 1.1 & 0.7 & .0 .5 & 1.25 \\
\hline $0.0 C$ & $B S$ & $w_{2}$ & D & A & 0.1 & -1.1 & -1.1 & -1.0 & -1.1 & 0.1 & 0.0 & $\cdot 1.1$ & -1.2 & $\cdot 1.2$ & 0.05 \\
\hline $0.0 C$ & $L R$ & w3 & 0 & $A$ & 0.1 & -1.0 & .0 .2 & -0.7 & -0.6 & 0.6 & 0.2 & -0.7 & -0.7 & .0 .8 & 0.10 \\
\hline $0.0 C$ & $B R$ & $w 2$ & 0 & $A$ & 0.1 & 1.1 & 1.3 & 0.4 & 0.9 & 0.5 & 0.2 & -0.2 & 0.8 & .0 .3 & 1.15 \\
\hline$A-D C$ & LR & W2 & 0 & $A$ & -0.6 & .0 .6 & -0.8 & -0.7 & $\cdot 0.7$ & 0.1 & 0.0 & -0.8 & .0 .1 & $\cdot 0.2$ & 0.09 \\
\hline $0.0 C$ & $B 2$ & H2 & D & $A$ & 0.1 & 0.2 & -0.2 & 0.0 & 0.0 & 0.2 & 0.0 & .0 .1 & .0 .1 & .0 .2 & 0.06 \\
\hline $0.0 C$ & LR & W1 & 0 & $A$ & 0.1 & 0.2 & -0.2 & 0.0 & 0.0 & 0.2 & 0.0 & .0 .1 & .0 .1 & .0 .2 & 0.05 \\
\hline $0.0 C$ & SW & $W 6$ & 0 & $A$ & 0.1 & 0.0 & 0.1 & 0.3 & 0.1 & 0.2 & 0.0 & 0.1 & 0.0 & 0.0 & 0.05 \\
\hline$C \cdot D C$ & LR & W3 & 0 & $A$ & .0 .7 & -0.7 & $\cdot 0.5$ & .0 .1 & -0.4 & 0.3 & 0.1 & .0 .5 & 0.3 & 0.2 & 0.09 \\
\hline$A=D C$ & HL & $W 2$ & 0 & $A$ & -0.6 & 0.0 & 0.1 & 0.5 & 0.2 & 0.3 & 0.1 & 0.1 & 0.8 & 0.7 & 0.10 \\
\hline$A=D C$ & LR & $w 3$ & 0 & A & -0.6 & 0.1 & 0.5 & 0.2 & 0.3 & 0.2 & 0.0 & 0.2 & 0.9 & 0.8 & 0.03 \\
\hline$D \cdot B A$ & LR & RC & $M$ & $A$ & .0 .6 & -1.0 & $\cdot 0.7$ & $\cdot 0.8$ & .0 .8 & 0.2 & 0.0 & -0.9 & $\cdot 0.2$ & -0.3 & 0.09 \\
\hline$C \cdot B A$ & OR & $R C$ & $M$ & $A$ & -0.8 & -1.4 & .0 .6 & -0.7 & .0 .9 & 0.4 & 0.2 & -0.9 & .0 .1 & .0 .1 & 0.03 \\
\hline$C \cdot B A$ & B3 & RC & $M$ & A & .0 .8 & $\cdot 0.7$ & -1.1 & .0 .7 & .0 .8 & 0.2 & 0.1 & .0 .9 & 0.0 & .0 .1 & 0.05 \\
\hline$B \cdot B A$ & HL & Wh & $P$ & $A$ & 0.0 & 0.0 & -0.3 & -0.3 & -0.2 & 0.2 & 0.0 & -0.2 & -0.2 & -0.2 & 0.01 \\
\hline$B \cdot B A$ & SH & H2 & $P$ & $A$ & 0.0 & 0.3 & 0.5 & .0 .1 & 0.0 & 0.4 & 0.2 & 0.0 & 0.0 & 0.0 & 0.02 \\
\hline $0.0 C$ & LR & WM & $P$ & A & & 0.9 & 0.0 & 0.2 & 0.4 & 0.5 & 0.2 & 0.3 & 0.4 & 0.3 & 0.04 \\
\hline$C \cdot B A$ & B3 & 144 & $P$ & A & 0.2 & 0.3 & 0.7 & 0.9 & 0.6 & 0.3 & 0.1 & 0.6 & 0.4 & 0.4 & 0.04 \\
\hline $0 . B A$ & BI & 43 & $P$ & $A$ & -0.4 & .0 .1 & 0.3 & -0.1 & 0.0 & 0.2 & 0.1 & 0.0 & 0.6 & 0.4 & 0.05 \\
\hline$D \cdot B A$ & $B 2$ & $W 2$ & $P$ & A & -0.4 & 0.0 & 0.6 & 0.3 & 0.3 & 0.3 & 0.1 & 0.2 & 0.7 & 0.6 & 0.06 \\
\hline$A \cdot B A$ & B1 & H1 & $P$ & A & .0 .1 & 0.4 & 0.9 & 1.2 & 0.8 & 0.4 & 0.2 & 0.7 & 0.9 & 0.8 & 0.11 \\
\hline$C \cdot B A$ & BA & 12 & $P$ & $A$ & 0.2 & 1.2 & 0.9 & 1.1 & 1.1 & 0.2 & 0.0 & 0.9 & 0.9 & 0.7 & 0.12 \\
\hline$A \cdot B A$ & 82 & HI & $P$ & A & .0 .1 & .0 .1 & -0.3 & 0.2 & -0.1 & 0.3 & 0.1 & .0 .2 & 0.0 & .0 .1 & 0.13 \\
\hline$C \cdot B A$ & $B A$ & $H_{4}$ & $P$ & A & 0.2 & 1.1 & 1.4 & 1.4 & 1.3 & 0.2 & 0.0 & 1.2 & 1.1 & 1.0 & 0.13 \\
\hline$C \cdot B A$ & $B A$ & H1 & $P$ & $A$ & 0.2 & 0.4 & 0.4 & 0.5 & 0.4 & 0.1 & 0.0 & 0.3 & 0.2 & 0.1 & 0.14 \\
\hline$C \cdot B A$ & OR & $C 2$ & $P$ & A & 0.2 & 0.1 & 0.5 & 0.3 & 0.3 & 0.2 & 0.0 & 0.2 & 0.1 & 0.0 & 0.15 \\
\hline$C \cdot B A$ & OR & H2 & $P$ & A & 0.2 & 1.3 & 0.7 & 0.6 & 0.9 & 0.4 & 0.1 & 0.7 & 0.7 & 0.5 & 0.15 \\
\hline$A-B A$ & DR & H2 & P & A & .0 .1 & 1.0 & 1.4 & 0.0 & 0.8 & 0.7 & 0.5 & 0.6 & 0.9 & 0.7 & 0.16 \\
\hline$C-B A$ & HL & 41 & $P$ & A & 0.2 & 0.3 & 0.2 & 0.7 & 0.4 & 0.3 & 0.1 & 0.2 & 0.2 & 0.0 & 0.19 \\
\hline$A \cdot B A$ & 83 & 14 & $P$ & A & -0.1 & 0.6 & 1.3 & 0.9 & 0.9 & 0.4 & 0.1 & 0.1 & 1.0 & 0.2 & 0.81 \\
\hline$B-B A$ & $K T$ & $W_{4}$ & P & A & 0.0 & 4.8 & 3.9 & 4.3 & 4.3 & 0.5 & 0.2 & 2.6 & 4.3 & 2.6 & 1.70 \\
\hline$A \cdot B A$ & $B A$ & $W 2$ & P & A & .0 .1 & 6.1 & 6.0 & 6.0 & 6.0 & 0.1 & 0.0 & 2.6 & 6.1 & 2.7 & 3.41 \\
\hline$E \cdot B A$ & B1 & WS & $H$ & A & 2.8 & 0.9 & 1.2 & 1.5 & 1.2 & 0.3 & 0.1 & 1.0 & -1.6 & -1.8 & 0.25 \\
\hline 6.06 & OR & $W$ & $y$ & A & 1.6 & 0.2 & 0.1 & 0.5 & 0.3 & 0.2 & 0.0 & 0.0 & -1.3 & -1.6 & 0.24 \\
\hline$E \cdot B A$ & LR & $M$ & $H$ & A & 2.8 & 2.9 & 2.5 & 2.9 & 2.8 & 0.2 & 0.1 & 1.4 & 0.0 & -1.4 & 1.37 \\
\hline$C \cdot O C$ & DR & OM & $u$ & A & 1.6 & 0.8 & 0.9 & 0.5 & 0.7 & 0.2 & 0.0 & 0.3 & .0 .9 & -1.3 & 0.39 \\
\hline$B \cdot O C$ & HL & $B M$ & $u$ & A & 0.2 & -0.5 & -0.8 & .1 .1 & -0.8 & 0.3 & 0.1 & .0 .9 & -1.0 & -1.1 & 0.07 \\
\hline$A-B A$ & DR & $B M$ & $y$ & A & 1.9 & 1.1 & 1.5 & 1.8 & 1.5 & 0.6 & 0.1 & 1.1 & $=0.6$ & -0.8 & 0.49 \\
\hline$B \cdot O C$ & OR & OM & $u$ & A & 0.5 & -0.1 & 0.1 & 0.1 & 0.0 & 0.1 & 0.0 & -0.1 & -0.5 & -0.6 & 0.12 \\
\hline$B \cdot B A$ & LR & BM & 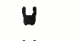 & $A$ & 0.0 & -0.6 & 0.0 & -0.3 & -0.3 & 0.3 & 0.1 & -0.3 & -0.3 & -0.3 & 0.02 \\
\hline$D \cdot B A$ & $K T$ & $M$ & $H$ & A & 1.6 & 1.4 & 1.2 & 1.6 & 1.4 & 0.2 & 0.0 & 1.3 & .0 .2 & -0.3 & 0.11 \\
\hline$A-B A$ & LR & 10 & $H$ & A & 1.9 & 1.5 & 2.5 & 1.7 & 1.9 & 0.5 & 0.3 & 1.7 & 0.0 & -0.2 & 0.18 \\
\hline $0.0 C$ & DR & OM & $H$ & A & 0.1 & 1.4 & 1.4 & 1.3 & 1.4 & 0.1 & 0.0 & 0.3 & 1.3 & 0.2 & 1.06 \\
\hline$D .0 C$ & 82 & US & $H$ & A & 0.1 & 2.3 & 2.0 & 2.0 & 2.1 & 0.2 & 0.0 & 0.7 & 2.0 & 0.6 & 1.36 \\
\hline $0.0 C$ & LR & $B M$ & 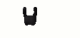 & A & 0.1 & 2.6 & 1.9 & 2.2 & 2.2 & 0.4 & 0.1 & 1.1 & 2.1 & 1.0 & 1.17 \\
\hline$B \cdot B A$ & SH & $M D$ & $H$ & A & 0.0 & 1.7 & 1.4 & 1.1 & 1.6 & 0.3 & 0.1 & 1.0 & 1.6 & 1.0 & 0.60 \\
\hline $0.0 C$ & LR & US & $u$ & A & 0.1 & 2.3 & 2.6 & 2.5 & 2.5 & 0.2 & 0.0 & 1.3 & 2.4 & 1.2 & 1.21 \\
\hline$B \cdot D C$ & B2 & BH & $H$ & A & 0.2 & 2.5 & 2.8 & 3.2 & 2.8 & 0.4 & 0.1 & 2.7 & 2.6 & 2.5 & 0.15 \\
\hline$A \cdot D C$ & EX & $O M$ & $H$ & A & 0.1 & 4.3 & 4.1 & 3.9 & 6.1 & 0.2 & 0.0 & 2.7 & 4.0 & 2.6 & 1.37 \\
\hline$B \cdot O C$ & B1 & BM & 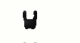 & A & 0.2 & 6.5 & 7.0 & 6.4 & 6.6 & 0.3 & 0.1 & 6.6 & 6.6 & 6.4 & 0.03 \\
\hline$A \cdot B A$ & LR & OM & $H$ & A & 1.9 & 10.6 & 10.3 & 10.3 & 10.4 & 0.2 & 0.0 & 8.5 & 8.5 & 6.6 & 1.95 \\
\hline$B \cdot O C$ & OR & $B M$ & $H$ & A & 0.2 & 7.8 & 7.7 & 7.9 & 7.8 & 0.1 & 0.0 & 7.8 & 7.6 & 7.6 & 0.03 \\
\hline$B \cdot B A$ & LR & WS & $H$ & A & 0.0 & 10.8 & 10.7 & 10.7 & 10.7 & 0.1 & 0.0 & 7.3 & 10.7 & 7.3 & 3.43 \\
\hline$E \cdot B A$ & B1 & UT & $H$ & A & 2.8 & 4.1 & 4.0 & 4.3 & 4.1 & 0.2 & 0.0 & 0.3 & 1.3 & -2.5 & 3.84 \\
\hline $0 . B A$ & OR & No & $H$ & A & 1.6 & 5.7 & 6.3 & 6.0 & 6.0 & 0.3 & 0.1 & 1.8 & 4.4 & 0.2 & 4.21 \\
\hline
\end{tabular}




\begin{tabular}{|c|c|c|c|c|c|c|c|c|c|c|c|c|c|c|c|}
\hline$C . O C$ & EX & $O M$ & $\forall$ & A & 1.6 & 21.7 & 22.1 & 20.3 & 21.4 & 0.9 & 0.9 & 7.3 & 19.8 & 5.7 & 16.10 \\
\hline$C \cdot B A$ & OR & $O M$ & $\forall$ & $A$ & 1.6 & 16.7 & 16.9 & 16.9 & 16.8 & 0.1 & 0.0 & 1.7 & 15.2 & 0.1 & 15.13 \\
\hline$E \cdot B A$ & LR & M & 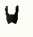 & A & 2.8 & 50.6 & 50.6 & 50.4 & 50.5 & 0.1 & 0.0 & 32.1 & 47.7 & 29.3 & 18.41 \\
\hline$A \cdot O C$ & $H L$ & OR & $H$ & A & 0.1 & 1.2 & 1.1 & 1.0 & 1.1 & 0.1 & 0.0 & -0.2 & 1.0 & -0.3 & 1.30 \\
\hline$A \cdot B A$ & $P R$ & $F$ & $H$ & A & .0 .2 & -0.8 & -0.1 & -0.3 & -0.6 & 0.6 & 0.1 & -0.6 & .0 .2 & -0.2 & 0.01 \\
\hline$A \cdot O C$ & $B A$ & OR & $H$ & A & 0.1 & 0.7 & 1.2 & 0.9 & 0.9 & 0.3 & 0.1 & 0.0 & 0.8 & .0 .1 & 0.95 \\
\hline$D \cdot B A$ & DR & SH & H & $A$ & 0.3 & 0.5 & 0.6 & 0.1 & 0.6 & 0.3 & 0.1 & 0.2 & 0.1 & -0.1 & 0.22 \\
\hline$D \cdot B A$ & 81 & OR & $H$ & $A$ & 0.3 & 0.6 & 0.7 & 0.9 & 0.7 & 0.2 & 0.0 & 0.6 & 0.4 & 0.1 & 0.29 \\
\hline $0 . B A$ & 82 & $O R$ & $\omega$ & A & 0.3 & 0.6 & 0.8 & 0.8 & 0.7 & 0.1 & 0.0 & 0.5 & 0.4 & 0.2 & 0.27 \\
\hline$A \cdot D C$ & $L R$ & $O R$ & $H$ & A & 0.1 & 1.2 & 1.2 & 0.7 & 1.0 & 0.3 & 0.1 & 0.4 & 0.9 & 0.3 & 0.61 \\
\hline$C \cdot B A$ & B1 & OR & $H$ & $A$ & 0.2 & 0.7 & 0.6 & 0.6 & 0.6 & 0.1 & 0.0 & 0.5 & 0.6 & 0.3 & 0.08 \\
\hline$B \cdot B A$ & $K T$ & OR & $H$ & $A$ & 0.0 & 0.7 & 0.2 & 0.4 & 0.6 & 0.3 & 0.1 & 0.6 & 0.4 & 0.4 & 0.05 \\
\hline$B \cdot B A$ & $B A$ & OR & $H$ & A & 0.0 & 0.7 & 0.7 & 0.9 & 0.8 & 0.1 & 0.0 & 0.7 & 0.8 & 0.7 & 0.10 \\
\hline$E \cdot B A$ & $B 2$ & $D R$ & $W$ & $A$ & 0.3 & 3.6 & 4.3 & 4.6 & 4.2 & 0.5 & 0.3 & 2.1 & 3.9 & 1.8 & 2.08 \\
\hline$A \cdot B A$ & $K T$ & OR & $W$ & $A$ & .0 .2 & 6.3 & 6.2 & 6.7 & 6.6 & 0.3 & 0.1 & 6.3 & 6.6 & 6.5 & 0.16 \\
\hline $0 . B A$ & EX & OR & 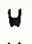 & $A$ & 0.3 & 21.0 & 22.8 & 22.4 & 22.1 & 0.9 & 0.9 & 21.3 & 21.8 & 21.0 & 0.75 \\
\hline$E \cdot B A$ & 83 & OR & $W$ & $A$ & 0.3 & 3.9 & 3.9 & 4.4 & 4.1 & 0.3 & 0.1 & 1.7 & 3.8 & 1.4 & 2.39 \\
\hline
\end{tabular}

Key: Houses were lettered A through E, Cities were identified by BA for Baltimore and OC for Washington, $O C$; Rooms are $L R=$ living room, $O R=$ dining room, $B A=$ bathroom, $B \#$ = bedroom, $H L=h a l l, E X=$ exterior, $K T$ = kitchen; Surfaces are labeled: $W H=$ wall, ST = stair, $R C=$ radiator cover, BM = baseboard molding,OM = door molding; WS = window sill; WT = window molding; $F=f l o o r ; ~ D R=$ door; $S H=$ shelf; substrates were labeled $C=$ concrete; $M=$ metat; $P=$ plaster; $D=$ gypsum; $W=$ wood; Instrument (inst.) are labeled $A$; $B$; or C. Bare corresponds to the reading over corresponding bare substrate; R1; R2; and R3; are the three replicate readings; mean is their mean; std. is an estimated standard devistion based on the three replicate readings; var is the square of the standard deviation; AA is the same as FAAS; XRF-AA is the difference between the mean of XRF readings and the FAMS result; Avg-Sub. is the difference between mean of XRF readings and the substate reading; XRF-SUb.-M is the difference between the substrate-corrected XRF reading and the FAAS result. 
Table A6. Field data taken with XRF-BO analyzer

\begin{tabular}{|c|c|c|c|c|c|c|c|c|c|c|c|c|c|c|c|}
\hline House & Roon & Surf. & sub. & inst. & Bare & $R 1$ & $R 2$ & R3 & Avg & std. & var. & $X R F-A A$ & Avg. Sub. & $\begin{array}{c}\text { XRF-SUb } \\
\text {-AA }\end{array}$ & \\
\hline$D \cdot B A$ & EX & ST & C & B & 1.1 & 1.4 & 1.5 & 1.3 & 1.4 & 0.1 & 0.0 & 1.0 & 0.3 & -0.1 & 0.36 \\
\hline$C \cdot O C$ & EX & $w 2$ & CM & B & 0.2 & 2.3 & 1.3 & 2.1 & 1.9 & 0.5 & 0.3 & 0.7 & 1.7 & 0.5 & 1.3 \\
\hline$A-D C$ & LR & 13 & 0 & 8 & 0.2 & 0.8 & 1.3 & 1.1 & 1.1 & 0.3 & 0.1 & 1.0 & 0.9 & 0.8 & 0.0 \\
\hline $0.0 C$ & LR & $W 1$ & 0 & B & 1.0 & 0.5 & 0.6 & 0.3 & 0.5 & 0.2 & 0.0 & 0.4 & -0.5 & .0 .6 & 0.1 \\
\hline $0.0 C$ & SH & 164 & 0 & 8 & 1.0 & 1.2 & 0.9 & 0.7 & 0.9 & 0.3 & 0.1 & 0.9 & -0.1 & .0 .1 & 0.1 \\
\hline $0.0 C$ & BS & $H_{2}$ & 0 & 8 & 1.0 & 0.8 & 0.5 & 0.8 & 0.7 & 0.2 & 0.0 & 0.7 & -0.3 & .0 .3 & 0.1 \\
\hline $0.0 \mathrm{C}$ & 82 & 12 & 0 & B & 1.0 & 1.0 & 0.2 & 1.0 & 0.7 & 0.5 & 0.2 & 0.7 & -0.3 & -0.3 & 0.1 \\
\hline$A \cdot D C$ & LR & 42 & 0 & B & 0.2 & -0.2 & -0.1 & 0.2 & 0.0 & 0.2 & 0.0 & -0.1 & .0 .2 & -0.3 & 0.1 \\
\hline$C \cdot O C$ & LR & 43 & 0 & 8 & 0.2 & 0.3 & 0.5 & 0.7 & 0.5 & 0.2 & 0.0 & 0.4 & 0.3 & 0.2 & 0.1 \\
\hline$A=D C$ & HL & H2 & 0 & B & 0.2 & 0.0 & 1.0 & 0.3 & 0.4 & 0.5 & 0.3 & 0.3 & 0.2 & 0.1 & 0.1 \\
\hline$D-D C$ & LR & 13 & 0 & B & 1.0 & 0.8 & 0.6 & 0.7 & 0.7 & 0.1 & 0.0 & 0.6 & -0.3 & -0.4 & 0.1 \\
\hline $0.0 C$ & BR & 42 & 0 & $B$ & 1.0 & 1.6 & 2.4 & 2.0 & 2.0 & 0.4 & 0.2 & 0.9 & 1.0 & -0.1 & 1.2 \\
\hline$C \cdot B A$ & 83 & $R C$ & $M$ & 8 & 1.4 & 1.7 & 1.4 & 1.4 & 1.5 & 0.2 & 0.0 & 1.4 & 0.1 & 0.0 & 0.05 \\
\hline$C \cdot 8 A$ & DR & RC & $M$ & B & 1.4 & 2.0 & 1.4 & 1.3 & 1.6 & 0.4 & 0.1 & 1.5 & 0.2 & 0.1 & 0.03 \\
\hline $0 . B A$ & LR & $R C$ & $M$ & B & 1.3 & 1.9 & 1.8 & 1.8 & 1.8 & 0.1 & 0.0 & 1.7 & 0.5 & 0.4 & 0.09 \\
\hline$A \cdot B A$ & $O R$ & 42 & $P$ & $B$ & 0.6 & 0.1 & 0.4 & 0.7 & 0.4 & 0.3 & 0.1 & 0.2 & -0.2 & .0 .4 & 0.16 \\
\hline$A \cdot B A$ & B1 & w1 & $P$ & $B$ & 0.6 & 0.6 & 0.1 & 0.4 & 0.4 & 0.3 & 0.1 & 0.3 & -0.2 & -0.3 & 0.11 \\
\hline$A=B A$ & 83 & 164 & $P$ & 8 & 0.6 & 0.9 & 1.2 & 1.3 & 1.1 & 0.2 & 0.0 & 0.3 & 0.5 & -0.3 & 0.81 \\
\hline$C-B A$ & DR & $C 2$ & $P$ & 8 & 0.2 & 0.2 & 0.3 & 0.4 & 0.3 & 0.1 & 0.0 & 0.2 & 0.1 & 0.0 & 0.15 \\
\hline$A \cdot B A$ & 82 & H1 & $P$ & 8 & 0.6 & 1.2 & 0.6 & 0.4 & 0.7 & 0.4 & 0.2 & 0.6 & 0.1 & 0.0 & 0.13 \\
\hline$B \cdot 8 A$ & HA & Wh & $P$ & 8 & 0.4 & 0.8 & 0.3 & 0.2 & 0.4 & 0.3 & 0.1 & 0.4 & 0.0 & 0.0 & 0.01 \\
\hline$C \cdot B A$ & OR & H2 & $P$ & B & 0.2 & 0.4 & 0.6 & 0.2 & 0.4 & 0.2 & 0.0 & 0.3 & 0.2 & 0.1 & 0.15 \\
\hline$C \cdot B A$ & BA & 146 & $P$ & 8 & 0.2 & 0.7 & 0.3 & 0.2 & 0.4 & 0.3 & 0.1 & 0.3 & 0.2 & 0.1 & 0.13 \\
\hline$C-B A$ & HL & H1 & $P$ & 8 & 0.2 & 0.6 & 0.5 & 0.3 & 0.5 & 0.2 & 0.0 & 0.3 & 0.3 & 0.1 & 0.19 \\
\hline$C \cdot B A$ & BA & $H 1$ & $P$ & B & 0.2 & 0.9 & 0.0 & 0.7 & 0.5 & 0.5 & 0.2 & 0.4 & 0.3 & 0.2 & 0.14 \\
\hline $0.8 A$ & B1 & H3 & $P$ & B & 0.1 & 0.0 & 0.6 & 0.6 & 0.4 & 0.3 & 0.1 & 0.4 & 0.3 & 0.3 & 0.05 \\
\hline $0 . B A$ & 82 & H2 & $P$ & $B$ & 0.1 & 0.6 & 0.5 & 0.2 & 0.4 & 0.2 & 0.0 & 0.4 & 0.3 & 0.3 & 0.06 \\
\hline$C \cdot B A$ & $8 A$ & W2 & $P$ & 8 & 0.2 & 0.5 & 0.7 & 0.7 & 0.6 & 0.1 & 0.0 & 0.5 & 0.4 & 0.3 & 0.12 \\
\hline $8 \cdot B A$ & SH & H2 & $P$ & 8 & 0.4 & 1.1 & 1.2 & 0.2 & 0.8 & 0.6 & 0.3 & 0.8 & 0.4 & 0.4 & 0.02 \\
\hline$D . D C$ & LR & H & $P$ & $B$ & & 0.8 & 0.6 & 0.5 & 0.6 & 0.2 & 0.0 & 0.6 & 0.6 & 0.6 & 0.0 \\
\hline$C \cdot B A$ & 83 & 14 & $P$ & 8 & 0.2 & 1.2 & 0.4 & 1.1 & 0.9 & 0.4 & 0.2 & 0.9 & 0.7 & 0.7 & 0.04 \\
\hline $8 \cdot B A$ & KT & $W 4$ & $P$ & 8 & 0.4 & 4.3 & 3.7 & 3.8 & 3.9 & 0.3 & 0.1 & 2.2 & 3.5 & 1.8 & 1.70 \\
\hline$E-B A$ & KT & $\mathbf{H 3}$ & $P$ & 8 & 0.2 & 3.5 & 3.7 & 4.0 & 3.7 & 0.3 & 0.1 & 3.7 & 3.5 & 3.5 & 0.00 \\
\hline$A-8 A$ & $8 A$ & H2 & $P$ & 8 & 0.6 & 0.6 & 0.6 & 0.2 & 0.5 & 0.2 & 0.1 & -2.9 & -0.1 & -3.5 & 3.41 \\
\hline$A-B A$ & LR & 10 & $W$ & $B$ & 0.9 & 0.4 & 0.7 & 0.2 & 0.4 & 0.3 & 0.1 & 0.2 & -0.5 & -0.7 & 0.18 \\
\hline$D \cdot D C$ & LR & $B M$ & $\boldsymbol{H}$ & 8 & 0.5 & 0.8 & 1.0 & 1.5 & 1.1 & 0.4 & 0.1 & -0.1 & 0.6 & -0.6 & 1.2 \\
\hline$D . D C$ & 82 & HS & $H$ & $B$ & 0.5 & 1.5 & 1.8 & 1.0 & 1.4 & 0.4 & 0.2 & 0.1 & 0.9 & -0.4 & 1.4 \\
\hline$C \cdot O C$ & OR & H & $H$ & 8 & 0.2 & 0.2 & 0.0 & 0.1 & 0.1 & 0.1 & 0.0 & -0.1 & .0 .1 & -0.3 & 0.2 \\
\hline$E-B A$ & 81 & us & $y$ & 8 & 0.4 & 0.5 & 0.4 & 0.5 & 0.5 & 0.1 & 0.0 & 0.2 & 0.1 & -0.2 & 0.25 \\
\hline$B \cdot B A$ & LR & $B M$ & $\boldsymbol{H}$ & $B$ & 0.0 & 0.0 & 0.0 & 0.1 & 0.0 & 0.1 & 0.0 & 0.0 & 0.0 & 0.0 & 0.02 \\
\hline$D \cdot D C$ & DR & $D M$ & $H$ & 8 & 0.5 & 1.8 & 1.6 & 1.4 & 1.6 & 0.2 & 0.0 & 0.5 & 1.1 & 0.0 & 1.1 \\
\hline$B \cdot D C$ & DR & DN & $H$ & $B$ & 0.1 & 0.4 & 0.4 & 0.2 & 0.3 & 0.1 & 0.0 & 0.2 & 0.2 & 0.1 & 0.1 \\
\hline $0.8 \mathrm{~A}$ & $K T$ & 10 & $H$ & $B$ & 0.3 & 0.8 & 0.4 & 0.4 & 0.5 & 0.2 & 0.1 & 0.4 & 0.2 & 0.1 & 0.11 \\
\hline$C-O C$ & OR & $O M$ & $H$ & 8 & 0.2 & 0.9 & 0.3 & 1.0 & 0.7 & 0.4 & 0.1 & 0.3 & 0.5 & 0.1 & 0.4 \\
\hline$A-B A$ & OR & BM & 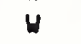 & $B$ & 0.9 & 2.1 & 1.1 & 1.3 & 1.5 & 0.5 & 0.3 & 1.1 & 0.6 & 0.2 & 0.41 \\
\hline $0.0 C$ & LR & WS & $H$ & B & 0.5 & 2.3 & 2.2 & 1.9 & 2.1 & 0.2 & 0.0 & 0.9 & 1.6 & 0.4 & 1.2 \\
\hline$B .0 C$ & HL & BM & $H$ & $B$ & 0.3 & 0.9 & 1.2 & 0.4 & 0.8 & 0.4 & 0.2 & 0.8 & 0.5 & 0.5 & 0.1 \\
\hline$B \cdot B A$ & SH & 10 & $H$ & 8 & 0.0 & 1.0 & 1.2 & 1.2 & 1.1 & 0.1 & 0.0 & 0.7 & 1.1 & 0.7 & 0.40 \\
\hline$E-B A$ & LR & 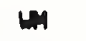 & $H$ & 8 & 0.4 & 2.7 & 2.5 & 2.5 & 2.6 & 0.1 & 0.0 & 1.2 & 2.2 & 0.8 & 1.37 \\
\hline$A-O C$ & EX & 10 & $H$ & 8 & 0.1 & 2.7 & 2.1 & 2.4 & 2.4 & 0.3 & 0.1 & 1.0 & 2.3 & 0.9 & 1.4 \\
\hline$B \cdot D C$ & 82 & BM & $y$ & 8 & 0.3 & 2.1 & 1.8 & 2.1 & 2.0 & 0.2 & 0.0 & 1.9 & 1.7 & 1.6 & 0.2 \\
\hline$B \cdot D C$ & B1 & BM & $y$ & B & 0.3 & 3.0 & 3.3 & 3.6 & 3.3 & 0.3 & 0.1 & 3.3 & 3.0 & 3.0 & 0.0 \\
\hline$B \cdot D C$ & DR & $B M$ & $W$ & 8 & 0.3 & 4.1 & 4.1 & 3.9 & 4.0 & 0.1 & 0.0 & 4.0 & 3.7 & 3.7 & 0.0 \\
\hline$A \cdot B A$ & LR & DM & $w$ & 8 & 0.9 & 8.8 & 7.8 & 8.9 & 8.5 & 0.6 & 0.4 & 6.6 & 7.6 & 5.7 & 1.95 \\
\hline$B \cdot B A$ & LR & us & $y$ & B & 0.0 & 9.4 & 9.7 & 9.3 & 9.5 & 0.2 & 0.0 & 6.0 & 9.5 & 6.0 & 3.43 \\
\hline$E-B A$ & 81 & UT & $\dot{H}$ & 8 & 0.4 & 5.3 & 4.2 & 4.4 & 4.6 & 0.6 & 0.3 & 0.8 & 4.2 & 0.4 & 3.84 \\
\hline
\end{tabular}




\begin{tabular}{|c|c|c|c|c|c|c|c|c|c|c|c|c|c|c|c|}
\hline $0.8 A$ & $D R$ & MO & $H$ & 8 & 0.3 & 4.4 & 4.6 & 4.3 & 4.6 & 0.2 & 0.0 & 0.2 & 4.1 & -0.1 & 4.21 \\
\hline$C \cdot D C$ & EX & $D M$ & $y$ & 8 & 0.2 & 10.0 & 10.0 & 10.0 & 10.0 & 0.0 & 0.0 & .4 .1 & 9.8 & -4.3 & 14.9 \\
\hline$C-B A$ & DR & $O H$ & $u$ & 8 & 0.5 & 10.0 & 10.0 & 10.0 & 10.0 & 0.0 & 0.0 & -5.1 & 9.5 & -5.6 & 15.13 \\
\hline$E \cdot B A$ & $L R$ & WM & $H$ & 8 & 0.4 & 10.0 & 10.0 & 10.0 & 10.0 & 0.0 & 0.0 & -8.4 & 9.6 & -8.8 & 18.41 \\
\hline$A-B A$ & $P R$ & $F$ & $\dot{u}$ & B & 0.9 & 0.2 & 0.0 & 0.4 & 0.2 & 0.2 & 0.0 & 0.2 & $\cdot 0.7$ & -0.7 & 0.01 \\
\hline$C \cdot 8 A$ & B1 & $D R$ & $H$ & 8 & 0.5 & 0.0 & 0.4 & 0.5 & 0.3 & 0.3 & 0.1 & 0.2 & $=0.2$ & -0.3 & 0.08 \\
\hline$D \cdot B A$ & $O R$ & SH & $y$ & 8 & 0.3 & 0.3 & 0.3 & 0.4 & 0.3 & 0.1 & 0.0 & 0.1 & 0.0 & -0.2 & 0.22 \\
\hline$A \cdot D C$ & HL & $D R$ & $y$ & B & 0.1 & 1.4 & 1.4 & 1.5 & 1.6 & 0.1 & 0.0 & 0.1 & 1.3 & 0.0 & 1.3 \\
\hline $0 . B A$ & 82 & DR & $y$ & 8 & 0.3 & 0.8 & 0.8 & 0.6 & 0.7 & 0.1 & 0.0 & 0.5 & 0.4 & 0.2 & 0.27 \\
\hline$E-8 A$ & 82 & $D R$ & $H$ & 8 & 0.4 & 2.5 & 2.6 & 2.9 & 2.7 & 0.2 & 0.0 & 0.6 & 2.3 & 0.2 & 2.08 \\
\hline$A \cdot D C$ & LR & $D R$ & $H$ & 8 & 0.1 & 1.3 & 0.9 & 0.6 & 0.9 & 0.4 & 0.1 & 0.3 & 0.8 & 0.2 & 0.6 \\
\hline $0.8 A$ & 81 & $D R$ & $H$ & 8 & 0.3 & 0.2 & 0.5 & 2.0 & 0.9 & 1.0 & 0.9 & 0.6 & 0.6 & 0.3 & 0.29 \\
\hline $8-8 A$ & $8 A$ & $O R$ & $H$ & 8 & 0.0 & 0.2 & 1.0 & 0.2 & 0.5 & 0.5 & 0.2 & 0.4 & 0.5 & 0.4 & 0.10 \\
\hline$A \cdot D C$ & 81 & OR & $H$ & 8 & 0.1 & 1.6 & 1.5 & 1.6 & 1.5 & 0.1 & 0.0 & 0.6 & 1.6 & 0.5 & 1.0 \\
\hline B-BA & KT & DR & u & 8 & 0.0 & 0.7 & 1.0 & 1.4 & 1.0 & 0.4 & 0.1 & 1.0 & 1.0 & 1.0 & 0.05 \\
\hline$A-B A$ & KT & DR & 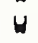 & 8 & 0.9 & 3.7 & 3.8 & 4.0 & 3.8 & 0.2 & 0.0 & 3.7 & 2.9 & 2.8 & 0.14 \\
\hline$E \cdot B A$ & 83 & DR & $H$ & 8 & 0.4 & 3.3 & 3.1 & 3.5 & 3.3 & 0.2 & 0.0 & 0.9 & 2.9 & 0.5 & 2.39 \\
\hline
\end{tabular}

Key: Sane as for table A5. 
Table A7. Field data taken with XRF-Cl analyzer

\begin{tabular}{|c|c|c|c|c|c|c|c|c|c|c|c|c|}
\hline House & Room & Surf. & sub. & Inst. & $R 1$ & 22 & R3 & Avg & std. & Var. & $X R F-A A$ & FAAS \\
\hline$A \cdot B A$ & $L R$ & MD & $8 \mathrm{~W}$ & $c \cdot 1$ & 1.3 & 1.1 & 1.2 & 1.2 & 0.1 & 0.0 & 1.0 & 0.18 \\
\hline$B-B A$ & HA & $W 4$ & $P$ & $c-1$ & 1.0 & 0.7 & & 0.9 & 0.2 & 0.0 & 0.9 & 0.01 \\
\hline$B-B A$ & SW & H2 & $P$ & $c-1$ & 1.5 & 1.4 & & 1.4 & 0.1 & 0.0 & 1.4 & 0.02 \\
\hline$A-B A$ & B1 & $w 1$ & $P$ & $c \cdot 1$ & 1.4 & 1.1 & 1.3 & 1.3 & 0.1 & 0.0 & 1.2 & 0.11 \\
\hline$A=B A$ & $B 2$ & $\forall 1$ & $P$ & $c-1$ & 0.4 & 0.7 & 0.8 & 0.6 & 0.2 & 0.0 & 0.5 & 0.13 \\
\hline$A \cdot B A$ & DR & $H_{2}$ & $P$ & $c-1$ & 1.0 & 1.2 & 1.0 & 1.1 & 0.1 & 0.0 & 0.9 & 0.16 \\
\hline$A-B A$ & 83 & $W 4$ & $P$ & $c-1$ & 1.1 & 1.0 & 0.8 & 1.0 & 0.1 & 0.0 & 0.2 & 0.81 \\
\hline B. BA & $K T$ & W6 & $P$ & $c-1$ & 2.6 & 2.7 & 2.9 & 2.7 & 0.1 & 0.0 & 1.0 & 1.70 \\
\hline$A-B A$ & BA & W2 & $P$ & $c \cdot 1$ & 3.6 & 3.6 & 3.8 & 3.7 & 0.1 & 0.0 & 0.2 & 3.41 \\
\hline$A \cdot B A$ & $P R$ & $F$ & $W$ & $c \cdot 1$ & 0.0 & 0.0 & 0.0 & 0.0 & 0.0 & 0.0 & 0.0 & 0.01 \\
\hline $8-8 A$ & LR & BM & $W$ & $c-1$ & 0.2 & 0.0 & 0.3 & 0.2 & 0.2 & 0.0 & 0.1 & 0.02 \\
\hline B-8A & $K T$ & SH & $H$ & $c \cdot 1$ & 0.2 & 0.3 & & 0.2 & 0.1 & 0.0 & 0.2 & 0.05 \\
\hline B. BA & BA & DR & $H$ & $c-1$ & 0.2 & 0.5 & & 0.3 & 0.2 & 0.0 & 0.2 & 0.10 \\
\hline$A-B A$ & $K T$ & $D R$ & $H$ & $c-1$ & 6.3 & 6.6 & 6.2 & 6.4 & 0.2 & 0.0 & 6.3 & 0.16 \\
\hline$A-B A$ & LR & $M D$ & $H$ & $c \cdot 1$ & 0.9 & 0.8 & 0.9 & 0.8 & 0.1 & 0.0 & 0.7 & 0.18 \\
\hline B-BA & SH & $M D$ & $H$ & $c-1$ & 1.4 & 1.5 & & 1.4 & 0.1 & 0.0 & 1.0 & 0.40 \\
\hline$A \cdot B A$ & $D R$ & $\sqrt[6]{3}$ & $H$ & $c-1$ & 0.6 & 0.4 & 0.8 & 0.6 & 0.2 & 0.0 & 0.2 & 0.41 \\
\hline$A-B A$ & LR & DM & $H$ & $c-1$ & 5.7 & 5.5 & 5.5 & 5.6 & 0.1 & 0.0 & 3.6 & 1.95 \\
\hline$B-B A$ & LR & US & $w$ & $c-1$ & 5.4 & 5.6 & 5.6 & 5.5 & 0.1 & 0.0 & 2.0 & 3.43 \\
\hline
\end{tabular}

Key: Same as for Table A5. 
rable A8. Field data taken with XRF-C2 analyzer

\begin{tabular}{|c|c|c|c|c|c|c|c|c|c|c|c|}
\hline House & Room & Surf. & sub. & RI & $R 2$ & R3 & Avg & std. & Var. & $X R F-A M$ & FAAS \\
\hline$B A-D$ & $K T$ & MO & $B W$ & 0.0 & & & 0.0 & & & 0.0 & 0.01 \\
\hline$B A-D$ & EX & ST & C & 0.0 & & & 0.0 & & & -0.4 & 0.36 \\
\hline$B A \cdot C$ & OR & RO & M & 0.0 & & & 0.0 & & & -0. & 0.1 \\
\hline$B A-C$ & OR & $R C$ & M & 0.7 & 0.0 & 0.0 & 0.2 & 0.2 & 0.4 & 0. & 0.03 \\
\hline$B A=D$ & $K T$ & $C A$ & $M$ & 0.5 & & & 0.5 & & & 0. & 0.0 \\
\hline$B A-B$ & HA & W6 & $P$ & 0.0 & 0.0 & 0.0 & 0.0 & 0.0 & 0.0 & 0 & 0.01 \\
\hline$B A \cdot B$ & SW & W2 & $P$ & 0.2 & 0.0 & 0.4 & 0.2 & 0.0 & 0.2 & 0. & 0.02 \\
\hline$B A \cdot C$ & $B 3$ & W6 & $P$ & 0.3 & 0.3 & 0.3 & 0.3 & 0.0 & 0.0 & 0 & 0.04 \\
\hline$B A \cdot C$ & OR & $C 2$ & $P$ & 0.2 & 0.5 & 0.4 & 0.6 & 0.0 & 0.2 & 0. & 0.15 \\
\hline$B A-B$ & KT & H2 & $P$ & 2.5 & 2.3 & 2.5 & 2.4 & 0.0 & 0.1 & 0 & 2.2 \\
\hline$B A-B$ & KT & W4 & P & 3.4 & 2.6 & 2.9 & 3.0 & 0.2 & 0 & & 1.70 \\
\hline$B A-B$ & $k$ & OR & $w$ & 0 & 0.0 & 0.0 & 0.0 & 0.0 & & -0 & 0.05 \\
\hline$B A-B$ & EX & DR & 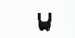 & 0.0 & 0.0 & 0.0 & 0.0 & 0 & & -0 & .2 \\
\hline$B A-B$ & BA & OR & $w$ & 0.0 & 0.0 & 0.0 & 0.0 & 0.0 & & -0.1 & 0.10 \\
\hline$B A-B$ & LR & BM & $u$ & 0.0 & 0.0 & 0.2 & 0.1 & 0.0 & 0.1 & 0.0 & 0.02 \\
\hline$B A-C$ & 81 & OR & $w$ & 0.0 & 0.0 & 0.3 & 0.1 & 0.0 & 0.2 & 0 . & 0.08 \\
\hline$B A-O$ & B1 & $O R$ & $H$ & 0.8 & 0.0 & 0.3 & 0.4 & 0.2 & 0.8 & 0. & 0.29 \\
\hline$B A-D$ & $O R$ & OM & $w$ & 0.6 & 1.1 & 0.5 & 0.7 & 0.1 & 0. & 0.5 & 0.2 \\
\hline$B A-D$ & HL & $\mathrm{OM}$ & $W$ & 6.6 & 6.8 & 6.2 & 6.5 & 0.1 & 0.3 & 1.4 & 5.1 \\
\hline$B A-B$ & BA & OR & $H$ & 7.7 & 8.5 & 7.4 & 7.9 & 0.3 & 0.6 & 3.8 & 4.1 \\
\hline$B A-C$ & LR & MO & $W$ & 9.0 & 9.2 & & 9.1 & & & -2.4 & 11.5 \\
\hline$B A \cdot C$ & OR & OF & $H$ & 11.7 & 10.9 & 10 & 11.1 & 0.3 & 0.6 & -4.1 & 15.13 \\
\hline$B A \cdot B$ & LR & WS & $H$ & 12.2 & 13.1 & 13.1 & 12.8 & 0.3 & 0.5 & 9.4 & 3.43 \\
\hline
\end{tabular}

Key: The key is the same as table $A 5$. 
4. TTLE MD SUETTIL

Methods for Measuring Lead Concentrations in Paint Film

5. AUTHOA(S)

M. Mcknight, W.E. Byrd, W.E. Roberts, and E.S. Lagergren

6. PERFORMIMG OROMNIZATION (IF JOINT OA OTHER THAN MIST, SEE MSTRUCTIONS)

U.S. DUPATMETT OF COMMERCE

MATIONAL INSTITUTE OF STANDARDS AND TECHNOLOOY

eNTHEASEURG, MD 20099

9. SFOMSORIMO ONQAMIZATION MAME AND COMPLETE ADDAESS (STRET, GT, STATE, ZP)

U.S. Department of Housing and Urban Development

10. SUFFIMENTAY MOTES

DOCAMATT DESCRIBES A COMPUTER PROQRAM; SF-16s, FIPS SOFTWAAE SUMMARY, B ATTACHED.

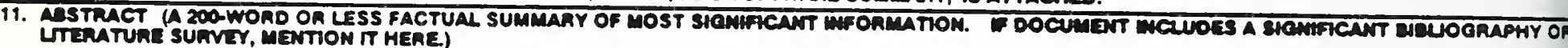

Recent legislation required the U.S. Deportment of Housing and Urben Development (mo) to establish procedures to abate lead. based paint in existing HW-assisted hassing. The legislation also required mo to assess the accuracy, precision, reliability, and safety of methods for measuring lead content of paint film and to imestigate the availability of testers and samplers. The Mational Institute of standerds and Technology was requested to carry out this assessment. After reviewing the literature for possible field wethods, two wethods were selected for further testing: chenical spot tests and methods based upon use of portable $x$-ray fluorescence (XRF) analyzers.

With regard to accuracy and precision of field mesurenents, it was concluded that 1) spot tests when carried out by an experiegeed analytical chemistry technicien cen detect the presence of lead in paint film having concentrations in excess of $1 \mathrm{mg} / \mathrm{cm}^{2}$ about 90 percent of the tim, 2) the estievte of the precision of a field mesurement procedure using lead-specific portable XRF analyzers (besed on three replicate reedigas and subetrate correction) for leed concentrations near $1 \mathrm{mg} / \mathrm{cm}$, is $\pm 0.6 \mathrm{mg} / \mathrm{cm}^{2}$ and the estimate of the biee is $0.2 \mathrm{~m} / \mathrm{cm}^{2}$; this results in 95 parcent confidence interval of $t 1.4 \mathrm{mg} / \mathrm{cm}^{2}$, and 3) based upon very prelininary mesurements wing the latest version of the spoctru analyzer portable XRF, the 95 percent confidence interval for field mesurements is estimted to be $0.5 \mathrm{~m} / \mathrm{cm}^{2}$.

In addition to field wthods, standord laboratory procedures cen be used to masure the leed content of paing samples to within a few percent of the quantity present over wide range extending from less then 0.1 to over $10 \mathrm{mg} / \mathrm{cm}^{2}$. Because they can have a large effect on the results, seple collection and seple disaolution procedures were also investigated. The results of the assesaments and the conclusian and recanindations baed upon the reaults are diacussed in this report.

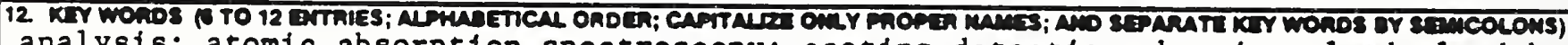
analysis; atomic absorption spectroscopy; coating detect1on; housing; lead; lead-based paint; measurement; microscopy; palnt; $x$-ray flourescence analyzers.

\section{AVAUNTr}

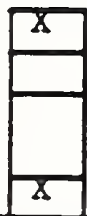

Uminm:o

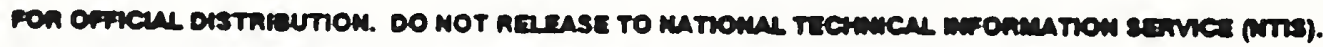

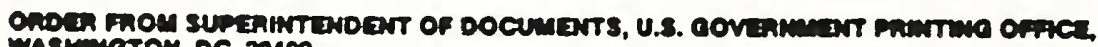
WAstumaton, DC 20402

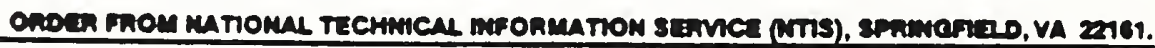

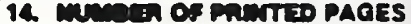

122 

